Cochrane Database of Systematic Reviews

\title{
Tonsillectomy versus tonsillotomy for obstructive sleep-disordered breathing in children (Review)
}

Blackshaw H, Springford LR, Zhang LY, Wang B, Venekamp RP, Schilder AGM

Blackshaw H, Springford LR, Zhang L-Y, Wang B, Venekamp RP, Schilder AGM.

Tonsillectomy versus tonsillotomy for obstructive sleep-disordered breathing in children.

Cochrane Database of Systematic Reviews 2020, Issue 4. Art. No.: CD011365.

DOI: 10.1002/14651858.CD011365.pub2.

www.cochranelibrary.com 
TABLE OF CONTENTS

HEADER 1

ABSTRACT

PLAIN LANGUAGE SUMMARY

SUMMARY OF FINDINGS

BACKGROUND

OBJECTIVES

METHODS

RESULTS

Figure 1.

Figure 2.

Figure 3.

Figure 4.

Figure 5.

Figure 6.

DISCUSSION

AUTHORS' CONCLUSIONS

ACKNOWLEDGEMENTS

REFERENCES

CHARACTERISTICS OF STUDIES

DATA AND ANALYSES

Analysis 1.1. Comparison 1: Tonsillectomy versus tonsillotomy, Outcome 1: Peri-operative blood loss ....................................

Analysis 1.2. Comparison 1: Tonsillectomy versus tonsillotomy, Outcome 2: Peri-operative blood loss (sensitivity analysis) ....

Analysis 1.3. Comparison 1: Tonsillectomy versus tonsillotomy, Outcome 3: Need for medical intervention within 7 days .......

Analysis 1.4. Comparison 1: Tonsillectomy versus tonsillotomy, Outcome 4: Need for medical intervention within 7 days (sensitivity analysis)

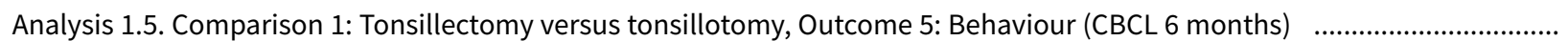

Analysis 1.6. Comparison 1: Tonsillectomy versus tonsillotomy, Outcome 6: Behaviour (CBCL 24 months)

Analysis 1.7. Comparison 1: Tonsillectomy versus tonsillotomy, Outcome 7: Measures of respiratory events during sleep (AHI 6 months)

Analysis 1.8. Comparison 1: Tonsillectomy versus tonsillotomy, Outcome 8: Recurrence of SDB symptoms (6 months) ............ Analysis 1.9. Comparison 1: Tonsillectomy versus tonsillotomy, Outcome 9: Recurrence of SDB symptoms (6 months sensitivity analysis)

Analysis 1.10. Comparison 1: Tonsillectomy versus tonsillotomy, Outcome 10: Recurrence of SDB symptoms (12 months) ....... Analysis 1.11. Comparison 1: Tonsillectomy versus tonsillotomy, Outcome 11: Recurrence of SDB symptoms (12 months sensitivity analysis)

Analysis 1.12. Comparison 1: Tonsillectomy versus tonsillotomy, Outcome 12: Recurrence of SDB symptoms (24 months) ...... Analysis 1.13. Comparison 1: Tonsillectomy versus tonsillotomy, Outcome 13: Reoperation rates (12 months) ........................ Analysis 1.14. Comparison 1: Tonsillectomy versus tonsillotomy, Outcome 14: Reoperation rates (18 months) ....................... Analysis 1.15. Comparison 1: Tonsillectomy versus tonsillotomy, Outcome 15: Incidence of throat infection (6 months) .......... Analysis 1.16. Comparison 1: Tonsillectomy versus tonsillotomy, Outcome 16: Incidence of throat infection (12 months) ........ Analysis 1.17. Comparison 1: Tonsillectomy versus tonsillotomy, Outcome 17: Incidence of throat infection (24 months) ........ Analysis 1.18. Comparison 1: Tonsillectomy versus tonsillotomy, Outcome 18: Duration of surgery Analysis 1.19. Comparison 1: Tonsillectomy versus tonsillotomy, Outcome 19: Duration of surgery (sensitivity analysis) .......... Analysis 1.20. Comparison 1: Tonsillectomy versus tonsillotomy, Outcome 20: Severity of postoperative pain (24 hours) ......... Analysis 1.21. Comparison 1: Tonsillectomy versus tonsillotomy, Outcome 21: Severity of postoperative pain (24 hours sensitivity analysis)

Analysis 1.22. Comparison 1: Tonsillectomy versus tonsillotomy, Outcome 22: Severity of postoperative pain (2 to 3 days) ..... Analysis 1.23. Comparison 1: Tonsillectomy versus tonsillotomy, Outcome 23: Severity of postoperative pain (2 to 3 days sensitivity analysis)

Analysis 1.24. Comparison 1: Tonsillectomy versus tonsillotomy, Outcome 24: Severity of postoperative pain (4 to 7 days) $\quad$..... Analysis 1.25. Comparison 1: Tonsillectomy versus tonsillotomy, Outcome 25: Severity of postoperative pain (4 to 7 days sensitivity analysis) 
Analysis 1.26. Comparison 1: Tonsillectomy versus tonsillotomy, Outcome 26: Days until analgesics no longer required .......... 71 Analysis 1.27. Comparison 1: Tonsillectomy versus tonsillotomy, Outcome 27: Days until analgesics no longer required (sensitivity analysis)

Analysis 1.28. Comparison 1: Tonsillectomy versus tonsillotomy, Outcome 28: Return to normal diet

Analysis 1.29. Comparison 1: Tonsillectomy versus tonsillotomy, Outcome 29: Return to normal diet (sensitivity analysis) .....

Analysis 1.30. Comparison 1: Tonsillectomy versus tonsillotomy, Outcome 30: Return to normal activity

Analysis 1.31. Comparison 1: Tonsillectomy versus tonsillotomy, Outcome 31: Return to normal activity (sensitivity analysis) .. 
[Intervention Review]

\section{Tonsillectomy versus tonsillotomy for obstructive sleep-disordered breathing in children}

Helen Blackshaw ${ }^{1,2 a}$, Laurie R Springford ${ }^{1,2 b}$, Lai-Ying Zhang 3 , Betty Wang 3 , Roderick P Venekamp ${ }^{4}$, Anne GM Schilder $1,2,5$

1evidENT, Ear Institute, University College London, London, UK. 2National Institute of Health Research, University College London Hospitals Biomedical Research Centre, London, UK. ${ }^{3}$ School of Medicine, The University of Queensland, Brisbane, Australia. 4 Julius Center for Health Sciences and Primary Care, University Medical Center Utrecht, Utrecht University, Utrecht, Netherlands. 5 Julius Center for Health Sciences and Primary Care \& Department of Otorhinolaryngology, University Medical Center Utrecht, Utrecht University, Utrecht, Netherlands

$a$ These authors contributed equally to this work.. $b$ These authors contributed equally to this work.

Contact address: Helen Blackshaw, h.blackshaw@ucl.ac.uk.

Editorial group: Cochrane ENT Group.

Publication status and date: New, published in Issue 4, 2020.

Citation: Blackshaw H, Springford LR, Zhang L-Y, Wang B, Venekamp RP, Schilder AGM. Tonsillectomy versus tonsillotomy for obstructive sleep-disordered breathing in children. Cochrane Database of Systematic Reviews 2020, Issue 4. Art. No.: CD011365. DOI: 10.1002/14651858.CD011365.pub2.

Copyright @ 2020 The Cochrane Collaboration. Published by John Wiley \& Sons, Ltd.

\section{A B S T R A C T}

\section{Background}

Obstructive sleep-disordered breathing (OSDB) is a condition encompassing breathing problems when asleep due to upper airway obstruction. In children, hypertrophy of the tonsils and/or adenoids is thought to be the commonest cause. As such, (adeno)tonsillectomy has long been the treatment of choice. A rise in partial removal of the tonsils over the last decade is due to the hypothesis that tonsillotomy is associated with lower postoperative morbidity and fewer complications.

\section{Objectives}

To assess whether partial removal of the tonsils (intracapsular tonsillotomy) is as effective as total removal of the tonsils (extracapsular tonsillectomy) in relieving signs and symptoms of OSDB in children, and has lower postoperative morbidity and fewer complications.

\section{Search methods}

We searched the Cochrane ENT Trials Register; Central Register of Controlled Trials (CENTRAL); MEDLINE; EMBASE; CINAHL; Web of Science; ClinicalTrials.gov; ICTRP and additional sources for published and unpublished trials. The search date was 22 July 2019.

\section{Selection criteria}

Randomised controlled trials (RCTs) comparing the effectiveness of (adeno)tonsillectomy with (adeno)tonsillotomy in children aged 2 to 16 years with OSDB.

\section{Data collection and analysis}

We used standard Cochrane methods and assessed the certainty of the evidence for our pre-defined outcomes using GRADE. Our primary outcomes were disease-specific quality of life, peri-operative blood loss and the proportion of children requiring postoperative medical intervention (with or without hospitalisation). Secondary outcomes included postoperative pain, return to normal activity, recurrence of oSDB symptoms as a result of tonsil regrowth and reoperation rates. 


\section{Main results}

We included 22 studies (1984 children), with predominantly unclear or high risk of bias. Three studies used polysomnography as part of their inclusion criteria. Follow-up duration ranged from six days to six years. Although 19 studies reported on some of our outcomes, we could only pool the results from a few due both to the variety of outcomes and the measurement instruments used, and an absence of combinable data.

\section{Disease-specific quality of life}

Four studies (540 children; 484 (90\%) analysed) reported this outcome; data could not be pooled due to the different outcome measurement instruments used. It is very uncertain whether there is any difference in disease-specific quality of life between the two surgical procedures in the short ( 0 to 6 months; 3 studies, 410 children), medium ( 7 to 13 months; 2 studies, 117 children) and long term (13 to 24 months; 1 study, 67 children) (very low-certainty evidence).

\section{Peri-operative blood loss}

We are uncertain whether tonsillotomy reduces peri-operative blood loss by a clinically meaningful amount (mean difference (MD) 14.06 $\mathrm{mL}, 95 \% \mathrm{Cl} 1.91$ to $26.21 \mathrm{~mL} ; 8$ studies, 610 children; very low-certainty evidence). In sensitivity analysis (restricted to three studies with low risk of bias) there was no evidence of a difference between the groups.

\section{Postoperative complications requiring medical intervention (with or without hospitalisation)}

The risk of postoperative complications in the first week after surgery was probably lower in children who underwent tonsillotomy (4.9\% versus $2.6 \%$, risk ratio (RR) $1.75,95 \% \mathrm{Cl} 1.06$ to $2.91 ; 16$ studies, 1416 children; moderate-certainty evidence).

\section{Postoperative pain}

Eleven studies (1017 children) reported this outcome. Pain was measured using various scales and scored by either children, parents, clinicians or study personnel.

When considering postoperative pain there was little or no difference between tonsillectomy and tonsillotomy at 24 hours (10-point scale) (MD 1.09, 95\% Cl 0.88 to 1.29; 4 studies, 368 children); at two to three days (MD 0.93, $95 \% \mathrm{Cl}-0.14$ to 2.00 ; 3 studies, 301 children); or at four to seven days (MD 1.07, $95 \% \mathrm{Cl}-0.40$ to $2.53 ; 4$ studies, 370 children) (all very low-certainty evidence). In sensitivity analysis (restricted to studies with low risk of bias), we found no evidence of a difference in mean pain scores between groups.

\section{Return to normal activity}

Tonsillotomy probably results in a faster return to normal activity. Children who underwent tonsillotomy were able to return to normal activity four days earlier (MD 3.84 days, 95\% Cl 0.23 to 7.44; 3 studies, 248 children; moderate-certainty evidence).

\section{Recurrence of OSDB and reoperation rates}

We are uncertain whether there is a difference between the groups in the short ( $R R 0.26,95 \% \mathrm{Cl} 0.03$ to $2.22 ; 3$ studies, 186 children), medium (RR $0.35,95 \% \mathrm{Cl} 0.04$ to 3.23; 4 studies, 206 children) or long term (RR $0.2195 \% \mathrm{Cl} 0.01$ to 4.13 ; 1 study, 65 children) (all very lowcertainty evidence).

\section{Authors' conclusions}

For children with oSDB selected for tonsil surgery, tonsillotomy probably results in a faster return to normal activity (four days) and in a slight reduction in postoperative complications requiring medical intervention in the first week after surgery.

This should be balanced against the clinical effectiveness of one operation over the other. However, this is not possible to determine in this review as data on the long-term effects of the two operations on OSDB symptoms, quality of life, oSDB recurrence and need for reoperation are limited and the evidence is of very low quality leading to a high degree of uncertainty about the results.

More robust data from high-quality cohort studies, which may be more appropriate for detecting differences in less common events in the long term, are required to inform guidance on which tonsil surgery technique is best for children with oSDB requiring surgery.

\section{PLAIN LANGUAGE SUMMARY}

\section{Tonsillectomy versus tonsillotomy for obstructive sleep-disordered breathing in children}

\section{Review question}

This review compared the benefits and harms of surgery to remove the complete tonsils (tonsillectomy) against surgery to remove part of the tonsils (tonsillotomy) in children with disturbed sleep caused by breathing problems due to blockage of the upper airways (called 
obstructive sleep-disordered breathing). We included any studies in which children had either a tonsillectomy or tonsillotomy, published up to July 2019.

\section{Background}

Obstructive sleep-disordered breathing can occur in both children and adults. It ranges in seriousness from simple snoring to obstructive sleep apnoea syndrome (OSAS), where episodes of complete blockage of the upper airways and difficulty breathing can cause oxygen levels in the blood to drop, waking the child from sleep. Enlargement of the tonsils and adenoids is thought to be the most common cause in children. As such, tonsillectomy with or without removal of the adenoid (adenoidectomy) is considered a valuable first treatment option for most children. Over the past decade, driven by the availability of new surgical technologies and devices, tonsillotomy has become more popular. It is thought that children recover more quickly from this operation and may have fewer problems than after tonsillectomy.

\section{Study characteristics}

We included 22 studies, with a total of 1984 children aged 2 to 16 years with symptoms of obstructive sleep-disordered breathing. In three studies, a sleep study was also performed as part of the diagnosis. Children underwent tonsillectomy or tonsillotomy, with or without removal of the adenoid, and were followed after the operation for six days to six years. Nineteen of these studies measured some of the data we were looking to collect and analyse. However, we could only combine results from a limited number of studies as each study measured different outcomes and used different measurement instruments to do this. There were also difficulties in accessing the raw data from lots of studies.

\section{Key results}

Children with obstructive sleep-disordered breathing who are selected for tonsil surgery and who have a tonsillotomy seem to have a faster recovery from the operation compared to children who have a tonsillectomy, in particular in terms of return to their normal activity (four days quicker). Children who have a tonsillotomy may also have a slightly lower risk of having problems after the operation that need treatment with medication or further surgery than those who have a tonsillectomy ( $2.6 \%$ versus $4.9 \%)$. Any potential differences in terms of blood loss during the operation $(14 \mathrm{~mL}$ ) and pain scores at 24 hours after the operation (1.09 of a point on a 10-point scale) in favour of tonsillotomy were not considered noticeable.

Very few studies measured the effects of the two operations on the signs and symptoms of obstructive sleep-disordered breathing itself, quality of life of the child, the recurrence of obstructive sleep-disordered breathing or the need for a reoperation. Those that did found no evidence of a difference between the children who underwent tonsillectomy or tonsillotomy but these findings should be interpreted with great caution since the evidence derived from these studies was mostly of very low certainty.

\section{Certainty of the evidence}

The large majority of the studies included in this review had an unclear to high risk of bias and the evidence for most outcomes was of low to very low quality, meaning that the results are very uncertain. This means that we need more information from well-designed studies on the long-term outcomes of tonsillectomy and tonsillotomy to help parents and ENT surgeons choose which type of tonsil operation is best for children with obstructive sleep-disordered breathing who require surgery. 
SUMMARY OF FINDINGS

Summary of findings 1 . Tonsillectomy compared to tonsillotomy for obstructive sleep-disordered breathing in children

Tonsillectomy compared to tonsillotomy for obstructive sleep-disordered breathing in children

Patient or population: children aged 2 years up to the age of 16 years with obstructive sleep-disordered breathing

Setting: secondary or tertiary care

Intervention: tonsillectomy

Comparison: tonsillotomy

\begin{tabular}{|c|c|c|c|c|c|c|}
\hline \multirow[t]{2}{*}{ Outcomes } & \multirow{2}{*}{$\begin{array}{l}\text { № of partici- } \\
\text { pants } \\
\text { (studies) }\end{array}$} & \multirow{2}{*}{$\begin{array}{l}\text { Relative ef- } \\
\text { fect } \\
(95 \% \mathrm{CI})\end{array}$} & \multicolumn{2}{|c|}{ Anticipated absolute effects* $(95 \% \mathrm{Cl})$} & \multirow{2}{*}{$\begin{array}{l}\text { Certainty of } \\
\text { the evidence } \\
\text { (GRADE) }\end{array}$} & \multirow[t]{2}{*}{ Comments } \\
\hline & & & $\begin{array}{l}\text { Risk with tonsilloto- } \\
\text { my }\end{array}$ & $\begin{array}{l}\text { Risk with tonsil- } \\
\text { lectomy }\end{array}$ & & \\
\hline
\end{tabular}

Clinical effectiveness

$410 \quad-\quad$ Three studies reported no evidence of a dif-

$\oplus \ominus \ominus \ominus$

It is very uncertain whether there is any differ-

expressed as dis-

ference between treatment groups at 0 to 6 very low 1

ease-specific quality

of life

(Measured using

a validated instru-

ment)

\section{Follow-up: 0 to 6}

months, 7 to 12

months and 13 to 24

months

Peri-operative blood

loss

(3 RCTs)

months

$79 \quad-\quad$ One study reported no evidence of a differ- $\oplus \oplus \ominus \ominus$

ence between treatment groups at 7 to 12 very low 2

months

(1 RCT)

161

(2 RCTs)

$-$

Two studies reported no evidence of a dif-

ference between treatment groups at 13 to

24 months

$610 \quad-\quad$ Peri-operative blood

loss volume ranged

MD $14.06 \mathrm{~mL}$ higher

(1.91 higher to

$\oplus \ominus \ominus \ominus$

(Volume measured in

26.21 higher)

$\oplus \ominus \ominus \ominus$

very low 3

ence in disease-specific quality of life in the short ( 0 to 6 months), medium (7 to 12 months) or long term (13 to 24 months)

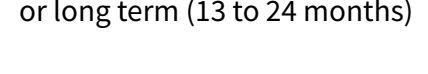

Postoperative com-

$\begin{array}{ll}1416 & \text { RR } 1.75 \\ (16 \mathrm{RCTs}) & (1.06 \text { to } 2.91)\end{array}$

medical intervention

(with or without hos-

pitalisation)

$\begin{array}{ll}\text { Study population (0 to } 7 \text { days) } & \begin{array}{c}\oplus \oplus \oplus \ominus \\ \text { moderate } 5\end{array} \\ 26 \text { per } 1000 & \begin{array}{l}46 \text { per } 1000 \\ (28 \text { to } 76)\end{array} \\ & \end{array}$

Although tonsillotomy might reduce peri-operative blood loss, the reduction was not clinically meaningful and the evidence is very uncertain.

A further 2 studies did not provide crude data; 1 reported no difference in blood loss and the other reported less bleeding in the children who underwent tonsillotomy.

The risk of postoperative complications in the first week after surgery was probably lower in children who underwent tonsillotomy.

One further study reported no complications requiring intervention. 


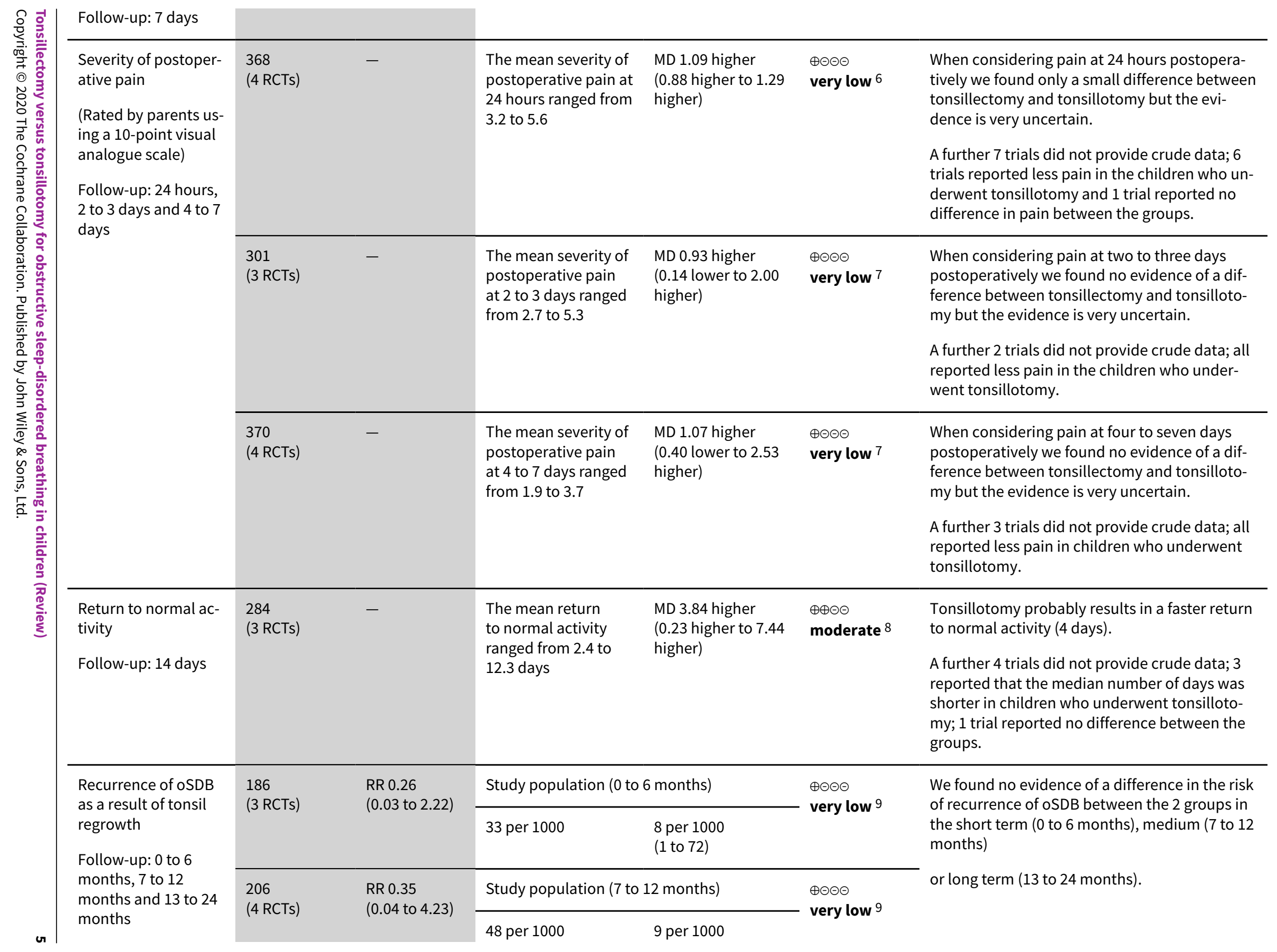


(1 to 60$)$

\begin{tabular}{ll}
\hline 65 & RR 0.21 \\
$(1 \mathrm{RCT})$ & (0.01 to 4.13)
\end{tabular}

Reoperation rates

Follow-up: 7 to 12

months and 13 to 24

months

$\begin{array}{ll}166 & \text { RR } 0.32 \\ \text { (2 RCTs) } & \text { (0.08 to } 1.28)\end{array}$

\begin{tabular}{ll}
\hline 41 & RR 0.35 \\
$(1 \mathrm{RCT})$ & $(0.02$ to 8.10
\end{tabular}

Study population (13 to 24 months)
Study population (13 to 24 months)

61 per 1000

13 per 1000

(1 to 250 )

Study population (7 to 12 months)

$\begin{array}{ll}\text { (1 RCT) } & \text { (0.02 to } 8.10)\end{array}$

$\oplus \ominus \ominus \ominus$

very low 9
92 per 1000

29 per 1000

(7 to 118 )

$\oplus \odot \odot \ominus$ very low 10

48 per 1000

17 per 1000

(1 to 386 )
One further trial did not provide crude data and reported no recurrence in either group at 13 to 24 months.

${ }^{\star}$ The risk in the intervention group (and its $95 \%$ confidence interval) is based on the assumed risk in the comparison group and the relative effect of the intervention (and its $95 \% \mathrm{Cl})$.

Cl: confidence interval; MD: mean difference; OSDB: obstructive sleep-disordered breathing; RCT: randomised controlled trial; RR: risk ratio

\section{GRADE Working Group grades of evidence}

High quality: We are very confident that the true effect lies close to that of the estimate of the effect

Moderate quality: We are moderately confident in the effect estimate: The true effect is likely to be close to the estimate of the effect, but there is a possibility that it is substantially different

Low quality: Our confidence in the effect estimate is limited: The true effect may be substantially different from the estimate of the effect

Very low quality: We have very little confidence in the effect estimate: The true effect is likely to be substantially different from the estimate of effect

1Our confidence in this estimate is 'very low' because of very serious limitations in study methodology, serious imprecision and suspected publication bias, with only three studies reporting on this outcome (in a manner that precluded meta-analysis).

2Our confidence in the estimate is 'very low' because of very serious limitations in study methodology, serious imprecision and suspected publication bias, with only one study reporting on this outcome.

${ }^{3}$ Our confidence in the estimate is 'very low' because of very serious limitations in study methodology, serious imprecision and suspected publication bias, with only two studies reporting on this outcome.

${ }^{4}$ Our confidence in the estimate is 'very low' due to inconsistency of effect estimates between main and sensitivity analyses as well as across individual trials (statistical heterogeneity) and imprecision of the evidence based on the wide confidence intervals.

5 Our confidence in the effect estimate is 'moderate' due to imprecision of the evidence based on the wide confidence intervals.

6Our confidence in the effect is 'very low' due to inconsistency of effect estimates between main and sensitivity analyses as well as across individual trials (statistical heterogeneity), imprecision of the evidence based on the wide confidence intervals and publication bias based on the small proportion of studies that reported data in a manner that permitted meta-analysis.

${ }^{7}$ Our confidence in the effect is 'very low' due to inconsistency of effect estimates across individual trials (statistical heterogeneity), imprecision of the evidence based on the wide confidence intervals and publication bias based on the small proportion of studies that reported data in a manner that permitted meta-analysis. 
Our confidence in the effect is 'moderate' due to imprecision of the evidence based on the wide confidence intervals and publication bias based on the small proportion of studies that reported data in a manner that permitted meta-analysis.

9 Our confidence in the effect is 'very low' due to very serious limitations in study methodology, inconsistency of effect estimates across individual trials (statistical heterogeneity), imprecision of the evidence and publication bias, with only a small number of studies reporting on this outcome.

10 Our confidence in the effect is 'very low' due to very serious limitations in study methodology, imprecision of the evidence and publication bias, with only one small study reporting on this outcome. 


\section{B A C K G R O U N D}

\section{Description of the condition}

Obstructive sleep-disordered breathing (OSDB) is a condition that encompasses problems breathing when asleep due to an obstruction of the upper airways and ranges in severity from simple snoring to obstructive sleep apnoea syndrome (OSAS). It affects both children and adults. Simple snoring, the mildest expression of oSDB, is not associated with arousal from sleep or episodes of low oxygen saturation in arterial blood. In contrast, OSAS, the most severe expression of oSDB, involves repeated episodes of restricted breathing (hypopnoea) and/or complete obstruction (apnoea) with reduction in the normal levels of oxygen saturation in arterial blood and arousal during sleep (Nespoli 2013). oSDB is a common condition in the paediatric population, with an estimated prevalence of primary snoring in children ranging from $8 \%$ to $27 \%$ and OSAS from 1\% to 5\% (Marcus 2012; Shine 2005).

In children, hypertrophy of the tonsils and adenoid tissue is thought to be the most common cause of oSDB; it causes narrowing of the airway, which is a particular problem during sleep when the muscles of the pharynx relax, leading to partial or complete obstruction of the airway (Marcus 2005). An overnight sleep study (polysomnography) is considered the most comprehensive investigation for diagnosing OSAS (Marcus 2012). In many countries, however, this test is not routinely performed in children with a suspected diagnosis of OSAS because of its high cost and limited availability (Friedman 2013; Marcus 2012; Pringle 2013). In everyday practice the severity of OSDB is usually assessed with a clinical history and examination, with some clinicians relying on overnight pulse oximetry (Pringle 2013).

Obstructive sleep-disordered breathing may have a considerable impact on children's quality of life, comparable in some aspects to that of juvenile rheumatoid arthritis (Baldassari 2008), and it has been linked with behavioural and neurocognitive morbidities (Beebe 2006; Owens 2009; Sedky 2014; Tauman 2011). Cognitive assessments of children with OSDB (either based on symptoms or on polysomnography) have shown a six-point lower score on the Wechsler preschool and Primary Scale Intelligence IQ test compared with those without OSDB (Gottileb 2004). Children with oSDB have also been shown to more likely to suffer from behavioural problems such as hyperactivity, emotional lability and aggression than children without sleep-disordered breathing (Rosen 2004). Furthermore, some children with longstanding untreated OSAS, the most severe form of oSDB, are at risk of severe health problems, including failure to thrive and cardiovascular diseases such as hypertension, pulmonary hypertension and left ventricular hypertrophy (Marcus 2001).

\section{Description of the intervention}

\section{Intervention}

Surgical removal of the palatine tonsils with or without removal of the adenoids, called (adeno)tonsillectomy, is a common surgical procedure in children (Erickson 2009; Patel 2014). In tonsillectomy, the tonsils are totally removed from their investing tissue in the oropharynx (extracapsular removal). The operation can be performed by various techniques including blunt dissection, guillotine knife, bipolar electrocautery, laser, microdebrider or coblation, according to the surgeon's preference. Adenoidectomy involves the removal of the adenoids (pharyngeal tonsil) from the nasopharynx; common techniques include curettage, suction cautery and microdebrider. (Adeno)tonsillectomy involves a general anaesthetic and can be performed as a day case or with an overnight stay (Cooper 2013; Lalakea 1999; Marcus 2012). Certain children undergoing surgery for OSDB are at increased risk of peri- and postoperative respiratory compromise (Baugh 2011; Fung 2010; Robb 2009; Schwengel 2009; Statham 2006). Guidelines from the American Academy of Pediatrics (Marcus 2012) and the UK Royal College of Paediatrics and Child Health (Royal College of Paediatrics and Child Health 2009) therefore recommend overnight observation for high-risk cases such as young children (below four years of age), those with certain comorbidities (cardiovascular, craniofacial, neuromuscular conditions) or children with severe OSAS (e.g. an oxygen saturation level in arterial blood of $80 \%$ or lower or an Apnoea/Hypopnoea Index (AHI) greater than 24).

Throat pain and reduced oral intake are common following (adeno)tonsillectomy with over 50\% of children still experiencing pain three days after the operation despite analgesia. Vomiting and nausea occur less frequently, with one in 10 children reporting vomiting several days postoperatively (Stanko 2013). An important complication is postoperative bleeding. Evidence is accumulating that the rate of this complication differs between surgical techniques used and across indications for surgery (Lowe 2007; Hallenstål 2017; Mueller 2015; Sarny 2011). Large audits and population-based studies have revealed postoperative bleeding rates of $3.7 \%$ to $11.1 \%$ for recurrent tonsillitis and $1.4 \%$ to $2.5 \%$ for upper airway obstruction, whilst studies have reported rates of $10 \%$ to $12.3 \%$ after tonsillectomy and $1.7 \%$ to $2.2 \%$ after tonsillotomy (Lowe 2007; Hallenstål 2017; Sarny 2011).

\section{Comparator}

Over the past decade there has been increasing interest in partial removal of the tonsils, known as tonsillotomy, which may be associated with lower postoperative morbidity and fewer complications than complete removal of the tonsils (tonsillectomy). Tonsillotomy, or intracapsular tonsil removal, aims to reduce the size of the tonsils without exposure of the pharyngeal muscles, which is inherent to extracapsular tonsillectomy techniques (see section above). Intracapsular tonsillotomy is achieved using microdebrider, coblation, radiofrequency and argon-assisted techniques.

\section{How the intervention might work}

In children, hypertrophy of the tonsils and adenoid tissue is thought to be the commonest cause of oSDB. Therefore, surgical removal of the adenoid tissue and palatine tonsils is widely considered an effective treatment for sleep-disordered breathing in children. Whilst tonsillotomy is thought to have the same beneficial effect as tonsillectomy on snoring and other symptoms of obstruction, the partial removal leaves residual tissue within the tonsillar bed, thereby reducing exposure and inflammation of the underlying pharyngeal muscles, which may result in less postoperative pain. In addition, there is decreased disruption of blood vessels beneath the tonsillar capsule, which may reduce the need for electrocautery and postoperative pain as well as reduce the risk of postoperative haemorrhage. As a consequence, this procedure may increase the rate of return to normal activity (Koltai 2003). However, regrowth of the tonsils is possible after tonsillotomy, which may lead to a recurrence of OSDB and episodes of tonsillitis (Sorin 2004). 


\section{Why it is important to do this review}

There is substantial evidence of the association between childhood OSDB and adverse health outcomes, particularly in those with OSAS. A recent Cochrane Review showed that children diagnosed with mild to moderate OSAS by polysomnography benefit from early adenotonsillectomy in terms of objective parameters of sleep and symptoms and behaviour as reported by caregivers (Venekamp 2015). With tonsillotomy increasingly offered worldwide as an alternative to tonsillectomy in the treatment of children with OSDB, this review aims to assess whether partial removal of the tonsils (intracapsular tonsillotomy) 1) is as effective as total removal of the tonsils (extracapsular tonsillectomy) in relieving the symptoms of oSDB; and 2) has lower postoperative morbidity and fewer complications than extracapsular tonsillectomy.

\section{O B JECTIVES}

To assess whether partial removal of the tonsils (intracapsular tonsillotomy) is as effective as total removal of the tonsils (extracapsular tonsillectomy) in relieving signs and symptoms of OSDB in children, and has lower postoperative morbidity and fewer complications.

\section{MET HOD S}

\section{Criteria for considering studies for this review \\ Types of studies}

Randomised controlled trials (RCTs) comparing the effectiveness of (adeno)tonsillectomy with (adeno)tonsillotomy in children with oSDB. We included trials reporting combined interventions (e.g. adenoidectomy in addition to tonsillectomy and tonsillotomy) if the decision to undertake an additional procedure was part of the study protocol (and not decided once the surgeon knew whether the child was randomised to one of the two groups), if they allow a direct comparison between the intervention and control group and if the two groups were not treated differently except for the type of tonsil surgery (tonsillectomy or tonsillotomy). We defined 'not treated differently' as a maximum of $10 \%$ difference between the intervention and control group in the proportion of children that underwent additional study procedures.

\section{Types of participants}

Children aged two years up to the age of 16 years with OSDB. We included RCTs where the diagnosis of OSDB was based upon clinical history and examination alone as well as those where overnight pulse oximetry and/or polysomnography was carried out to confirm the diagnosis. We excluded studies in children with central SDB (e.g. SDB related to neurological conditions or brain injury), and in children with combinations of central and obstructive SDB.

\section{Types of interventions}

\section{Intervention group}

(Adeno)tonsillectomy, irrespective of the surgical technique used.

\section{Comparator group}

(Adeno)tonsillotomy, irrespective of the surgical technique used.
The sole comparison was therefore (adeno)tonsillectomy versus (adeno)tonsillotomy.

\section{Types of outcome measures}

We analysed the primary and secondary outcomes listed below in this review, but we did not use these as a basis for including or excluding studies.

\section{Primary outcomes}

- Clinical effectiveness expressed as disease-specific quality of life using any validated instrument, such as Obstructive Sleep Apnoea 18 (OSA-18) or Obstructive Sleep Disorders 6-survey (OSD-6; see the Spruyt 2011 review for a comprehensive list) and/or disease-specific symptom scores using any validated instrument, such as the Paediatric Sleep Questionnaire (PSQ; see the Spruyt 2011 review for a comprehensive list) at 0 to 6 months (short term), 7 to 12 months (medium term) and 13 to 24 months (long term).

- Peri- and postoperative morbidity and complications expressed as:

- peri-operative blood loss (volume measured);

- proportion of children requiring medical intervention (with or without hospitalisation), within the first seven days after surgery, due to haemorrhage from the tonsillar bed, infection or dehydration.

\section{Secondary outcomes}

At 0 to 6 months (short-term), 7 to 12 months (medium-term) and 13 to 24 months (long-term):

- Clinical effectiveness expressed as:

- behaviour (using a validated instrument);

- measures of respiratory events during sleep (e.g. Apnoea Hypopnoea Index (AHI), Respiratory Disturbance Index (RDI), oxygen desaturations, respiratory event-related arousals);

- recurrence of OSDB as a result of tonsil regrowth (using clinical history and examination with or without pulse oximetry or polysomnography);

- reoperation rates;

- incidence of throat infection (tonsillitis).

- Peri- and postoperative morbidity and complications expressed as:

- duration of surgery;

- (severity of) postoperative pain (using a validated instrument) in the short ( 24 hours), medium ( 2 to 3 days) and long term (4 to 7 days);

- days until analgesics no longer required;

- return to normal diet;

- return to normal activity.

\section{Search methods for identification of studies}

The Cochrane ENT Information Specialist conducted systematic searches for randomised controlled trials and controlled clinical trials. There were no language, publication year or publication status restrictions. The date of the search was 22 July 2019. 


\section{Electronic searches}

The Information Specialist searched:

- the Cochrane ENT Trials Register (searched via the Cochrane Register of Studies 22 July 2019);

- the Cochrane Central Register of Controlled Trials (searched via the Cochrane Register of Studies) (CENTRAL 2019, Issue 7);

- Ovid MEDLINE, Epub Ahead of Print, In-Process \& Other NonIndexed Citations, and Ovid MEDLINE(R) Daily (1946 to 22 July 2019);

- Ovid EMBASE (1974 to 22 July 2019);

- LILACS (Latin American and Caribbean Health Science Information database) (searched lilacs.bvsalud.org 22 July 2019);

- Web of Knowledge, Web of Science (1945 to 22 July 2019);

- CNKI, www.cnki.com.cn (searched via Google Scholar 22 July 2019);

- ClinicalTrials.gov (searched via clinicaltrials.gov and the Cochrane Register of Studies 22 July 2019);

- World Health Organization (WHO) International Clinical Trials Registry Platform (ICTRP) (searched via www.who.int/ictrp and the Cochrane Register of Studies 22 July 2019).

In searches prior to September 2016, we also searched PubMed (as a top-up to searches to Ovid MEDLINE) 1946 to July 2015. In searches prior to July 2019, we also searched CINAHL, KoreaMed, IndMed, PakMediNet and ISRCTN to June 2017.

The Information Specialist modelled subject strategies for databases on the search strategy designed for CENTRAL. Where appropriate, they were combined with subject strategy adaptations of the highly sensitive search strategy designed by Cochrane for identifying randomised controlled trials and controlled clinical trials (as described in the Cochrane Handbook for Systematic Reviews of Interventions). Search strategies for major databases including CENTRAL are provided in Appendix 1. In June 2019, the Information Specialist made changes to the search of CENTRAL. Details of the previous search are in Appendix 2. The search of CENTRAL performed in July 2019 was run over all years.

\section{Searching other resources}

We scanned the reference lists of identified publications for additional trials and contacted trial authors where necessary. In addition, the Information Specialist searched Ovid MEDLINE and Google to retrieve existing systematic reviews relevant to this systematic review, so that we could scan their reference lists for additional trials. The Information Specialist also ran nonsystematic searches of Google Scholar to retrieve grey literature and other sources of potential trials.

We did not perform a separate search for adverse effects. We considered adverse effects described in the included studies only.

\section{Data collection and analysis}

\section{Selection of studies}

Five review authors (HB and either RPV, LZ or BW plus RPV and LRS for most recent searches) independently screened the titles and abstracts obtained from the database searches and citations of relevant systematic review articles to assess their potential relevance for full review. The same five review authors (HB and either RPV, LZ or BW plus RPV and LRS for most recent searches) independently reviewed the full text of potentially relevant titles and abstracts against the inclusion and exclusion criteria. Disagreements were resolved by discussion. We documented the exclusion of any studies from the review and described the reasons for exclusion in the Characteristics of excluded studies table.

\section{Data extraction and management}

Five review authors (HB and LRS plus either RPV, LZ or BW) independently extracted data from the included studies using standardised forms. We extracted the following information from each study:

- Trial characteristics: setting, design and method of data analysis.

- Participants: study population, number of children in each group and patient characteristics such as age, gender and how a diagnosis of OSDB was made.

- Interventions: type of surgical procedure including technique and concurrent procedures.

- Outcomes: primary and secondary outcomes recorded, time points and adverse events related to the intervention.

We pre-specified the time points of interest for the outcomes in this review. Where studies reported data at multiple time points, we only extracted the longest available data within the time points of interest. For example, for 'medium-term' follow-up periods, our time point is defined as ' 7 to 12 months' post-randomisation. If a study had reported data at 9 and 12 months, we extracted and analysed the data for the 12-month follow-up.

\section{Assessment of risk of bias in included studies}

Five review authors (HB and LRS plus either RPV, LZ or BW) independently assessed the methodological quality of the included trials. Any disagreements were resolved by discussion. Guided by the Cochrane Handbook for Systematic Reviews of Interventions, we judged the following domains as high, low or unclear risk of bias:

- sequence generation (selection bias);

- allocation concealment (selection bias);

- blinding of participants and personnel (performance bias);

- blinding of outcome assessment (detection bias);

- incomplete outcome data (attrition bias);

- selective outcome reporting (reporting bias); and

- other sources of bias.

\section{Method of Zelen}

For studies using the 'method of Zelen' for randomisation, whereby patients are randomised before being contacted about the study, the number of participants were reported as those randomised minus those who declined to enter the study or who were excluded due to the exclusion criteria. Those children who agreed to participate in the study, but later refused to undergo surgery or spontaneously recovered, were reported as lost to follow-up. We judged studies using the 'method of Zelen' randomisation procedure to have a high risk of attrition bias if the proportion of randomised children not included in the study was greater than $20 \%$. 
We presented the results of the 'Risk of bias' assessment in a 'Risk of bias' graph and summary figure.

\section{Measures of treatment effect}

We expressed the pooled measures of treatment effect for dichotomous outcomes as a risk ratio (RR) with accompanying 95\% confidence interval $(\mathrm{Cl})$. For the key outcomes presented in the 'Summary of findings' table, we also expressed the results as absolute numbers based on the pooled results and compared to the assumed risk. Where appropriate, we calculated the number needed to treat to benefit (NNTB) using the pooled results.

We expressed continuous outcome variables either as a mean difference (MD) with $95 \% \mathrm{Cl}$, if reported on the same scale, or as a standardised mean difference (SMD) with $95 \% \mathrm{Cl}$, if different continuous scales were used.

\section{Unit of analysis issues}

We aimed to include all relevant RCTs irrespective of design. We identified no studies with non-standard designs, such as cross-over or cluster-randomised trials.

\section{Dealing with missing data}

To address any concerns about missing data, we contacted trial authors from 16 included individual studies multiple times to request further data (Beriat 2013; Borgstrom 2017; Chaidas 2013; Chan 2004; Chang 2005; Chang 2008; Coticchia 2006; Densert 2001; Derkay 2006; Ericsson 2009; Hultcrantz 1999; Hultcrantz 2004; Kordeluk 2016; Korkmaz 2008; Park 2007; Skoulakis 2007). We had five responses regarding seven of the included studies (Chaidas 2013; Chang 2005; Chang 2008; Derkay 2006; Hultcrantz 1999; Hultcrantz 2004; Park 2007), and one trial author provided additional data (Derkay 2006).

We analysed the available data based on the intention-to-treat (ITT) principle, whereby participants are analysed in the groups to which they were randomised. For continuous outcomes, we calculated missing statistics, such as standard deviations (SDs), from other available statistics (e.g. $P$ values) according to the methods described in the Cochrane Handbook for Systematic Reviews of Interventions (Higgins 2019). Apart from imputations for missing standard deviations, we did not conduct any other imputations. We extracted and analysed all data using the available case analysis method.

\section{Assessment of heterogeneity}

First, we assessed the level of clinical diversity between studies by reviewing the differences in the types of participants recruited, the way the diagnosis of OSDB was made, the interventions used and the outcomes measured between studies. Next, we assessed the statistical heterogeneity for each outcome by using the $\mathrm{Chi}^{2}$ test, with a significance level set at $P$ value $<0.10$, and the $I^{2}$ statistic, with $1^{2}$ values over $50 \%$ suggesting substantial heterogeneity (Higgins 2003).

\section{Assessment of reporting biases}

For each study, we searched the internet and ClinicalTrials.gov (http://clinicaltrials.gov/) for available study protocols. Whenever possible, we assessed whether the outcomes reported in the publications of the studies were listed in the registered trial protocol. More formal assessments using funnel plots would have been conducted if sufficient studies had been available.

\section{Data synthesis}

We performed data analysis according to the ITT principle, i.e. we analysed all participants in the group to which they were originally allocated.

In the absence of significant clinical diversity, we performed meta-analyses. We calculated treatment differences with the Mantel-Haenszel method using a fixed-effect model where no substantial heterogeneity was present $\left(I^{2}\right.$ values $\left.<50 \%\right)$. If statistical heterogeneity was detected but unresolved by subgroup analysis, we applied a random-effects model (DerSimonian and Laird) to provide a more conservative estimate of the effect. Where appropriate, we calculated the NNTB for dichotomous outcomes using the results of the meta-analysis (which itself uses risk ratio) based on the average risk of the control groups in the included studies ('study population') (Higgins 2019).

Where we decided to refrain from pooling the study results because of clinical diversity, we reported the effect estimates as presented by the individual studies.

\section{Subgroup analysis and investigation of heterogeneity}

We had planned to perform the following subgroup analyses, however the data did not allow for this:

- sleep-disordered breathing severity (OSAS versus less severe sleep-disordered breathing);

- sleep-disordered breathing diagnosis (clinical diagnosis alone versus diagnosis based on polysomnography);

- age (younger than three, three to seven, and above seven years);

- body weight (obese versus non-obese children);

- race (African-American versus other).

\section{Sensitivity analysis}

To assess the robustness of the review findings, we performed a sensitivity analysis in which studies classified as having a high risk of bias were excluded. We defined high risk of bias as high risk of allocation concealment bias or attrition bias (overall loss to followup of more than $20 \%$ or differential follow-up observed, or both).

\section{Summary of findings and assessment of the certainty of the evidence}

We used the GRADE approach to rate the overall certainty of evidence for each outcome. There are four possible ratings: high, moderate, low and very low. A 'high certainty of evidence' rating implies that we feel confident about the effect estimate and that further research is very unlikely to change our confidence in the effect estimate. In contrast, a 'very low certainty of evidence' rating implies that our confidence in the effect estimate is very uncertain.

Evidence from RCTs that do not have serious limitations is rated as 'high certainty'. However, several factors can contribute to downgrading of the evidence to moderate, low or very low. The degree of downgrading depends on each of the following factors:

- study limitations (risk of bias);

- indirectness of evidence; 
- imprecision;

- inconsistency;

- publication bias.

We included a 'Summary of findings' table for the main comparison (Summary of findings 1), constructed according to the description in the Cochrane Handbook for Systematic Reviews of Interventions (Higgins 2019).

We reported the following seven outcomes in the 'Summary of findings' table:

- disease-specific quality of life;

- peri-operative blood loss;

- proportion of children requiring postoperative medical intervention (with or without hospitalisation) due to haemorrhage, infection and dehydration;

- postoperative pain;

- return to normal activity;

- recurrence of obstructive sleep-disordered breathing symptoms as a result of tonsil regrowth;
- reoperation rates.

\section{RES U L T S}

\section{Description of studies}

For details of the included trials see the Characteristics of included studies table. The reasons for excluding studies from the review are shown in the Characteristics of excluded studies table. Details of ongoing studies are presented in the Characteristics of ongoing studies table.

\section{Results of the search}

The searches retrieved a total of 1556 records and three further records were identified through screening reference lists of relevant systematic reviews. Removing duplicates left 448 unique records. After screening titles and abstracts, we identified 42 potentially eligible publications. We excluded 12 studies (see Characteristics of excluded studies table), leaving 30 publications related to 22 individual studies eligible for inclusion (Figure 1). 
Figure 1. Process for sifting search results and selecting studies for inclusion.

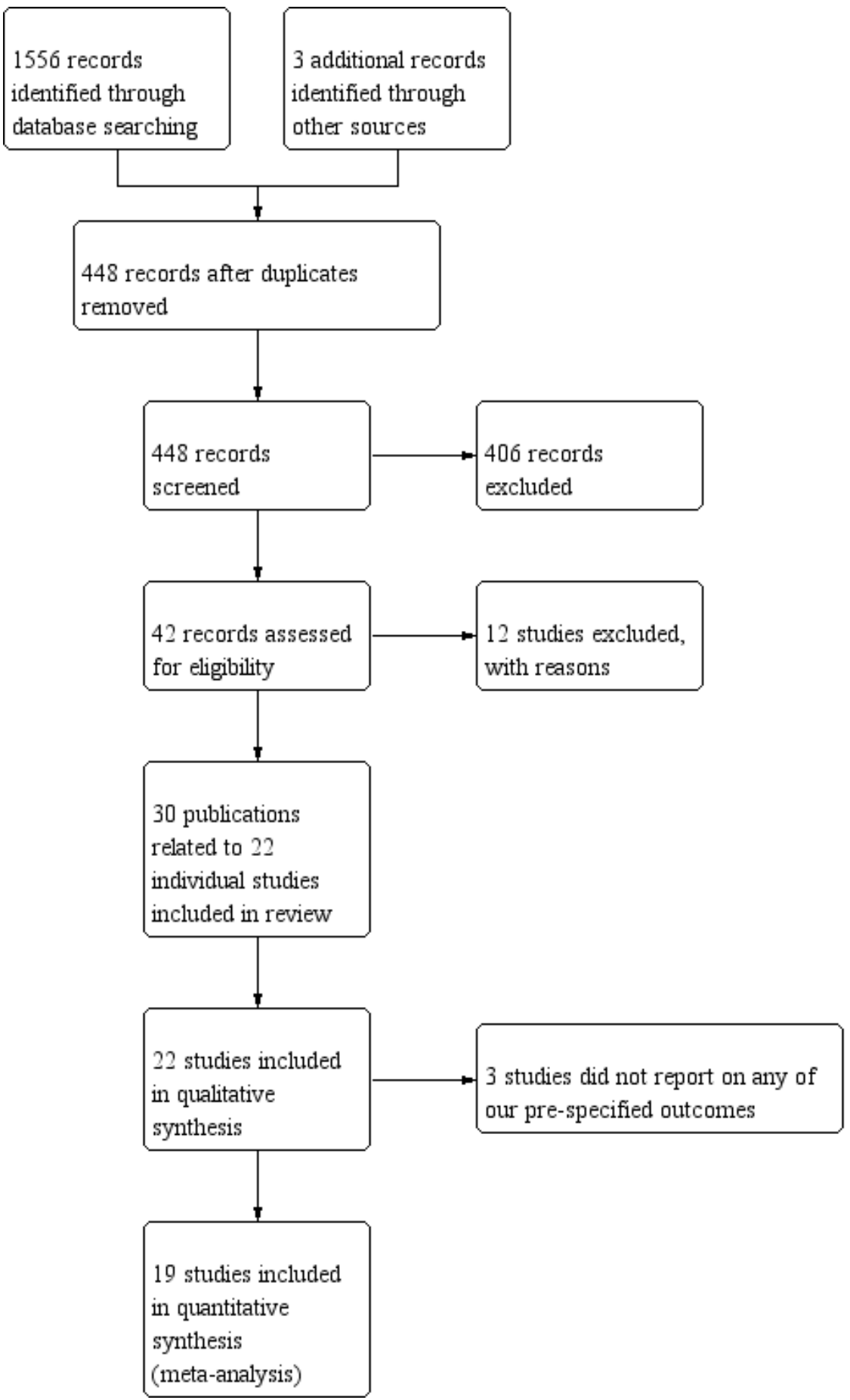

We identified one ongoing trial (see Characteristics of ongoing studies table).

\section{Included studies}

For details of the included studies see the Characteristics of included studies table.

\section{Design}

All 22 included studies were parallel-group RCTs: six (26\%) were double-blinded, three (14\%) were participant-blinded, one $(5 \%)$ was assessor-blinded and 12 (55\%) were open-label trials.

\section{Participants and setting}

Sample sizes of the included trials ranged from 23 to 300 children. The participants in all studies were children aged from 2 to 16 years with a history of sleep-disordered breathing or obstructive 
symptoms and tonsil hypertrophy. Only three studies (14\%) used polysomnography as part of the inclusion criteria. All trials were conducted in secondary care with seven studies (32\%) taking place in the USA, six (26\%) in Sweden, three (14\%) in China, two (9\%) in Greece, two (9\%) in Turkey, one (5\%) in Israel and one (5\%) in Lebanon.

\section{Interventions and comparators}

In the included studies a range of surgical techniques were performed. Tonsillectomy was mostly performed using blunt dissection (41\%) and electrocautery (36\%), while tonsillotomy was mostly achieved using coblation (27\%), microdebrider (23\%) and radiofrequency (18\%). Concurrent adenoidectomy was performed in all children in nine studies $(41 \%)$ and in a proportion of children in five studies (22\%). In seven studies the proportion was not stated $(32 \%)$ and in one study all of the children had previously undergone adenoidectomy (5\%). Further details of the interventions in each study are given in the 'Overview of interventions' table (Table 1).

\section{Outcomes}

Nineteen of the included studies (86\%) reported our pre-specified primary and secondary outcomes, the details of which can be found in the 'Primary outcomes' (Table 2) and 'Secondary outcomes' (Table 3) tables. Three studies (14\%) did not report on any of our pre-specified primary or secondary outcomes (Bitar 2016; Dai 2014; Lundeborg 2009).

\section{Funding and conflicts of interest}

Four studies (18\%) were financially supported by pharmaceutical companies: Medtronics Corporation (Bitar 2016; Derkay 2006 2; ArthroCare Corporation (Chan 2004); and Somnus Medical
Technologies (Coticchia 2006). Three studies (14\%) were funded by government grants: Research Council of South East Sweden (Ericsson 2009; Hultcrantz 1999; Hultcrantz 2004). One study (5\%) was funded by charitable foundations: the Samaritan Foundation, the Freemason Child House Foundation in Stockholm and the Acta Otolaryngologica Foundation (Borgstrom 2017). Funding was not described in 14 studies (63\%) (Beriat 2013; Chaidas 2013; Chang 2005; Chang 2008; Dai 2014; Densert 2001; Kordeluk 2016; Korkmaz 2008; Li 2013; Lundeborg 2009; Park 2007; Skoulakis 2007; Sobol 2006; Zhou 2016).

\section{Excluded studies}

We excluded 12 studies after reviewing the full text (Characteristics of excluded studies), mainly because these studies were not RCTs (four studies), included a different study population (three studies) or did not compare tonsillectomy versus tonsillotomy (two studies).

\section{Ongoing studies}

We found one ongoing trial comparing adenotonsillectomy versus adenotonsillectomy in Swedish children aged two to six years with tonsil hypertrophy and moderate to severe OSA confirmed by nocturnal polysomnography (see Characteristics of ongoing studies table) with a 10-year follow-up period. Some of the results of this study have been included in this review (Borgstrom 2017), but the long-term results are still pending (follow-up of participants is ongoing).

\section{Risk of bias in included studies}

Details of the 'Risk of bias' assessment of the included studies are presented in Figure 2 and Figure 3.

\section{Figure 2. 'Risk of bias' graph: review authors' judgements about each risk of bias item presented as percentages across all included studies.}

Random sequence generation (selection bias)

Allocation concealment (selection bias)

Blinding of participants and personnel (performance bias): All outcomes

Blinding of outcome assessment (detection bias): All outcomes Incomplete outcome data (attrition bias): All outcomes

Selective reporting (reporting bias)

Other bias
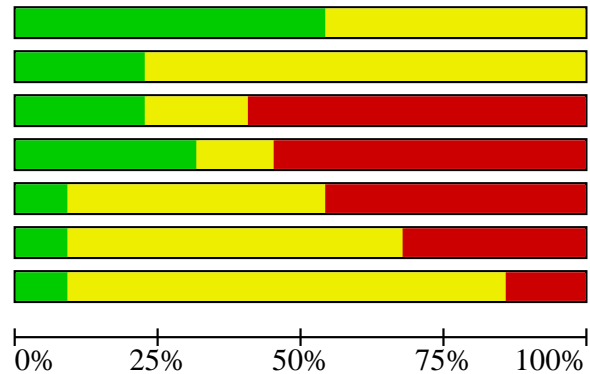

Low risk of bias

Unclear risk of bias

High risk of bias 
Figure 3. 'Risk of bias' summary: review authors' judgements about each risk of bias item for each included study.

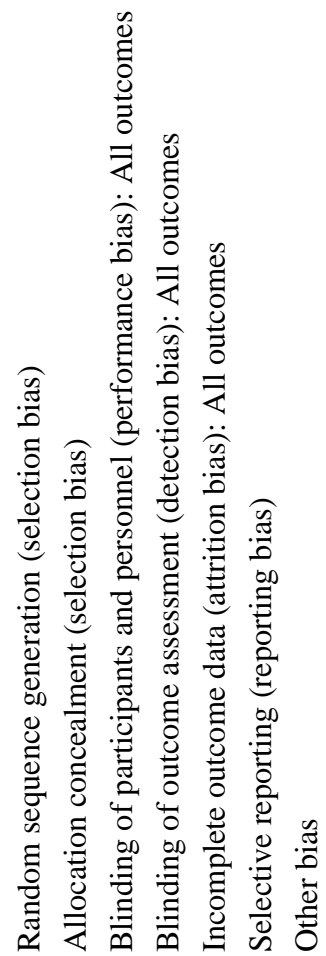

Beriat 2013

Bitar 2016

Borgstrom 2017

Chaidas 2013

Chan 2004

Chang 2005

Chang 2008

Coticchia 2006

Dai 2014

Densert 2001

Derkay 2006

Ericsson 2009

Hultcrantz 1999

Hultcrantz 2004

Kordeluk 2016

Korkmaz 2008

Li 2013

Lundeborg 2009

Park 2007

Skoulakis 2007

Sobol 2006

Zhou 2016

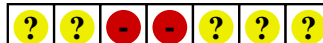


Figure 3. (Continued)

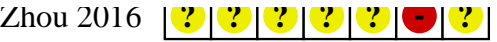

\section{Allocation}

\section{Sequence generation}

The method of random sequence generation was adequately described in 12 studies (55\%) and unclear in 10 studies (45\%).

\section{Allocation concealment}

Allocation concealment was adequately described in five studies $(23 \%)$ and unclear in 17 studies $(77 \%)$.

\section{Blinding}

We judged the risk of bias for blinding of participants and personnel (performance bias) as low in five studies (23\%), unclear in four studies (18\%) and high in 13 studies (59\%). We judged the risk of bias for blinding of outcome assessment (detection bias) as low in seven studies (32\%), unclear in three studies (14\%) and high in 12 studies (55\%).

\section{Incomplete outcome data}

We judged the risk of bias for incomplete outcome data as low in two studies (9\%), unclear in 11 studies (50\%) and high in nine studies (41\%).

\section{Selective reporting}

We judged the risk of bias for selective reporting as low in two studies (9\%) and high in seven studies (32\%). We could not retrieve trial protocols for the remaining 13 studies (59\%) and therefore could not determine the risk of selective outcome reporting bias for these studies.

\section{Other potential sources of bias}

We judged the risk of other potential sources of bias as low in two studies (9\%), unclear in 17 studies (77\%) and high in three studies (14\%).

\section{Effects of interventions}

See: Summary of findings $\mathbf{1}$ Tonsillectomy compared to tonsillotomy for obstructive sleep-disordered breathing in children

See 'Summary of findings' table for the main comparison (Summary of findings 1 ).

\section{Comparison: (adeno)tonsillectomy versus (adeno)tonsillotomy}

\section{Primary outcomes}

\section{Clinical effectiveness expressed as disease-specific quality of life using any validated instrument}

\section{Short-term (0 to 6 months)}

Three studies reported this outcome.

One study (300 children included in analysis) used a validated quality of life survey evaluating physical suffering, sleep disturbance, speech or swallowing problems, emotional distress, activity limitations and caregiver concern on 0 to 6 scales and stated that at one month "no significant differences between the groups in presurgical to postsurgical changes" were observed (Derkay 2006).

One study measured snoring, apnoea and well-being using a visual analogue scale (VAS) where the intensity of symptoms was marked on a $150 \mathrm{~mm}$-long line (Densert 2001). This study did not report the number of children randomised to each arm (a total of 43 children were randomised; 43 (100\%) were included in analysis). At three months the scores were similar in the tonsillotomy and tonsillectomy groups for snoring (9 versus 13), apnoea (9 versus 9) and well-being (11 versus 14) with no differences after tonsillotomy compared to tonsillectomy in the mean difference from baseline scores for snoring (112 versus 104), apnoea (62 versus 66) and wellbeing (85 versus 46 ).

One other study (118 randomised children; 67 (57\%) included in analysis) measured disease-specific quality of life at six months using the OSA-18 questionnaire, an 18-item instrument are scored on a seven-point scale and totalled, providing a severity score of 18 to 126, with lower scores representing higher quality of life (Ericsson 2009). The median total OSA-18 scores at six months were not different between children who underwent tonsillectomy and those who underwent tonsillotomy: 25 (IQR 23 to 32 ) versus 27 (IQR 22 to 34$)$.

\section{Certainty of the evidence}

We consider the evidence for this outcome to be of very low certainty; we downgraded it from high to very low certainty due to very serious limitations in study methodology, serious imprecision and suspected publication bias, with only three studies reporting on this outcome (in a manner that precluded meta-analysis).

\section{Medium-term ( 7 to 12 months)}

One study (79 randomised children; 74 (94\%) included in the analysis) reported this outcome (Borgstrom 2017). This study measured disease-specific quality of life at 12 months using the OSA-18 questionnaire (Borgstrom 2017). There was no evidence of a difference in mean change scores between the groups at 12 months (MD -1.17, 95\% confidence interval (CI) -9.92 to 7.58 ).

\section{Certainty of the evidence}

We consider the evidence for this outcome to be of very low certainty; we downgraded it from high to very low certainty due to serious limitations in study methodology, serious imprecision and suspected publication bias, with only with only one small study reporting on this outcome.

\section{Long-term (13 to 24 months)}

Two studies reported on this outcome.

One study measured disease-specific quality of life at 24 months using the OSA-18 questionnaire (Ericsson 2009). This study (118 randomised children; 64 (54\%) included in analysis) stated there 
"was no difference between the tonsillotomy and tonsillectomy groups in the improvement of scores after 2 years".

One study measured snoring, apnoea and well-being using a VAS where the intensity of symptoms was marked on a $150 \mathrm{~mm}$-long line (Densert 2001). This study did not report the number of children randomised to each arm (a total of 43 children were randomised; $43(100 \%)$ were included in analysis). At 24 months the scores were similar in the tonsillotomy and tonsillectomy groups for snoring (10 versus 17 ), apnoea ( 0 versus 1 ) and well-being ( 24 versus 11 ) with no differences after tonsillotomy compared to tonsillectomy in the mean difference from baseline scores for snoring (111 versus 100), apnoea (71 versus 74 ) and well-being (72 versus 49$)$.

\section{Certainty of the evidence}

We consider the evidence for this outcome to be of very low certainty; we downgraded it from high to very low certainty due to very serious limitations in study methodology, imprecision of the evidence and suspected publication bias, with only two studies reporting on this outcome (in a manner that precluded metaanalysis).

\section{Peri-and postoperative morbidity and complications}

Peri-operative blood loss (volume measured)

Ten studies reported this outcome.

We were unable to include two studies in meta-analysis. One of these studies ( 55 randomised children; 43 (78\%) children included in analysis) stated that "blood loss did not differ significantly between treatment groups $(p=0.77) "$ (Chan 2004). The other study (30 randomised children; $30(100 \%)$ children included in analysis) stated that "intraoperative bleeding was significantly smaller" in the children who underwent tonsillotomy than those who underwent tonsillectomy (Skoulakis 2007).

We could therefore combine data from eight studies (702 randomised children; 610 (87\%) included in analysis) (Beriat 2013; Chaidas 2013; Chang 2005; Hultcrantz 1999; Hultcrantz 2004; Korkmaz 2008; Park 2007; Sobol 2006). Mean blood loss (mL) was lower in children who underwent tonsillotomy than those who underwent tonsillectomy, but this was not clinically meaningful (MD $14.06 \mathrm{~mL}, 95 \% \mathrm{Cl} 1.91 \mathrm{~mL}$ to $26.21 \mathrm{~mL} ; \mathrm{I}^{2}=88 \%$, random-effects model) (Analysis 1.1; Figure 4).

\section{Figure 4. Forest plot of comparison: 1 Tonsillectomy versus tonsillotomy, outcome: 1.1 Peri-operative blood loss} $[\mathrm{mL}]$.

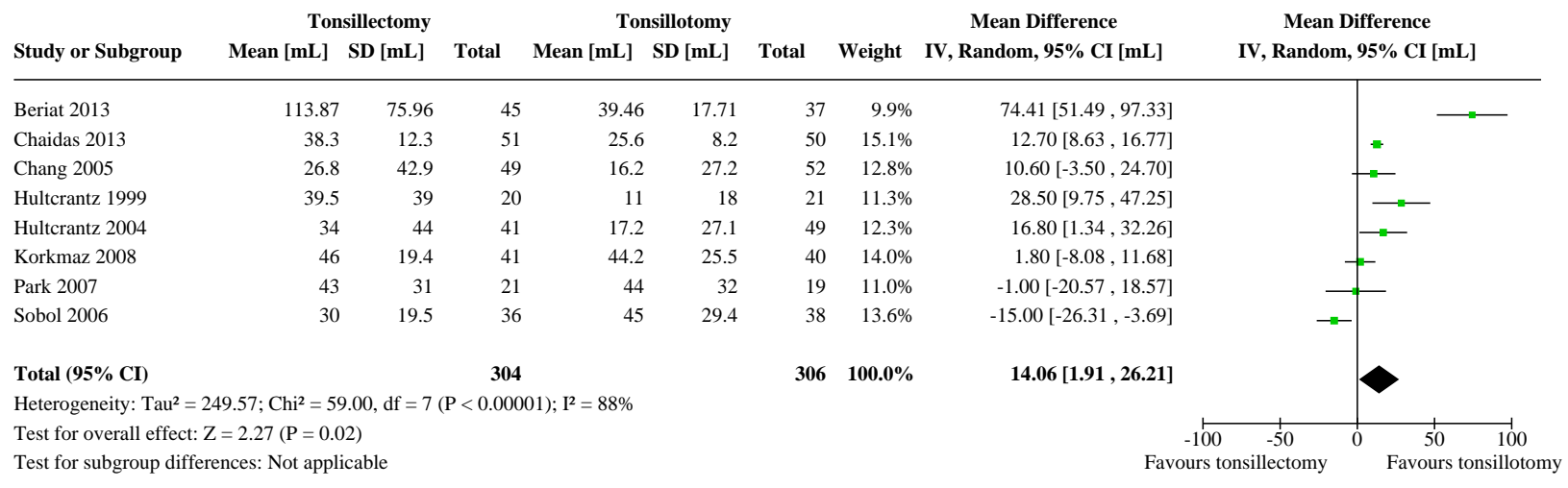

In a sensitivity analysis, where we excluded studies classified as high risk of bias, we could combine data from only three studies (196 randomised children; 196 (100\%) included in analysis) (Beriat 2013; Park 2007; Sobol 2006). In this analysis, we found no evidence of a difference in mean blood loss $(\mathrm{mL})$ between children who underwent tonsillectomy and those who underwent tonsillotomy (MD $18.71 \mathrm{~mL}, 95 \% \mathrm{Cl}-30.45 \mathrm{~mL}$ to $67.87 \mathrm{~mL} ; \mathrm{I}^{2}=96 \%$, randomeffects model) (Analysis 1.2).

\section{Certainty of the evidence}

We consider the evidence for this outcome to be of very low certainty; we downgraded it from high to very low certainty due to inconsistency of effect estimates between main and sensitivity analyses as well as across individual studies (statistical heterogeneity) and imprecision of the evidence based on the wide confidence intervals.

Proportion of children requiring medical intervention with or without hospitalisation, within the first seven days after surgery, due to haemorrhage from the tonsillar bed, infection or dehydration
One study did not report the number of children randomised to each arm, which precluded the data from being included in the meta-analysis. This study (43 randomised children; 43 $(100 \%)$ included in analysis) stated that "there were no cases of postoperative bleeding" in the children who underwent tonsillotomy and for those undergoing tonsillectomy "there were no cases of excessive postoperative bleeding" and "no episodes of bleeding occurred in either group of patients later in the postoperative period" (Densert 2001).

We could therefore combine data from 16 studies (1562 randomised children; 1416 (91\%) included in analysis) (Beriat 2013; Borgstrom 2017; Chaidas 2013; Chan 2004; Chang 2005; Chang 2008; Coticchia 2006; Derkay 2006; Ericsson 2009; Hultcrantz 1999; Hultcrantz 2004; Kordeluk 2016; Li 2013; Park 2007; Skoulakis 2007; Zhou 2016). The risk of requiring medical intervention, with or without hospitalisation, within the first seven days after surgery was higher in children who underwent tonsillectomy than those who underwent tonsillotomy (4.9\% versus $2.6 \%$, risk ratio (RR) 1.75 , 95\% $\mathrm{Cl} 1.06$ to $2.91 ; \mathrm{I}^{2}=10 \%$, fixed-effect model) (Analysis 1.3; Figure 5).

Seventeen studies reported this outcome. 
Figure 5. Forest plot of comparison: 1 Tonsillectomy versus tonsillotomy, outcome: 1.3 Need for medical intervention within 7 days.

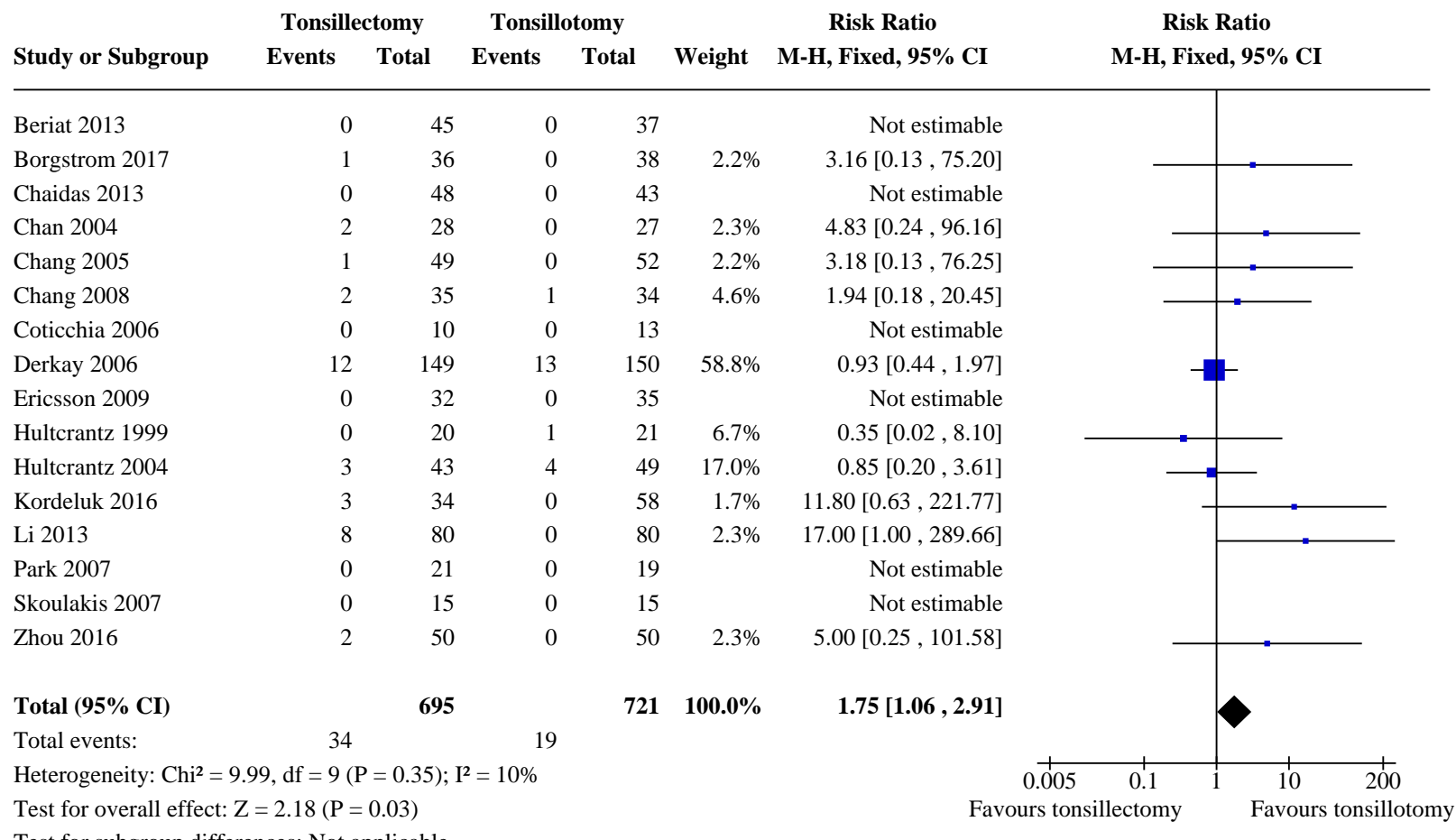

In a sensitivity analysis, where we excluded studies classified as high risk of bias, we could combine data from 10 studies (881 randomised children; 867 (98\%) included in analysis) (Beriat 2013; Borgstrom 2017; Chan 2004; Chang 2008; Coticchia 2006; Derkay 2006; Kordeluk 2016; Park 2007; Skoulakis 2007; Zhou 2016). As per the main analysis, the risk of requiring medical intervention, with or without hospitalisation, within the first days of surgery was higher in the tonsillectomy group but the magnitude of the effect became smaller $\left(5.2 \%\right.$ versus $3.2 \%$, RR $1.57,95 \% \mathrm{Cl} 0.86$ to $2.86 ; \mathrm{I}^{2}=0 \%$, fixed-effect model) (Analysis 1.4).

\section{Certainty of the evidence}

We consider the evidence for this outcome to be of moderate certainty; we downgraded it from high to moderate certainty due to imprecision of the evidence based on the wide confidence intervals.

\section{Secondary outcomes}

\section{Clinical effectiveness}

\section{Behaviour}

\section{Short-term (0 to 6 months)}

One study (118 randomised children; 67 (57\%) included in analysis) measured child behaviour at six months using the Child Behaviour Checklist (CBCL) questionnaire, where scores range from 0 to 226 with higher scores indicating greater behavioural problems (Ericsson 2009). There was no evidence of a difference in mean total CBCL score at six months between children who underwent tonsillectomy and those who underwent tonsillotomy (MD -6.00, $95 \% \mathrm{Cl}-12.98$ to 0.98 ) (Analysis 1.5).

\section{Certainty of the evidence}

We consider the evidence for this outcome to be of very low certainty; we downgraded it from high to very low certainty due to very serious limitations in study methodology, imprecision of the evidence and publication bias, with only one small study reporting on this outcome.

\section{Medium-term ( 7 to 12 months)}

One study (150 randomised children; 92 (61\%) included in analysis) measured child behaviour at 12 months using the $\mathrm{CBCL}$ questionnaire (Hultcrantz 2004). This study stated that "both groups showed the same degree of improvement of the scores on the $\mathrm{CBCL}(\mathrm{p}<0.01)$ ".

\section{Certainty of the evidence}

We consider the evidence for this outcome to be of very low certainty; we downgraded it from high to very low certainty due to very serious limitations in study methodology, imprecision of the evidence and publication bias, with only one small study reporting on this outcome.

\section{Long-term (13 to 24 months)}

One study (118 randomised children; 67 (57\%) included in analysis) measured child behaviour at 24 months using the $\mathrm{CBCL}$ questionnaire (Ericsson 2009). There was no evidence of a difference in mean total $\mathrm{CBCL}$ score at 24 months between children who underwent tonsillectomy and those who underwent tonsillotomy (MD $-0.30,95 \% \mathrm{Cl}-8.95$ to 8.35 ) (Analysis 1.6 ). 


\section{Certainty of the evidence}

We consider the evidence for this outcome to be of very low certainty; we downgraded it from high to very low certainty due to very serious limitations in study methodology, imprecision of the evidence and publication bias, with only one small study reporting on this outcome.

\section{Measures of respiratory events during sleep}

\section{Short-term (0 to 6 months)}

Two studies reported this outcome.

One study (27 randomised children; 23 (85\%) included in analysis) measured respiratory events during sleep at three months using the Respiratory Distress Index (RDI), a formula used to calculate the average number of episodes of apnoea, hypopnoea and respiratory event-related arousal per hour of sleep, where a higher score indicates a higher number of respiratory events (Coticchia 2006). The study reported no evidence of a difference in median change in $\mathrm{RDI}$ from baseline between children who underwent tonsillectomy and those who underwent tonsillotomy: 6.5 versus $5.6(P>0.99)$.

The other study (100 randomised children; 25 (25\%) included in analysis) measured respiratory events during sleep at three to six months using the Apnoea Hypopnoea Index (AHI), a formula used to calculate the number of apnoea and hypopnoea events per hour of sleep where a higher score indicates a higher number of respiratory events (Kordeluk 2016). The study reported no evidence of a difference in mean change in $\mathrm{AHI}$ from baseline between children who underwent tonsillectomy and those who underwent tonsillotomy (MD $-0.58,95 \% \mathrm{Cl}-5.43$ to 4.27 , fixed-effect model) (Analysis 1.7).

\section{Certainty of the evidence}

We consider the evidence for this outcome to be of very low certainty; we downgraded it from high to very low certainty due to very serious limitations in study methodology (in particular high risk of attrition bias in one study), imprecision of the evidence and publication bias, with only two small studies reporting on this outcome (in a manner that precluded meta-analysis).

\section{Medium-term ( 7 to 12 months)}

One study (79 randomised children; 74 (94\%) included in analysis) measured respiratory events during sleep at 12 months using a number of polysomnography variables (Borgstrom 2017). This study reported no evidence of a difference in change scores between the groups from the polysomnography data; the mean difference in change score between groups for the $\mathrm{AHI}$ was 0.83 $(95 \% \mathrm{Cl}-3.23$ to $4.88, \mathrm{P}=0.69)$ and the mean difference in change score between groups for the RDI was $0.84(95 \% \mathrm{Cl}-3.11$ to $4.78, \mathrm{P}$ $=0.67$ ).

\section{Certainty of the evidence}

We consider the evidence for this outcome to be of very low certainty; we downgraded it from high to low certainty due to imprecision of the evidence and publication bias, with only one small study reporting on this outcome.

\section{Recurrence of OSDB as a result of tonsil regrowth}

\section{Short-term ( 0 to 6 months)}

For this outcome, we could combine data from three studies (205 randomised children; 186 (91\%) included in analysis) (Chan 2004; Hultcrantz 1999; Zhou 2016). We found no evidence of a difference in the risk of recurrence of OSDB due to tonsil regrowth within six months between children who underwent tonsillectomy and those who underwent tonsillotomy ( $0 \%$ versus $3.2 \%$, RR $0.26,95 \% \mathrm{Cl} 0.03$ to $2.22, \mathrm{I}^{2}=0 \%$, fixed-effect model) (Analysis 1.8).

In a sensitivity analysis, where we excluded studies classified as high risk of bias, two studies could be included. One study ( 55 randomised children; 43 (78\%) included in analysis) reported no recurrence of OSDB at three months in either treatment group (Chan 2004). The other study (100 randomised children; 100 (100\%) included in analysis) reported no evidence of a difference in the risk of recurrence of oSDB due to tonsil regrowth at six months was observed between the two groups ( $0 \%$ versus $4 \%$, RR $0.20,95 \% \mathrm{Cl}$ 0.01 to 4.06) (Analysis 1.9) (Zhou 2016).

\section{Certainty of the evidence}

We consider the evidence for this outcome to be of very low certainty; we downgraded it from high to very low certainty due to very serious limitations in study methodology, imprecision of the evidence and publication bias, with only three small studies reporting on this outcome.

\section{Medium-term ( 7 to 12 months)}

For this outcome, we could combine data from four studies (Chan 2004; Hultcrantz 1999; Hultcrantz 2004; Skoulakis 2007) (285 randomised children; 206 (72\%) included in analysis). We found no evidence of a difference in the risk of recurrence of OSDB due to tonsil regrowth at 12 months between children who underwent tonsillectomy and those who underwent tonsillotomy ( $0 \%$ versus $1.8 \%$, RR $0.35,95 \% \mathrm{Cl} 0.04$ to $4.23 ; \mathrm{I}^{2}=0 \%$, fixed-effect model) (Analysis 1.10).

In a sensitivity analysis, where we excluded studies classified as high risk of bias, we could use data from two studies. One study (30 randomised children; 30 (100\%) included in analysis) reported no tonsil regrowth at 12 months in either treatment group (Skoulakis 2007). The other study (55 randomised children; 43 (78\%) included in analysis), reported no evidence of a difference in the risk of recurrence of OSDB due to tonsil regrowth at 12 months between children who underwent tonsillectomy and those who underwent tonsillotomy ( $0 \%$ versus $4.5 \%$, RR $0.35,95 \% \mathrm{Cl} 0.01$ to 8.11 ) (Analysis 1.11) (Chan 2004).

\section{Certainty of the evidence}

We consider the evidence for this outcome to be of very low certainty; we downgraded it from high to very low certainty due to very serious limitations in study methodology, imprecision of the evidence and publication bias, with only five small studies reporting on this outcome.

\section{Long-term (13 to 24 months)}

Two studies reported this outcome. 
One study did not report the number of children randomised to each arm, which precluded meta-analysis ( 43 randomised children; 41 (95\%) included in analysis) and stated that "there was no statistically significant difference in clinical symptoms between the two groups" at 24 months (Densert 2001).

The other study (118 randomised children; 65 (55\%) included in analysis) reported no evidence of a difference in the risk of recurrence of OSDB due to tonsil regrowth at 24 months between children who underwent tonsillectomy and tonsillotomy ( $0 \%$ versus $6 \%$, RR $0.21,95 \% \mathrm{Cl} 0.01$ to 4.13 ) (Analysis 1.12) (Ericsson 2009).

\section{Certainty of the evidence}

We consider the evidence for this outcome to be of very low certainty; we downgraded it from high to very low certainty due to very serious limitations in study methodology, imprecision of the evidence and publication bias, with only two small studies reporting on this outcome.

\section{Reoperation rates}

\section{Medium-term ( 7 to 12 months)}

Two studies reported this outcome (195 randomised children; 166 (85\%) included in analysis) (Borgstrom 2017; Hultcrantz 2004). We found no evidence of a difference in the risk of reoperation at 12 months between children who underwent tonsillectomy and those who underwent tonsillotomy $(2.5 \%$ versus $9.1 \%$, RR $0.32,95 \% \mathrm{Cl}$ 0.08 to $1.28,1^{2}=38 \%$, fixed-effect model) (Analysis 1.13 ).

\section{Certainty of the evidence}

We consider the evidence for this outcome to be of very low certainty; we downgraded it from high to very low certainty due to very serious limitations in study methodology, imprecision of the evidence and publication bias, with only two small studies reporting on this outcome.

\section{Long-term (13 to 24 months)}

One study reported this outcome (50 randomised children; 41 (82\%) included in analysis) (Hultcrantz 1999). This study reported no evidence of a difference in the risk of reoperation at 18 months between children who underwent tonsillectomy and those who underwent tonsillotomy ( $0 \%$ versus $4.8 \%$, RR $0.35,95 \% \mathrm{Cl} 0.02$ to 8.10) (Analysis 1.14).

\section{Certainty of the evidence}

We consider the evidence for this outcome to be of very low certainty; we downgraded it from high to very low certainty due to very serious limitations in study methodology, imprecision of the evidence and publication bias, with only one small study reporting on this outcome.

\section{Incidence of throat infection (tonsillitis)}

\section{Short-term (0 to 6 months)}

Two studies reported this outcome.

One study (55 randomised children; 43 (78\%) included in the analysis) stated that "treatment groups did not differ in the incidence of sore throat between the 14 day and 3 month visits" (Chan 2004).

The other study (118 randomised children; 67 (55\%) included in analysis) (Ericsson 2009), reported no evidence of a difference in the risk of throat infections at six months between children who underwent tonsillectomy and those who underwent tonsillotomy (6.3\% versus $11.4 \%$, RR $0.55,95 \% \mathrm{Cl} 0.11$ to 2.79 ) (Analysis 1.15 ).

\section{Certainty of the evidence}

We consider the evidence for this outcome to be of very low certainty; we downgraded it from high to very low certainty due to very serious limitations in study methodology, imprecision of the evidence and publication bias, with only two small studies reporting on this outcome.

\section{Medium-term ( 7 to 12 months)}

Three studies reported this outcome.

One study (55 randomised children; 43 (78\%) included in the analysis) stated that "treatment groups did not differ in incidence of sore throat between 3 and 12 months postoperatively" (Chan 2004).

Based on the other two studies (198 randomised children; 174 (88\%) included in analysis) (Beriat 2013; Hultcrantz 2004), we found no evidence of a difference in the risk of throat infections at 12 months between children who underwent tonsillectomy and those who underwent tonsillotomy (4.5\% versus $9.3 \%$, RR $0.56,95 \% \mathrm{Cl}$ 0.19 to $1.65, \mathrm{I}^{2}=0 \%$, fixed-effect model) (Analysis 1.16 ).

\section{Certainty of the evidence}

We consider the evidence for this outcome to be of very low certainty; we downgraded it from high to very low certainty due to very serious limitations in study methodology, imprecision of the evidence and publication bias, with only three small studies reporting on this outcome.

\section{Long-term (13 to 24 months)}

Two studies reported this outcome.

One study did not report the number of children randomised to each arm, which precluded meta-analysis (43 randomised children; 41 (95\%) included in the analysis) and stated that "at the 2year follow-up there was no difference in the frequency of throat infections between the two groups of patients" (Densert 2001).

In the other study (118 randomised children; 65 (55\%) included in analysis) (Ericsson 2009), tonsillectomy was associated with a reduced risk of experiencing throat infections at 24 months compared with tonsillotomy (3.1\% versus $24.2 \%$, RR $0.13,95 \% \mathrm{Cl}$ 0.02 to 0.97 ) (Analysis 1.17).

\section{Certainty of the evidence}

We consider the evidence for this outcome to be of very low certainty; we downgraded it from high to very low certainty due to very serious limitations in study methodology, inconsistency of effect estimates across studies, imprecision of the evidence and publication bias, with only two small studies reporting on this outcome. 


\section{Peri-and postoperative morbidity and complications}

\section{Duration of surgery}

Eleven studies reported this outcome.

One study (300 randomised children; 300 (100\%) included in analysis) reported data in a manner that precluded meta-analysis (Derkay 2006). Median surgical time was shorter for tonsillotomy than tonsillectomy: 8 minutes with electrocautery (IQR 6 to 10) versus 10 minutes with the microdebrider (IQR 8 to 12 ).

One study (43 randomised children; $43(100 \%)$ included in the analysis) did not report the number of children randomised to each arm, precluding meta-analysis, and stated that "the surgical time was significantly shorter for the tonsillotomy group" (Densert 2001).

One study (30 randomised children; $30(100 \%)$ included in the analysis) did not report quantitative data and stated that "the mean time in the operating room was approximately the same for both operations" (Skoulakis 2007).

We could therefore combine data from eight studies (656 randomised children; $566(86 \%)$ included in analysis) (Beriat 2013; Chaidas 2013; Chan 2004; Hultcrantz 1999; Hultcrantz 2004; Korkmaz 2008; Park 2007; Sobol 2006). Duration of surgery was on average one minute shorter in favour of tonsillectomy (MD -0.99, $95 \% \mathrm{Cl}-1.97$ to $-0.02 ; \mathrm{I}^{2}=80 \%$, random-effects model) (Analysis 1.18).

In a sensitivity analysis, where we excluded studies classified as high risk of bias, we could combine data from four studies (251 randomised children; 251 (100\%) included in analysis) (Beriat 2013; Chan 2004; Park 2007; Sobol 2006). Duration of surgery was on average 2.5 minutes shorter in favour of tonsillectomy (MD -2.59, $95 \% \mathrm{Cl}-7.72$ to $2.53 ; \mathrm{I}^{2}=86 \%$, random-effects model) (Analysis 1.19).

\section{Certainty of the evidence}

We consider the evidence for this outcome to be of low certainty; we downgraded it from high to low certainty due to inconsistency of effect estimates across individual studies (statistical heterogeneity) and imprecision of the evidence based on the wide confidence intervals.

\section{Severity of postoperative pain}

\section{Short-term (24 hours)}

Eleven studies reported this outcome using visual or verbal analogue scales with differing anchor points, scored by either the children, the parents or study/clinical staff. Due to the differences in the measures used, together with the reporting of the data often precluding meta-analysis, we have summarised these details in the 'Reporting of short-term pain' table to enable comparison (Table 4).

Overall, six studies (473 randomised children; 355 (75\%) included in the analysis) reported findings in a manner that precluded meta-analysis, but stated that "pain was significantly lower" in children who underwent tonsillotomy than those who underwent tonsillectomy (Beriat 2013; Densert 2001; Ericsson 2009; Hultcrantz 1999; Hultcrantz 2004; Skoulakis 2007). One study (226 children included in the analysis) reported no evidence of a difference in median pain scores between groups: 3 (IQR 2 to 4) in both the tonsillectomy and tonsillotomy group (Derkay 2006).

We could therefore only combine data from only four studies (397 randomised children; 368 (93\%) included in analysis) (Chang 2005; Chang 2008; Kordeluk 2016; Li 2013; Park 2007). In three of these studies pain was scored by the parents using the Wong-Baker FACES pain 10-point rating scale (Chang 2005; Chang 2008; Park 2007). For the other study that used a five-point VAS we converted the data into the equivalent scale to permit meta-analysis (Li 2013). The mean pain score was one point lower in children who underwent tonsillotomy than in those who underwent tonsillectomy (MD 1.09, $95 \% \mathrm{Cl} 0.88$ to $1.29 ; \mathrm{I}^{2}=0 \%$, fixed-effect model) (Analysis 1.20 ).

In a sensitivity analysis, where we excluded studies classified as high risk of bias, we could combine data from two studies (109 randomised children; 109 (100\%) included in analysis) (Chang 2008; Park 2007). In this analysis, we found no evidence of a difference in the mean pain score at 24 hours between children who underwent tonsillectomy and those who underwent tonsillotomy (MD 0.46, $95 \% \mathrm{Cl}-0.39$ to $1.31 ; \mathrm{I}^{2}=0 \%$, fixed-effect model) (Analysis 1.21 ).

\section{Certainty of the evidence}

We consider the evidence for this outcome to be of very low certainty; we downgraded it from high to very low certainty due to inconsistency of effect estimates between main and sensitivity analyses as well as across individual studies (statistical heterogeneity), imprecision of the evidence based on the wide confidence intervals and publication bias based on the small proportion of studies that reported data in a manner that permitted meta-analysis.

\section{Medium-term (two to three days)}

Five studies reported this outcome using visual or verbal analogue five-point or 10-point scales scored either by the children or the parents. The methods of reporting are summarised in the 'Reporting of medium-term pain' table for comparison (Table 5).

Overall, two studies (148 randomised children; 97 (66\%) included in analysis) provided data that precluded meta-analysis but stated that "pain was significantly lower" in children who underwent tonsillotomy compared to children who underwent tonsillectomy (Ericsson 2009; Skoulakis 2007).

We could therefore combine data from three studies (328 randomised children; 301 (92\%) included in analysis) (Chang 2005; Li 2013; Park 2007). In two of these studies pain was scored by the parents using the Wong-Baker FACES pain 10-point rating scale (Chang 2005; Park 2007). For the other study that used a five-point VAS we converted the data into the equivalent scale to permit metaanalysis (Li 2013). We found no evidence of a difference in the mean pain score at two to three days between children who underwent tonsillectomy and those who underwent tonsillotomy (MD 0.93, $95 \% \mathrm{Cl}-0.14$ to $2.00 ; 1^{2}=83 \%$, random-effects model) (Analysis 1.22).

In a sensitivity analysis, where we excluded studies classified as high risk of bias, we could use only one study (40 randomised children; 40 (100\%) included in analysis) (Park 2007). This study reported no evidence of a difference in mean pain score at day three between children who underwent tonsillectomy and those who underwent tonsillotomy (MD $-0.60,95 \% \mathrm{Cl}-1.78$ to 0.58 ) (Analysis 1.23). 


\section{Certainty of the evidence}

We consider the evidence for this outcome to be of very low certainty; we downgraded it from high to very low certainty due to inconsistency of effect estimates across individual studies (statistical heterogeneity), imprecision of the evidence based on the wide confidence intervals and publication bias based on the small proportion of studies that reported data in a manner that permitted meta-analysis.

\section{Long-term (four to seven days)}

Seven studies reported this outcome using visual or verbal analogue five-point or 10-point scales scored either by the children or the parents. The methods of reporting are summarised in the 'Reporting of long-term pain' table for comparison (Table 6).

Overall, three studies ( 230 randomised children; 179 (78\%) included in analysis) provided data that precluded meta-analysis but stated that "pain was significantly lower" in children who underwent tonsillotomy compared to children who underwent tonsillectomy (Beriat 2013; Ericsson 2009; Skoulakis 2007).

We could therefore combine data from four studies (397 randomised children; 370 (93\%) included in analysis) (Chang 2005; Chang 2008; Li 2013; Park 2007). In three of these studies pain was scored by the parents using the Wong-Baker FACES pain 10-point rating scale (Chang 2005; Chang 2008; Park 2007). For the other study that used a five-point VAS we converted the data into the equivalent scale to permit meta-analysis (Li 2013). We found no evidence of a difference in the mean pain score at four to seven days between children who underwent tonsillectomy and those who underwent tonsillotomy (MD $1.07,95 \% \mathrm{Cl}-0.40$ to $2.53 ; \mathrm{I}^{2}=$ 93\%, random-effects model) (Analysis 1.24).

In a sensitivity analysis, where we excluded studies classified as high risk of bias, we could use two studies (109 randomised children; 109 (100\%) included in analysis) (Chang 2008; Park 2007). In this analysis, we found no evidence of a difference in the mean pain score at four to seven days between children who underwent tonsillectomy and those who underwent tonsillotomy (MD 0.87, $95 \% \mathrm{Cl}-0.89$ to $2.64 ; I^{2}=73 \%$, random-effects model) (Analysis 1.25 ).

\section{Certainty of the evidence}

We consider the evidence for this outcome to be of very low certainty; we downgraded it from high to very low certainty due to inconsistency of effect estimates across individual studies (statistical heterogeneity), imprecision of the evidence based on the wide confidence intervals and publication bias based on the small proportion of studies that reported data in a manner that permitted meta-analysis.

\section{Days until analgesics no longer required}

Six studies reported this outcome.

Three studies provided data that precluded meta-analysis but reported that the median number of days until analgesics were no longer required was shorter in children who underwent tonsillotomy than in those who underwent tonsillectomy: 6.4 days versus 11.0 days (55 randomised children; $43(78 \%)$ included in analysis) (Chan 2004); 4 days (IQR 2 to 7 ) versus 6.5 days (IQR 4 to 9.5) $\mathrm{P}<0.0001$ (224 included in analysis) (Derkay 2006); and 5 days
(IQR 3 to 6) versus 8 days (IQR 6 to 9) P $<0.00001$ (118 randomised children; 67 (57\%) included in analysis) (Ericsson 2009).

We could therefore combine data from three studies (325 randomised children; 267 (82\%) included in analysis) (Chaidas 2013; Hultcrantz 2004; Sobol 2006). The mean number of days until analgesics were no longer required was 2.8 days lower in children who underwent tonsillotomy than in those who underwent tonsillectomy (MD 2.78, 95\% Cl 1.92 to $3.64 ; \mathrm{I}^{2}=69 \%$, random-effects model) (Analysis 1.26).

In sensitivity analysis, where we excluded studies classified as high risk of bias, we could use only one study (74 randomised children; 74 (100\%) included in analysis) (Sobol 2006). In this study, we found no evidence of a difference in the mean number of days until analgesics were no longer required between children who underwent tonsillectomy and those who underwent tonsillotomy (MD 1.30, 95\% Cl -0.17 to 2.77) (Analysis 1.27).

\section{Certainty of the evidence}

We consider the evidence for this outcome to be of low certainty; we downgraded it from high to low certainty due to inconsistency of effect estimates between main and sensitivity analysis and publication bias based on the small proportion of studies that reported data in a manner that permitted meta-analysis.

\section{Return to normal diet}

Eight studies reported this outcome.

Two studies reported that the median numbers of days until children were able to return to a normal diet was shorter in children who underwent tonsillotomy than in those who underwent tonsillectomy: 4.4 days versus 7.5 days ( 55 randomised children; 43 (78\%) included in analysis) (Chan 2004); and 3 days (IQR 1 to 6 ) versus 7 days (IQR 5 to 9 ) $P<0.00001$ (118 randomised children; 67 (57\%) included in analysis) (Ericsson 2009).

One study (50 randomised children; 41 (82\%) included in analysis stated that "children who underwent tonsillotomy returned to a normal diet three days before the children who underwent tonsillectomy" (Hultcrantz 1999).

One study (30 randomised children; 30 (100\%) included in analysis) stated that "the tonsillotomy group returned to a normal diet 4 days earlier than the tonsillectomy group, thus the time needed for a return to a normal eating routine was significantly less for the tonsillotomy group ( $p<0.001) "$ (Skoulakis 2007).

One study (23 randomised children; 23 (100\%) included in analysis) stated that "by postoperative day 7,11 of $13(85 \%)$ of tonsillotomy patients resumed a normal diet, whereas none of the 7 tonsillectomy patients were on a normal diet at day 7 " (Coticchia 2006).

One study (246 included in analysis) reported no evidence of a difference in the median number of days until children were able to return to a normal diet between children who underwent tonsillotomy and those who underwent tonsillectomy; 3 days (IQR 2 to 7 ) versus 3.5 days (IQR 1.5 to 6.5) (Derkay 2006).

We could therefore combine data from two studies (157 randomised children; 157 (100\%) included in analysis) (Chaidas 2013; Sobol 2006). The mean number of days until children 
were able to return to a normal diet was around three days lower in children who underwent tonsillotomy than in those who underwent tonsillectomy (MD 2.60, 95\% $\mathrm{Cl} 1.16$ to $4.04 ; \mathrm{I}^{2}=79 \%$, random-effects model) (Analysis 1.28; Figure 6).

\section{Figure 6. Forest plot of comparison: 1 Tonsillectomy versus tonsillotomy, outcome: 1.28 Return to normal diet} [days].

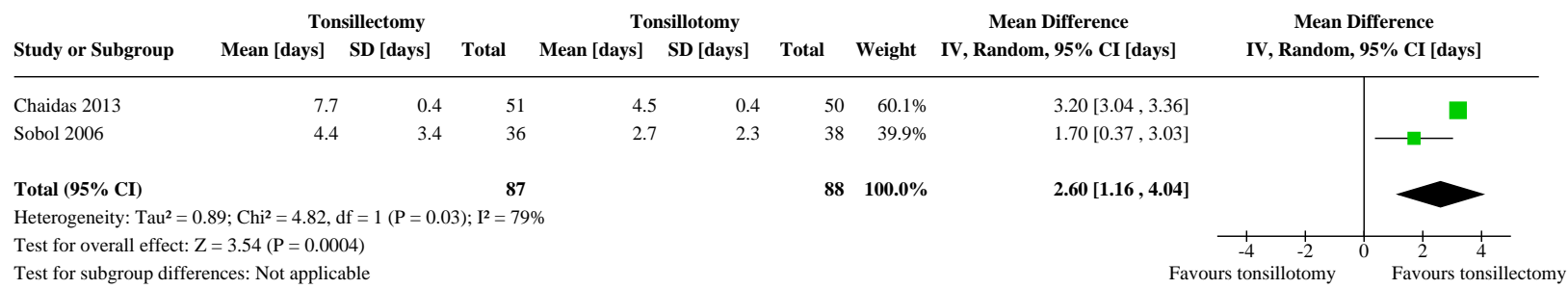

In a sensitivity analysis, where we excluded studies classified as high risk of bias, we could use only one study (74 randomised children; 74 (100\%) included in analysis) (Sobol 2006). This study reported evidence of a difference of around two days in favour of the tonsillotomy group (MD $1.70,95 \% \mathrm{Cl} 0.37$ to 3.03 , randomeffects model) (Analysis 1.29).

\section{Certainty of the evidence}

We consider the evidence for this outcome to be of moderate certainty; we downgraded it from high to moderate certainty due to imprecision of the evidence based on the wide confidence intervals and publication bias based on the small proportion of studies that reported data in a manner that permitted meta-analysis.

\section{Return to normal activity}

Seven studies measured this outcome.

Three studies provided data that precluded meta-analysis but reported that the median numbers of days until children were able to return to normal activity was shorter in children who underwent tonsillotomy than in those who underwent tonsillectomy: 4.1 days versus 8.0 days (55 randomised children; 43 (78\%) included in analysis) (Chan 2004); 2.5 days (IQR 1 to 5 ) versus 4 days (IQR 2.5 to 6.5$) \mathrm{P}<0.01$ (256 included in analysis) (Derkay 2006); and 6 days (IQR 4 to 7 ) versus 9 days (IQR 7 to 10$) P<0.00001$ (118 randomised children; 67 (57\%) included in analysis) (Ericsson 2009). Conversely, one study (40 randomised children; 39 (98\%) included in analysis) stated that the "proportion of patients resuming normal activity were not different between the two groups at days 1, 3, 5 and 7" (Park 2007).

We could therefore combine data from only three studies (306 randomised children; 248 (81\%) included in analysis) (Beriat 2013; Hultcrantz 2004; Sobol 2006). The mean number of days until children were able to return to normal activity was around four days lower in children who underwent tonsillotomy than in those who underwent tonsillectomy (MD 3.84, 95\% Cl 0.23 to $7.44 ; 1^{2}=97 \%$, random-effects model) (Analysis 1.30).

In a sensitivity analysis, where we excluded studies classified as high risk of bias, we could use two studies (156 randomised children; 156 (100\%) included in analysis) (Beriat 2013; Sobol 2006). In this sensitivity analysis, we found similar results as observed in our main analysis (MD $4.24,95 \% \mathrm{Cl}-1.30$ to 9.78 , random-effects model) (Analysis 1.31).

\section{Certainty of the evidence}

We consider the evidence for this outcome to be of moderate certainty; we downgraded it from high to moderate certainty due to imprecision of the evidence based on the wide confidence intervals and publication bias based on the small proportion of studies that reported data in a manner that permitted meta-analysis.

\section{DISCUSSION}

\section{Summary of main results}

For children with obstructive sleep-disordered breathing (oSDB) selected for tonsil surgery, tonsillotomy probably offers short-term benefits over tonsillectomy, in particular faster return to normal activity (four days), and probably results in a slight reduction in postoperative complications requiring medical intervention (with or without hospitalisation) in the first seven days after surgery.

This should be balanced against the clinical effectiveness of one operation over the other in the short and long term. Data on the effects of the two operations on the resolution of signs and symptoms of OSDB itself, quality of life and behaviour of the child, recurrence of OSDB, the incidence of throat infections and the need for a reoperation are limited. Although studies reporting these outcomes found no differences between the two surgical procedures, these findings should be interpreted with great caution since the evidence derived from these studies was mostly of very low certainty.

\section{Overall completeness and applicability of evidence}

Although studies in this review did include clinically relevant patient populations (children aged 2 to 16 years undergoing tonsil surgery for oSDB symptoms), we were not able to perform important subgroup analyses (such as for SDB severity, method of SDB diagnosis and age) to investigate whether results differ among clinically relevant subgroups.

The majority of the studies in this review focused on collecting peri- and postoperative morbidity outcomes. The postoperative morbidity data were, however, often reported in a non-standardised way, which hampers the interpretation and applicability of study findings.

Moreover, very few studies collected data on oSDB symptoms, despite this being the prime reason for performing surgery in this patient population. In those that did, there was a lack of 
standardised data collection and reporting, which severely limits the interpretation and applicability of study findings.

Finally, albeit of significant interest, we cannot draw any meaningful conclusions regarding the impact of the type of surgical instrument used and techniques applied on peri- and postoperative morbidity and clinical effectiveness outcomes such as recurrence of oSDB and re-operation rates based on the findings from this review.

\section{Quality of the evidence}

Despite the large number of studies included in this review (22 studies with 1984 children), the body of evidence is generally of low to very low certainty and it precludes robust conclusions. The majority of the studies had a small sample size with lots of limitations in their designs. Major methodological concerns included the lack of blinding in most studies and the use of the 'method of Zelen' for randomisation, which resulted in a large number of the patients randomised not being included in the analysis and a high risk of attrition bias. Other major limitations of the studies were the great diversity in the outcome measurement instruments used and the large heterogeneity in outcome reporting.

For some outcomes, most notably mean peri-operative blood loss and return to normal activity, we found that one study reported the largest differences between groups (in favour of tonsillotomy) for unclear reasons (Beriat 2013). Since we were able to include only three studies for the return to normal activity outcome metaanalysis, this outlier substantially impacted the overall treatment effect for this outcome. Although all three trials showed a similar direction of effect (in favour of tonsillotomy), the overall treatment effect size for the return to normal activity outcome (difference of four days) should therefore be interpreted with some caution.

\section{Potential biases in the review process}

We made only minor changes to the pre-specified review protocol, Blackshaw 2014, when drafting the full review (see Differences between protocol and review section).

We found two studies that were reported in a language other than English (Li 2013; Zhou 2016), and we relied upon translation and interpretation from an author within our team. To avoid selective reporting bias within our review, we included these studies in our meta-analyses, as per most recent Cochrane guidance (Higgins 2019).

In the event that we perceived data to be missing or not available in the required format, we contacted the trial authors of the individual included studies. Despite multiple attempts we received only five responses regarding seven of the included studies (Chaidas 2013; Chang 2005; Chang 2008; Derkay 2006; Hultcrantz 1999; Hultcrantz 2004; Park 2007), with only one trial author providing additional data (Derkay 2006). For each outcome, we narratively summarised the data from studies that did report on one of our outcomes of interest but in such a manner that these data could not be pooled to investigate whether this may have introduced (reporting) bias. For the majority of outcomes, narrative results were comparable with those observed in meta-analyses.

\section{Agreements and disagreements with other studies or reviews}

Our review findings are in agreement with those of other recent systematic reviews comparing tonsillotomy and tonsillectomy in children with oSDB (Gorman 2017; Kim 2017; Sathe 2017; Wang 2015; Zhang 2017).

With regard to the short-term recovery benefits, these reviews also reported less postoperative bleeding (Kim 2017; Wang 2015), together with a faster return to diet and activity (Kim 2017; Sathe 2017; Zhang 2017). These findings are also in line with a recent study investigating self-reported postoperative recovery in children undergoing tonsillectomy and tonsillotomy conducted in Sweden (Eriksson 2017), which found less postoperative morbidity and a faster time to normal activity in those undergoing tonsillotomy.

Gorman 2017 specifically set out to examine improvements in disease-specific quality of life by analysing all studies, irrespective of design, which measured OSA-18 scores following tonsillectomy or tonsillotomy in children with oSDB. Their meta-analyses of 16 studies (one of which was a randomised controlled trial (RCT) and included in our review) also found no evidence of a difference in OSA-18 scores between the two groups. This finding is in agreement with the results found by Sathe 2017 (which analysed 13 of the RCTs included in our review, together with three studies that we had excluded because tonsillotomy was performed on one tonsil and tonsillectomy on the other within the child), Kim 2017 (which analysed 10 of the RCTs included in our review, together with five trials that we had excluded for including adults, unbalanced concomitant surgery and tonsillotomy on one tonsil), Zhang 2017 (which analysed 16 of the RCTs in our review together with 13 nonrandomised trials) and Wang 2015 (which analysed five of the RCTs in our review together with a further five non-randomised trials). All concluded that there was no difference between the groups in those trials measuring disease-specific quality of life.

Our findings that the long-term implications of tonsillotomy were not explored in the majority of studies were mirrored by other reviewers (Gorman 2017; Kim 2017; Sathe 2017; Wang 2015; Zhang 2017), who commented that few studies measured respiratory events, behaviour, throat infections or re-operation rates. In those that did, no differences were observed between the groups, with the level of the evidence being very low quality. However, one review did report a higher risk (risk ratio 3.33) of recurrence of oSDB in the tonsillotomy group (Wang 2015), which was also seen when just analysing the non-randomised trials within that meta-analysis (RR 11.89). Two reviews reported no significant group differences in throat infections or recurrence of oSDB symptoms (Sathe 2017; Zhang 2017), and commented that recurrence relied on patientreported data rather than polysomnography findings, with no studies looking beyond five years of follow-up. This matched our findings that very few trials measured re-operation rates in the long term, which did not enable us to draw robust conclusions.

Cohort studies may provide a better method for capturing rare events following surgery in the long term. The Nordic countries (Denmark, Finland, Norway and Sweden) are known for holding high-quality healthcare registries (Ruohoalho 2018), with Sweden in particular holding over 100 medical quality registers of which nine are focused on ENT. Recently, data from the Swedish National Patient Register (NPR) have been investigated retrospectively to look for rates of re-operation in children undergoing tonsillectomy 
and tonsillotomy. The NPR contains individually based information on both in- and outpatient care and is considered complete for both in- and outpatient care from 2004 onward. With data collected from a national registry with a high degree of completeness, this type of study avoids the main weaknesses of single-centre studies in which surgery at other institutions is missed. In Sweden, tonsillotomy comprised $72 \%$ of tonsil surgeries in children with upper airway obstruction due to tonsil hypertrophy in 2012 (Stalfors 2014). The reoperation rate after tonsillotomy has been quoted as "significantly higher" in the Swedish population than after tonsillectomy; among 41,401 children who underwent a first tonsil surgery between 2004 to 2013, the risk for a second tonsil surgery performed due to hypertrophy of the tonsils and/ or adenoids within three years was found to be $8.1 \%$ to $9.4 \%$ for (adeno)tonsillotomy and $4.5 \%$ to $6.8 \%$ for (adeno)tonsillectomy (Sunnergren 2017). The reason for this remains unclear; a large population-based study has linked it to young age at initial operation (Odhagen 2016). Our data revealed differences in the surgical technique used within the included studies. Seven studies in this review described a 'class ' technique (where the palatine arches are used to determine the plane of tonsil resection; Windfuhr 2013) (Bitar 2016; Borgstrom 2017; Ericsson 2009; Hultcrantz 1999; Hultcrantz 2004; Kordeluk 2016; Lundeborg 2009) and five a 'class 2 ' technique (where most of the tonsil tissue is removed with preservation of the inner surface of the capsule; Windfuhr 2013) (Beriat 2013; Chan 2004; Chang 2005; Chang 2008; Derkay 2006). In eight studies the surgical technique used was unclear (Chaidas 2013; Coticchia 2006; Dai 2014; Densert 2001; Korkmaz 2008; Park 2007; Skoulakis 2007; Sobol 2006). Five of the seven studies using the 'class 1' technique were performed in Sweden whereas four of the five studies using a 'class 2 ' technique were performed in the USA. This is in agreement with data from a recent review indicating that a 'class 2 ' technique is predominantly used in the USA while a 'class 1 ' technique is preferentially used within countries such as Sweden and Germany (Windfuhr 2015). The differences between these operations may have important implications for tonsil regrowth and reoperation rates (Windfuhr 2015). However, tonsil regrowth rates after tonsillotomy ranged from $0 \%$ to $26.9 \%$ in this review, with the author concluding that risk factors for regrowth are still a matter of speculation (Windfuhr 2015).

\section{AUTHORS' CONCLUSIONS}

\section{Implications for practice}

For children with obstructive sleep-disordered breathing (oSDB) selected for tonsil surgery, tonsillotomy probably results in a faster return to normal activity (four days) and in a slight reduction in postoperative complications requiring medical intervention with or without re-hospitalisation. Evidence on most other primary and secondary outcomes such as disease-specific quality of life, peri-operative blood loss, postoperative pain and analgesic use, measures of respiratory events, behaviour, recurrence of OSDB as a result of tonsil regrowth, re-operation rates and incidence of throat infection was of very low certainty, which prevent us from drawing firm conclusions. The type of surgical instrument used and techniques applied might impact on peri- and postoperative morbidity and clinical effectiveness outcomes such as recurrence of OSDB and re-operation rates, but we cannot draw any meaningful conclusions on this subject based on the current review.

In conclusion, our review found no robust evidence on the clinical effectiveness of one operation over the other, making us unable to carefully balance the benefits of tonsillotomy for short-term recovery and the slight reduction in postoperative complications requiring medical intervention against the possible recurrence of oSDB or the need for a reoperation. Until more robust evidence becomes available, it seems to be justified for ENT surgeons to use the surgical technique of their own preference.

\section{Implications for research}

We recommend further high-quality prospective observational studies, such as cohort studies facilitated by surgical registries and patient databases. These should enrol children with oSDB selected for tonsil surgery and should evaluate whether any benefits of tonsillotomy in short-term recovery are matched by longterm effectiveness. These studies should capture both short-term outcomes such as bleeding and re-hospitalisation rates and longterm (> 3 years) clinical effectiveness outcomes including diseasespecific quality of life using validated instruments, incidence of throat infections, recurrence of OSDB and re-operation rates, and should also weigh the costs of tonsillotomy and tonsillectomy against their benefits. Such future studies should also include information on the surgical technique applied (class 1 versus class 2 ) and the surgical instrument used for the operation.

Equally important is the need for outcomes research to explore which outcome measures and instruments best capture the impact of oSDB and its treatment on children and their families (Venekamp 2017). To achieve this, stakeholders involved in the care of children with oSDB could work together to develop a core set of outcomes including those reported by children and their caregivers, to be used clinically and across future childhood oSDB research.

\section{ACK N O WLEDGEMENTS}

We gratefully acknowledge the assistance received from the staff at the Cochrane ENT editorial base and thank Samantha Cox for her support with the search strategy and searches.

This project was supported by the National Institute for Health Research, via Cochrane Infrastructure, Cochrane Programme Grant or Cochrane Incentive funding to Cochrane ENT. The views and opinions expressed therein are those of the authors and do not necessarily reflect those of the Systematic Reviews Programme, NIHR, NHS or the Department of Health. 


\section{R E F E R E N C E S}

\section{References to studies included in this review}

\section{Beriat 2013 \{published data only\}}

Beriat GK, Ezerarslan H, Kocatürk S. Microdebrider tonsillotomy in children with obstructive tonsillar hypertrophy [Obstrüktif tonsil hipertrofisi olan cocuk hastalarda mikrodebrider tonsillotomi]. Journal of Clinical and Analytical Medicine 2013; 4(6):462-5.

\section{Bitar 2016 \{published data only\}}

Bitar MA, Rameh C, Ataya NF, Najarian A, Chakhtoura M, Abdelnoor A. Alterations in humoral immunity after partial versus total tonsillectomy: a pilot study and systematic review of literature. Journal of Pediatrics Review 2016; 4(2):e6214. [DOI: 10.17795/jpr-6214]

\section{Borgstrom 2017 \{published data only\}}

ZZZ <accessionId ref="info:x-wiley/clinicalTrialsGov/

NCT01676181"> ZZZNCT01676181

Borgström A, Nerfeldt P, Friberg D. Adenotonsillotomy versus adenotonsillectomy in pediatric obstructive sleep apnea: an RCT. Pediatrics 2017; 139(4):e20163314. [DOI: 10.1542/ peds.2016-3314]

. ATT compared with ATE in OSAS children [Randomised surgical intervention study between adenotonsillectomy and adenotonsillotomy in children with obstructive sleep apnea syndrome]. https://clinicaltrials.gov/show/NCT01676181 (first received 30 August 2012)

\section{Chaidas 2013 \{published data only\}}

Chaidas KS, Kaditis AG, Papadakis CE, Papandreou N, Koltsidopoulos P, Skoulakis CE. Tonsilloplasty versus tonsillectomy in children with sleep-disordered breathing: short- and long-term outcomes. Laryngoscope 2013; 123:1294-9.

\section{Chan 2004 \{published data only\}}

Chan KH, Friedman NR, Allen GC, Yaremchuk K, Wirtschafter A, Bikhazi N, et al. Randomized, controlled, multisite study of intracapsular tonsillectomy using low-temperature plasma excision. Archives of Otolaryngology--Head \& Neck Surgery 2004; 130(11):1303-7. [DOI: 10.1001/archotol.130.11.1303]

\section{Chang 2005 \{published data only\}}

Chang KW. Randomized controlled trial of coblation versus electrocautery tonsillectomy. Otolaryngology Head and Neck Surgery 2005; 132(2):273-80. [DOI: 10.1016/ j.otohns.2004.11.002]

\section{Chang 2008 \{published data only\}}

Chang KW. Intracapsular versus subcapsular coblation tonsillectomy. Otolaryngology - Head and Neck Surgery 2008; 138:153-7.

\section{Coticchia 2006 \{published data only\}}

Coticchia JM, Yun RD, Nelson L, Koempel J. Temperaturecontrolled radiofrequency treatment of tonsillar hypertrophy for reduction of upper airway obstruction in pediatric patients.
Archives of Otolaryngology--Head \& Neck Surgery 2006; 132(4):425-31. [DOI: 10.1001/archotol.132.4.425]

Dai 2014 \{published data only\}

Dai ZY, Huang DY, Zhou CY. Effects of partial tonsillectomy on the immune functions of children with obstructive sleep apnea-hypopnea syndrome at early stage. Genetics and Molecular Research 2014; 13(2):3895-902. [DOI: 10.4238/2014.January.24.15]

Densert 2001 \{published data only\}

Densert O, Desai H, Eliasson A, Frederiksen L, Andersson D, Olaison J, et al. Tonsillotomy in children with tonsillar hypertrophy. Acta Otolaryngologica 2001; 121(7):854-8.

Derkay 2006 \{published data only\}

Derkay CS, Darrow DH, Welch C, Sinacori JT. Post-tonsillectomy morbidity and quality of life in pediatric patients with obstructive tonsils and adenoid: microdebrider vs electrocautery. Otolaryngology - Head and Neck Surgery 2006; 134(1):114-20.

\section{Ericsson 2009 \{published data only\}}

Ericsson E, Graf J, Lundeborg-Hammarstrom I, Hultcrantz E. Tonsillotomy versus tonsillectomy on young children: 2 year post surgery follow up. Journal of Otolaryngology - Head and Neck Surgery 2014; 43(1):26.

* Ericsson E, Lundeborg I, Hultcrantz E. Child behavior and quality of life before and after tonsillotomy versus tonsillectomy. International Journal of Pediatric Otorhinolaryngology 2009; 73:1254-92.

Kallunki J, Marcusson A, Ericsson E. Tonsillotomy versus tonsillectomy-a randomized trial regarding dentofacial morphology and post-operative growth in children with tonsillar hypertrophy. European Journal of Orthodontics 2014; 36:471-8.

\section{Hultcrantz 1999 \{published data only\}}

Hultcrantz E, Linder A, Markström A. Long-term effects of intracapsular partial tonsillectomy (tonsillotomy) compared with full tonsillectomy. International Journal of Pediatric Otorhinolaryngology 2005; 69:463-9.

* Hultcrantz E, Linder A, Markstrom A. Tonsillectomy or tonsillotomy?--A randomized study comparing postoperative pain and long-term effects. International Journal of Pediatric Otorhinolaryngology 1999; 51:171-6.

\section{Hultcrantz 2004 \{published data only\}}

Ericsson E, Graf J, Hultcrantz E. Paediatric tonsillotomy with radiofrequency technique: long term follow-up. Laryngoscope 2006; 116(10):1851-7.

Ericsson E, Wadsby M, Hultcrantz E. Pre-surgical child behaviour ratings and pain management after two different techniques of tonsil surgery. International Journal of Pediatric Otorhinolaryngology 2006; 70(10):1749-58. 
* Hultcrantz E, Ericsson E, Graf J. Intracapsular tonsillectomy with RF surgery versus regular tonsillectomy: one-year results. Otolaryngology - Head and Neck Surgery 2004; 131(2):P108.

Kordeluk 2016 \{published data only\}

ZZZ <accessionId ref="info:x-wiley/clinicalTrialsGov/

NCT01319058"> ZZZNCT01319058

* Kordeluk S, Goldbart A, Novack L, Kaplan DM, El-Saied S, Alwalidi M, et al. Randomized study comparing inflammatory response after tonsillectomy versus tonsillotomy. European Archives of Oto-rhino-laryngology 2016; 273(11):3993-4001.

. Outcome of laser or debrider tonsillotomy versus tonsillectomy in obstructive sleep apnea [Laser or debrider tonsillotomy versus monopolar tonsillectomy in obstructive sleep apnea; inflammation AS a determinate of outcome]. https://clinicaltrials.gov/show/NCT01319058 (first received 21 March 2011).

\section{Korkmaz 2008 \{published data only\}}

Korkmaz O, Bektas D, Cobanoglu B, Caylan R. Partial tonsillectomy with scalpel in children with obstructive tonsillar hypertrophy. International Journal of Pediatric Otorhinolaryngology 2008; 72(7):1007-12.

\section{Li 2013 \{published data only\}}

Li D, Zhang QF, Zhang X. Partial tonsillectomy vs tonsillectomy with coblation in children with obstructive sleep apnea hypopnea syndrome. Journal of Clinical Otorhinolaryngology, Head and Neck Surgery (China) 2013; 27(5):281-3.

\section{Lundeborg 2009 \{published data only\}}

Lundeborg I, Ericsson E, Hultcrantz E, McAllister A. Acoustic and perceptual aspects of vocal function in children with adenotonsillar hypertrophy-effects of surgery. Journal of Voice 2012; 26(4):480-7.

Lundeborg I, Ericsson E, Hultcrantz E, McAllister AM. Influence of adenotonsillar hypertrophy on /s/-articulation in children-effects of surgery. Logopedics Phoniatrics Vocology 2011; 36:100-8.

* Lundeborg I, McAllister A, Graf J, Ericsson E, Hultcrantz E. Oral motor dysfunction in children with adenotonsillar hypertrophy--effects of surgery. Logopedics Phoniatrics Vocology 2009; 34(3):111-6.

Lundeborg I, McAllister A, Samuelsson C, Ericsson E, Hultcrantz E. Phonological development in children with obstructive sleep-disordered breathing. Clinical Linguistics \& Phonetics 2009; 23(10):751-61.

\section{Park 2007 \{published data only\}}

Park A, Proctor MD, Alder S, Muntz H. Subtotal bipolar tonsillectomy does not decrease postoperative pain compared to total monopolar tonsillectomy. International Journal of Pediatric Otorhinolaryngology 2007; 71(8):1205-10.

\section{Skoulakis 2007 \{published data only\}}

Skoulakis CE, Papadakis CE, Manios AG, Moshotzopoulos PD, Theos EA, Valagiannis DE. Tonsilloplasty in children with obstructive symptoms. Journal of Otolaryngology 2007; 36(4):240-6.

Sobol 2006 \{published data only\}

Sobol SE, Wetmore RF, Marsh RR, Stow J, Jacobs IN. Postoperative recovery after microdebrider intracapsular or monopolar electrocautery tonsillectomy: a prospective, randomized, single-blinded study. Archives of Otolaryngology-Head \& Neck Surgery 2006; 132(3):270-4.

\section{Zhou 2016 \{published data only\}}

Zhou J, Wang Y, Li Y. Effects of different surgical procedures on immunity of children with obstructive sleep apnea hypopnea syndrome. Journal of Clinical Otorhinolaryngology, Head and Neck Surgery (China) 2016; 30(5):396-8.

\section{References to studies excluded from this review}

Babademez 2011 \{published data only\}

Babademez MA, Yurekli MF, Acar B, Gunby E. Comparison of radiofrequency ablation, laser and coblator techniques in reduction of tonsil size. Acta Otolaryngologica 2011; 131:750-6.

\section{Bitar 2008 \{published data only\}}

Bitar M, Rameh C. Microdebrider-assisted partial tonsillectomy: short- and long-term outcomes. European Archives of Oto-rhinolaryngology 2008; 256:459-63.

\section{Cantarella 2012 \{published data only\}}

Cantarella G, Viglione S, Forti S, Minetti A, Pignataro L. Comparing postoperative quality of life in children after microdebrider intracapsular tonsillotomy and tonsillectomy. Auris Nasus Larynx 2012; 39:407-10.

\section{Cao 2018 \{published data only\}}

Cao YC, Wang XY, Xu WW, Li JD, Yu QH. The effects of tonsillectomy by low-temperature plasma on the growth development and psychological behavior in children with obstructive sleep apnea hypopnea syndrome. Medicine (Baltimore) 2018; 97(47):e13205.

\section{Esteller 2016 \{published data only\}}

Esteller E, Villatoro JC, Pedemonte G, Agüero A, Ademà JM, Girabent-Farrésc M. Surgical treatment for childhood obstructive sleep apnoea: cold-knife tonsillar dissection versus bipolar radiofrequency thermal ablation [Tratamiento quirúrgicodel síndrome de apnea obstructiva del sue no infantil: comparación entre adenoamigdalectomía extracapsular con bisturí frío y reducciónmediante radiofrecuencia bipolar]. Acta Otorrinolaringologica Espanola 2016; 67(6):261-7.

\section{Gabr 2014 \{published data only\}}

Gabr SI, Harhash KA, El Fouly MS, Kamel AA, Eldwebes MM. Microdebrider intracapsular tonsillotomy versus conventional extracapsular tonsillectomy. Egyptian Journal of Otolaryngology 2014; 30:220-4. 
Hagerdorn 2005 \{published data only\}

Hagerdorn H, Andratschke M. Tonsillectomy versus laser tonsillotomy for tonsillar hyperplasia in children. MMW Fortschritte der Medizin 2005; 147(17):45-9.

Oubaid Ahmed 2018 \{published data only\}

Oubaid Ahmed N, Sultan Safaa Sahib N. Comparing postoperative morbidity after microdebrider intracapsular tonsillotomy and cold steel dissection tonsillectomy. Journal of University of Babylon, Pure and Applied Sciences 2018; 26(9):225-31.

\section{Pfaar 2007 \{published data only\}}

Pfaar O, Spielhaupter M, Schirkowski A, Wrede H, Mosges R, Hormann K, et al. Treatment of hypertrophic palatine tonsils using bipolar radiofrequency-induced thermotherapy (RFITT). Acta Otolaryngologica 2007; 127:1176-81.

\section{Pruegsanusak 2010 \{published data only\}}

Pruegsanusak K, Wongsuwan K, Wongkittithawon J. A randomized controlled trial for perioperative morbidity in microdebrider versus cold instrument dissection tonsillectomy. Journal of the Medical Association of Thailand 2010; 93(5):558-65.

\section{Vlastos 2008 \{published data only\}}

Vlastos IM, Parpounas K, Economides J, Helmis G, Koudoumnakis E, Houlakis M. Tonsillectomy versus tonsillotomy performed with scissors in children with tonsillar hypertrophy. International Journal of Pediatric Otorhinolaryngology 2008; 72(6):857-63.

\section{Wireklint 2012 \{published data only\}}

Wireklint S, Ericsson E. Health-related quality of life after tonsillotomy versus tonsillectomy in young adults: 6 years postsurgery follow-up. European Archives of Oto-rhinolaryngology 2012; 269:1951-8.

\section{References to ongoing studies}

NCT01676181 \{published data only\}

. Randomised surgical intervention study between adenotonsillectomy and adenotonsillotomy in children with obstructive sleep apnea syndrome. https://clinicaltrials.gov/ ct2/show/NCT01676181 (first received 30 August 2012). [NCT01676181]

\section{Additional references}

\section{Baldassari 2008}

Baldassari CM, Mitchell RB, Schubert C, Rudnick EF. Pediatric obstructive sleep apnea and quality of life: a meta-analysis. Otolaryngology - Head and Neck Surgery 2008; 138(3):265-73.

\section{Baugh 2011}

Baugh RF, Archer SM, Mitchell RB, Rosenfeld RM, Amin R, Burns JJ, et al, American Academy of Otolaryngology-Head and Neck Surgery Foundation. Clinical practice guideline: tonsillectomy in children. Otolaryngology - Head \& Neck Surgery 2011; 144(1 Suppl):S1-30. [DOI: 10.1177/0194599810389949]

\section{Beebe 2006}

Beebe DW. Neurobehavioral morbidity associated with disordered breathing during sleep in children: a comprehensive review. Sleep 2006; 29(9):1115-34.

\section{Cooper 2013}

Cooper L, Ford K, Bajaj Y. Paediatric adenotonsillectomy as a daycase for obstructive sleep apnoea: how we do it in a tertiary unit. International Journal of Pediatric Otorhinolaryngology 2013; 77(11):1877-80.

\section{Erickson 2009}

Erickson BK, Larson DR, St Sauver JL, Meverden RA, Orvidas LJ. Changes in incidence and indications of tonsillectomy and adenotonsillectomy, 1970-2005. Otolaryngology - Head and Neck Surgery 2009; 140(6):894-901.

\section{Eriksson 2017}

Eriksson M, Nilsson U, Bramhagen AC, Idvall E, Ericsson E. Selfreported postoperative recovery in children after tonsillectomy compared to tonsillotomy. International Journal of Pediatric Otorhinolaryngology 2017; 96:47-54.

\section{Friedman 2013}

Friedman NR, Perkins JN, McNair B, Mitchell RB. Current practice patterns for sleep-disordered breathing in children. Laryngoscope 2013; 123(4):1055-8.

\section{Fung 2010}

Fung E, Cave D, Witmans M, Gan K, El-Hakim H. Postoperative respiratory complications and recovery in obese children following adenotonsillectomy for sleep-disordered breathing: a case-control study. Otolaryngology - Head and Neck Surgery 2010; 142(6):898-905.

\section{Gorman 2017}

Gorman D, Ogston S, Hussain SS. Improvement in symptoms of obstructive sleep apnoea in children following tonsillectomy versus tonsillotomy: a systematic review and meta-analysis. Clinical Otolaryngology 2017; 42(2):275-82.

\section{Gottileb 2004}

Gottlieb DJ, Chase C, Vezina RM, Heeren TC, Corwin MJ, Auerbach SH, et al. Sleep-disordered breathing symptoms are associated with poorer cognitive function in 5-year-old children. Journal of Pediatrics 2004; 145(4):458-64.

\section{Hallenstål 2017}

Hallenstål N, Sunnergren O, Ericsson E, Hemlin C, Hessén Söderman AC, Nerfeldt P, et al. Tonsil surgery in Sweden 2013-2015. Indications, surgical methods and patient-reported outcomes from the National Tonsil Surgery Register. Acta Otolaryngologica 2017; 137(10):1096-1103.

\section{Higgins 2003}

Higgins JPT, Thompson SG, Deeks JJ, Altman DG. Measuring inconsistency in meta-analyses. BMJ 2003; 327(7414):557-60.

\section{Higgins 2019}

Higgins JPT, Thomas J, Chandler J, Cumpston M, Li T, Page MJ, Cochrane Handbook for Systematic Reviews of Interventions 
version 6.0 (updated July 2019). Cochrane, 2019. Available from www.training.cochrane.org/handbook.

\section{Kim 2017}

Kim JS, Kwon SH, Lee EJ, Yoon YJ. Can intracapsular tonsillectomy be an alternative to classical tonsillectomy? A meta-analysis. Otolaryngology - Head and Neck Surgery 2017; 157(2):178-89.

\section{Koltai 2003}

Koltai PJ, Solares CA, Koempel JA, Hirose K, Abelson TI, Krakovitz PR, et al. Intracapsular tonsillar reduction (partial tonsillectomy): reviving a historical procedure for obstructive sleep disordered breathing in children. Otolaryngology - Head and Neck Surgery 2003; 129(5):532-8.

\section{Lalakea 1999}

Lalakea ML, Marquez-Biggs I, Messner AH. Safety of pediatric short-stay tonsillectomy. Archives of Otolaryngology - Head and Neck Surgery 1999; 125(7):749-52.

\section{Lowe 2007}

Lowe D, van der Meulen J, Cromwell D, Lewsey J, Copley L, Browne J. Key messages from the National Prospective Tonsillectomy Audit. Laryngoscope 2007; 117(4):717-24.

\section{Marcus 2001}

Marcus CL. Sleep-disordered breathing in children. American Journal of Respiratory and Critical Care Medicine 2001; 164(1):16-30.

\section{Marcus 2005}

Marcus CL, Katz ES, Lutz J, Black CA, Galster P, Carson KA. Upper airway dynamic responses in children with the obstructive sleep apnea syndrome. Pediatric Research 2005; 57(1):99-107.

\section{Marcus 2012}

Marcus CL, Brooks LJ, Draper KA, Gozal D, Halbower AC, Jones J, et al. Diagnosis and management of childhood obstructive sleep apnea syndrome. Pediatrics 2012; 130:e714-55.

\section{Mueller 2015}

Mueller J, Boeger D, Buentzel J, Esser D, Hoffmann K, Jecker P. Population-based analysis of tonsil surgery and postoperative hemorrhage. European Archives of Otorhinolaryngology 2015; 272(12):3769-77.

\section{Nespoli 2013}

Nespoli L, Caprioglio A, Luigia B, Nosetti L. Obstructive sleep apnea syndrome in childhood. Early Human Development 2013; 89:33-7.

\section{Odhagen 2016}

Odhagen E, Sunnergren O, Hemlin C, Hessén Söderman AC, Ericsson E, Stalfors J. Risk of reoperation after tonsillotomy versus tonsillectomy: a population-based cohort study. European Archives of Otorhinolaryngology 2016; 273(10):3263-8.

\section{Owens 2009}

Owens JA. Neurocognitive and behavorial impact of sleep disordered breathing in children. Pediatric Pulmonology 2009; 44(5):417-22.

\section{Patel 2014}

Patel HH, Straight CE, Lehman EB, Tanner M, Carr MM. Indications for tonsillectomy: a 10 year retrospective review. International Journal of Pediatric Otorhinolaryngology 2014; 78(12):2151-5.

\section{Pringle 2013}

Pringle MB, Natesh BG, Buchanan EM. National UK survey on the assessment and surgical management of suspected paediatric obstructive sleep apnoea syndrome. International Journal of Pediatric Otorhinolaryngology 2013; 77(10):1689-96.

\section{Robb 2009}

Robb PJ, Bew S, Kubba H, Murphy N, Primhak R, , et al. Tonsillectomy and adenoidectomy in children with sleep related breathing disorders: consensus statement of a UK multidisciplinary working party. Clinical Otolaryngology 2009; 34(1):61-3.

\section{Rosen 2004}

Rosen CL, Storfer-Isser A, Taylor HG, Kirchner HL, Emancipator JL, Redline S. Increased behavioral morbidity in school-aged children with sleep-disordered breathing. Pediatrics 2004; 114(6):1640-8.

\section{Ruohoalho 2018}

Ruohoalho J, Østvoll E, Bratt M, Bugten V, Bäck L, Mäkitie A, et al. Systematic review of tonsil surgery quality registers and introduction of the Nordic Tonsil Surgery Register Collaboration. European Archives of Oto-rhino-laryngology 2018; 275(6):1353-63.

\section{Sarny 2011}

Sarny S, Habermann W, Ossimitz G, Schmid C, Stammberger H. Tonsilar haemorrhage and re-admission: a questionnaire based study. European Archives of Otorhinolaryngology 2011; 268(12):1803-7.

\section{Sathe 2017}

Sathe N, Chinnadurai S, McPheeters M, Francis DO. Comparative effectiveness of partial versus total tonsillectomy in children. Otolaryngology - Head and Neck Surgery 2017; 156(3):456-63.

\section{Schwengel 2009}

Schwengel DA, Sterni LM, Tunkel DE, Heitmiller ES. Perioperative management of children with obstructive sleep apnea. Anesthesia \& Analgesia 2009; 109(1):60-75.

\section{Sedky 2014}

Sedky S, Bennett DS, Carvalho KS. Attention deficit hyperactivity disorder and sleep disordered breathing in pediatric populations: a meta-analysis. Sleep Medicine Reviews 2014; 18(4):349-56. 


\section{Shine 2005}

Shine NP, Coates HL, Lannigan FJ. Obstructive sleep apnea, morbid obesity, and adenotonsillar surgery: a review of the literature. International Journal of Pediatric Otorhinolaryngology 2005; 69:1475-82.

\section{Sorin 2004}

Sorin A, Bent JP, April MM, Ward RF. Complications of microdebrider-assisted powered intracapsular tonsillectomy and adenoidectomy. Laryngoscope 2004; 114(2):297-300.

\section{Spruyt 2011}

Spruyt K, Gozal D. Pediatric sleep questionnaires as diagnostic or epidemiological tools: a review of currently available instruments. Sleep Medicine Reviews 2011; 15(1):19-32.

\section{Stalfors 2014}

Stalfors J, Ericsson E, Hemlin C, , Odhagen E, Sunnergren O. Annual report 2013 of The National Tonsil Surgery Register in Sweden. Stockholm, Sweden: Karolinska University Hospital, 2014.

\section{Stanko 2013}

Stanko D, Bergesio R, Davies K, Hegarty M, von UngernSternberg BS. Postoperative pain, nausea and vomiting following adeno-tonsillectomy - a long-term follow-up. Pediatric Anesthesia 2013; 23(8):690-6.

\section{Statham 2006}

Statham MM, Elluru RG, Buncher R, Kalra M. Adenotonsillectomy for obstructive sleep apnea syndrome in young children: prevalence of pulmonary complications. Archives of Otolaryngology--Head and Neck Surgery 2006; 132(5):476-80.

\section{Sunnergren 2017}

Sunnergren O, Odhagen E, Stalfors J. Incidence of second surgery following pediatric adenotonsillar surgery: a population-based cohort study. European Archives of Otorhinolaryngology 2017; 274(7):2945-51.

\section{Tauman 2011}

Tauman R, Gozal D. Obstructive sleep apnea syndrome in children. Expert Review of Respiratory Medicine 2011; 5(3):425-40.

\section{CHARACTERISTICS OF STUDIES}

Characteristics of included studies [ordered by study ID]

\section{Venekamp 2015}

Venekamp RP, Hearne BJ, Chandrasekharan D, Blackshaw $\mathrm{H}$, Lim J, Schilder AGM. Tonsillectomy or adenotonsillectomy versus non-surgical management for obstructive sleep-disordered breathing in children. Cochrane Database of Systematic Reviews 2015, Issue 10. [DOI: 10.1002/14651858.CD011165.pub2]

\section{Venekamp 2017}

Venekamp RP, Chandrasekharan D, Abel F, Blackshaw $\mathrm{H}$, Kreis IA, Evans HER, et al. Research into childhood obstructive sleep-disordered breathing: a systematic review. Chest 2017; 152(1):51-7.

\section{Wang 2015}

Wang H, Fu Y, Feng Y, Guan J, Yin S. Tonsillectomy versus tonsillotomy for sleep-disordered breathing in children: a meta analysis. PLoS One 2015; 10(3):e0121500.

\section{Windfuhr 2013}

Windfuhr JP, Werner JA. Tonsillotomy: it's time to clarify the facts. European Archives of Otorhinolaryngology 2013; 270(12):2985-96.

\section{Windfuhr 2015}

Windfuhr JP, Savva K, Dahm JD, Werner JA. Tonsillotomy: facts and fiction. European Archives of Otorhinolaryngology 2015; 272(4):949-69.

\section{Zhang 2017}

Zhang LY, Zhong L, David M, Cervin A. Tonsillectomy or tonsillotomy? A systematic review for paediatric sleepdisordered breathing. International Journal of Pediatric Otorhinolaryngology 2017; 103:41-50.

\section{References to other published versions of this review Blackshaw 2014}

Blackshaw H, Zhang LY, Venekamp RP, Wang B, Chandrasekharan D, Schilder AGM. Tonsillectomy versus tonsillotomy for sleep-disordered breathing in children. Cochrane Database of Systematic Reviews 2014, Issue 11. [DOI: 10.1002/14651858.CD011365]

* Indicates the major publication for the study

Beriat 2013

\section{Study characteristics}

\begin{tabular}{ll}
\hline Methods & Non-blinded, parallel-group randomised controlled surgical trial with 1-year duration of follow-up \\
\hline Participants & Setting: Bulanik State Hospital, Turkey \\
& Sample size:
\end{tabular}


Beriat 2013 (Continued)

- Number randomised: 82 children

- Number completed: 82 children

Participant (baseline) characteristics:

- Age: 4 to 12 years

- Gender: $56 \%$ boys, $44 \%$ girls

Inclusion criteria: children who suffer from snoring, evidenced apnoea, sleeping with mouth open. Diagnosis was "obstructed airway" according to tonsil hypertrophy based upon the information given by parents and clinical inspection.

Exclusion criteria: children with successive streptococcal tonsillitis attack more than 3 times within 2 years; peritonsillar abscess history; chronic infected tonsillitis during consultation (upon pressure, tonsils generates pus); obese children who possibly have complex obstructive sleep apnoea syndrome; craniofacial abnormalities and coagulopathy

Interventions

Intervention group: tonsillectomy by conventional cold steel dissection (TE) ( $n=45)$

Comparator group: intracapsular tonsillotomy (TT) using microdebrider $(n=37)$

Use of additional interventions: none stated

Outcomes

Short-term outcomes ( 2 weeks): intraoperative blood loss, operation time, postoperative pain, analgesic use, otalgia, sore throat, transition to painless oral nutrition

Long-term outcomes (1 year): throat infections

Notes Participants lost to short-term follow-up total: $0 \%$

Participants lost to long-term follow-up total: $0 \%$

\section{Risk of bias}

\begin{tabular}{|c|c|c|}
\hline Bias & Authors' judgement & Support for judgement \\
\hline $\begin{array}{l}\text { Random sequence genera- } \\
\text { tion (selection bias) }\end{array}$ & Unclear risk & Quote: "Through random selection"; no further information provided \\
\hline $\begin{array}{l}\text { Allocation concealment } \\
\text { (selection bias) }\end{array}$ & Unclear risk & Quote: "Through random selection"; no further information provided \\
\hline $\begin{array}{l}\text { Blinding of participants } \\
\text { and personnel (perfor- } \\
\text { mance bias) } \\
\text { All outcomes }\end{array}$ & High risk & Not blinded \\
\hline $\begin{array}{l}\text { Blinding of outcome as- } \\
\text { sessment (detection bias) } \\
\text { All outcomes }\end{array}$ & High risk & Not blinded \\
\hline $\begin{array}{l}\text { Incomplete outcome data } \\
\text { (attrition bias) } \\
\text { All outcomes }\end{array}$ & Unclear risk & No loss to follow-up in short term; not stated for long term \\
\hline $\begin{array}{l}\text { Selective reporting (re- } \\
\text { porting bias) }\end{array}$ & Unclear risk & $\begin{array}{l}\text { No protocol available; insufficient information to permit a judgement of low or } \\
\text { high risk }\end{array}$ \\
\hline Other bias & Unclear risk & $\begin{array}{l}\text { Baseline characteristics: balanced } \\
\text { ITT analysis: performed }\end{array}$ \\
\hline
\end{tabular}


Beriat 2013 (Continued)

Formal sample size calculations: not performed

Use of co-interventions: not performed

Bitar 2016

\section{Study characteristics}

\begin{tabular}{ll}
\hline Methods & Double-blinded, parallel-group randomised controlled surgical trial with 1-year duration of follow-up \\
\hline Participants & Setting: Department of Otolaryngology Head and Neck Surgery, Beirut, Lebanon \\
Sample size: & - Number randomised: 26 children \\
- Number completed: 19 children \\
Participant (baseline) characteristics: \\
- Age: 3 to 10 years \\
- Gender: not stated \\
Inclusion criteria: children with a history of symptoms suggestive of upper airway obstruction for at \\
least 3 months duration \\
Exclusion criteria: children with a history of recurrent tonsillitis, immunodeficiency, chronic infec- \\
tions, or receiving immune-stimulants or suppressants
\end{tabular}

\begin{tabular}{ll}
\hline Interventions & Intervention group: tonsillectomy by blunt dissection and electrocautery $(T E)(n=8)$ \\
& Comparator group: intracapsular tonsillotomy by microdebrider (TT) $(n=11)$ \\
& Use of additional interventions: none stated \\
\hline Outcomes & Short-term outcomes ( $\mathbf{3}$ months): humoral immunity (serum IgG, IgM, IgA, salivary IgA) \\
& $\begin{array}{l}\text { Long-term outcomes (1 year): clinical history including febrile illness, doctor visits, antibiotic uptake, } \\
\text { change in allergic rhinitis and emergence of chronic diseases }\end{array}$
\end{tabular}

Notes Participants lost to follow-up total: $27 \%$

\section{Risk of bias}

\begin{tabular}{lll}
\hline Bias & Authors' judgement & Support for judgement \\
\hline $\begin{array}{l}\text { Random sequence genera- } \\
\text { tion (selection bias) }\end{array}$ & Unclear risk & Method not described \\
\hline $\begin{array}{l}\text { Allocation concealment } \\
\text { (selection bias) }\end{array}$ & Unclear risk & Method not described \\
\hline $\begin{array}{l}\text { Blinding of participants } \\
\text { and personnel (perfor- } \\
\text { mance bias) }\end{array}$ & High risk \\
$\begin{array}{l}\text { All outcomes } \\
\text { Blinding of outcome as- } \\
\text { sessment (detection bias) } \\
\text { All outcomes }\end{array}$ & High risk & Not blinded \\
\hline \hline
\end{tabular}


Bitar 2016 (Continued)

\begin{tabular}{|c|c|c|}
\hline $\begin{array}{l}\text { Incomplete outcome data } \\
\text { (attrition bias) } \\
\text { All outcomes }\end{array}$ & High risk & $27 \%(7 / 26)$ not included in the analysis \\
\hline $\begin{array}{l}\text { Selective reporting (re- } \\
\text { porting bias) }\end{array}$ & Unclear risk & $\begin{array}{l}\text { No protocol available; insufficient information to permit a judgement of low or } \\
\text { high risk }\end{array}$ \\
\hline \multirow[t]{4}{*}{ Other bias } & High risk & Baseline characteristics: not stated \\
\hline & & ITT analysis: performed \\
\hline & & Formal sample size calculations: not performed \\
\hline & & Use of co-interventions: not performed \\
\hline
\end{tabular}

Borgstrom 2017

\section{Study characteristics}

\begin{tabular}{l} 
Methods $\begin{array}{l}\text { Double-blinded, parallel-group randomised controlled non-inferiority surgical trial with 1-year dura- } \\
\text { tion of follow-up }\end{array}$ \\
\hline Setting: Karolinska University Hospital, Stockholm, Sweden \\
Sample size: \\
- Number randomised: 79 children \\
- Number completed: 74 children \\
Participant (baseline) characteristics: \\
- Age: 2 to 6 years \\
- Gender: $67 \%$ boys, $23 \%$ girls \\
Inclusion criteria: age 2 to 6 years, history or symptoms of OSA, tonsil hypertrophy 3 or 4 (scale 1 to 4 \\
according to Brodsky 11 ), Apnea Hypopnea Index (AHI) of $\geq 5$ and $\leq 30$ events/hour sleep \\
Exclusion criteria: craniofacial abnormality, neuromuscular disease, chromosomal abnormality, obe- \\
sity (BMI z score > 1.67), previous adenotonsillar surgery, bleeding disorder, cardiopulmonary disease, \\
history of recurrent tonsillitis and parents with insufficient knowledge of the Swedish language
\end{tabular}

\begin{tabular}{|c|c|c|}
\hline Interventions & \multicolumn{2}{|c|}{$\begin{array}{l}\text { Intervention group: tonsillectomy by cold steel dissection (TE) ( } n=40) \\
\text { Comparator group: intracapsular tonsillotomy by coblation }(T T)(n=39) \\
\text { Use of additional interventions: concurrent adenoidectomy in all children }\end{array}$} \\
\hline Outcomes & \multicolumn{2}{|c|}{$\begin{array}{l}\text { Long-term outcomes (1 year): postoperative complications, respiratory events during sleep } \\
\text { (polysomnography), disease-specific quality of life, general quality of life, reoperation rates }\end{array}$} \\
\hline Notes & \multicolumn{2}{|c|}{ Participants lost to follow-up total: $6 \%$} \\
\hline \multicolumn{3}{|l|}{ Risk of bias } \\
\hline Bias & Authors' judgement & Support for judgement \\
\hline $\begin{array}{l}\text { Random sequence genera- } \\
\text { tion (selection bias) }\end{array}$ & Low risk & $\begin{array}{l}\text { Quote: "Before study start, } 90 \text { sealed envelopes were randomly mixed } \\
\text { ATE and } 45 \text { for ATT, giving a 1:1 allocation ratio" }\end{array}$ \\
\hline
\end{tabular}




\section{Borgstrom 2017 (Continued)}

Allocation concealment Low risk Quote: "The envelopes were placed at the operating room and opened by the (selection bias) surgeon"

Blinding of participants Low risk and personnel (perfor-

Quote: "Only the surgeon and the staff in the operating room knew which mance bias)

All outcomes surgical method was performed. The surgeon did not meet the patients or parents after surgery; they were discharged by another doctor the day after surgery."

\section{Blinding of outcome as- Low risk} sessment (detection bias)

All outcomes
Quote: "patients and care providers were blinded to intervention method, as was the technologist interpreting the PSGs"

Incomplete outcome data Unclear risk 6\% (5/79) not included in the analysis

(attrition bias)

All outcomes

\begin{tabular}{|c|c|c|}
\hline $\begin{array}{l}\text { Selective reporting (re- } \\
\text { porting bias) }\end{array}$ & Low risk & Clinical Trial Registration \#NCT01676181 \\
\hline \multirow[t]{4}{*}{ Other bias } & Low risk & Baseline characteristics: balanced \\
\hline & & ITT analysis: performed \\
\hline & & Formal sample size calculations: performed \\
\hline & & $\begin{array}{l}\text { Use of co-interventions: balanced, all children received concurrent adenoidec- } \\
\text { tomy }\end{array}$ \\
\hline
\end{tabular}

\section{Chaidas 2013}

\section{Study characteristics}

\begin{tabular}{ll}
\hline Methods & Non-blinded, parallel-group randomised controlled surgical trial with 6-year duration of follow-up \\
\hline Participants & Setting: acute care hospital and ENT clinic, Athens, Greece \\
Sample size: & Number randomised: 101 children (118 screened, 17 excluded) \\
- Number completed: 90 children \\
Participant (baseline) characteristics: \\
- Age: 3 to 9 years \\
- Gender: $52 \%$ males, $48 \%$ females \\
Inclusion criteria: children with obstructive SDB based on 1) parental report of loud snoring $>3$ nights \\
per week (habitual snoring) present for at least 6 months; and 2) tonsil size $\leq 3+($ obstructing $>50 \%$ of \\
the oropharynx) \\
Exclusion criteria: children with 1) history of neuromuscular or genetic disorders; 2 ) presence of cran- \\
iofacial abnormalities; 3) history of recurrent throat infections; 4) children whose parents refused the \\
selected surgical method
\end{tabular}

Interventions Intervention group: tonsillectomy (TE) by blunt dissection $(\mathrm{n}=51)$

Comparator group: tonsilloplasty (tonsillotomy, TT) by cold dissection ( $n=50)$ 
Use of additional interventions: all children received adenoidectomy, 20\% received tympanotomy (10 children in each group)

\begin{tabular}{|c|c|c|}
\hline Outcomes & \multicolumn{2}{|c|}{$\begin{array}{l}\text { Short-term outcomes ( } 10 \text { days): duration of surgery, intraoperative bleeding, postoperative pain, } \\
\text { time to return to normal diet } \\
\text { Long-term outcomes ( } 6 \text { years): recurrence of oSDB symptoms, eating difficulties, throat infections per } \\
\text { year, ENT infections per year, tonsil regrowth, revision of surgery }\end{array}$} \\
\hline Notes & \multicolumn{2}{|c|}{$\begin{array}{l}\text { Participants lost to short-term follow-up: } 0 \% \\
\text { Participants lost to long-term follow-up: } 10 \% \text { (6\% TE and 14\% TT) }\end{array}$} \\
\hline Risk of bias & & \\
\hline Bias & Authors' judgement & Support for judgement \\
\hline $\begin{array}{l}\text { Random sequence genera- } \\
\text { tion (selection bias) }\end{array}$ & Low risk & $\begin{array}{l}\text { Quote: "Randomization was performed in subjects from the waiting list using a } \\
\text { table of random numbers and the patient record number" }\end{array}$ \\
\hline $\begin{array}{l}\text { Allocation concealment } \\
\text { (selection bias) }\end{array}$ & Unclear risk & Method not described \\
\hline $\begin{array}{l}\text { Blinding of participants } \\
\text { and personnel (perfor- } \\
\text { mance bias) } \\
\text { All outcomes }\end{array}$ & High risk & Not blinded \\
\hline $\begin{array}{l}\text { Blinding of outcome as- } \\
\text { sessment (detection bias) } \\
\text { All outcomes }\end{array}$ & High risk & Not blinded \\
\hline $\begin{array}{l}\text { Incomplete outcome data } \\
\text { (attrition bias) } \\
\text { All outcomes }\end{array}$ & High risk & $10 \%$ dropout for long-term follow-up \\
\hline $\begin{array}{l}\text { Selective reporting (re- } \\
\text { porting bias) }\end{array}$ & Unclear risk & $\begin{array}{l}\text { No protocol available; insufficient information to permit a judgement of low or } \\
\text { high risk }\end{array}$ \\
\hline Other bias & Unclear risk & $\begin{array}{l}\text { Baseline characteristics: balanced } \\
\text { ITT analysis: performed } \\
\text { Formal sample size calculations: not performed } \\
\text { Use of co-interventions: balanced (all children received adenoidectomy, tym- } \\
\text { panotomy performed in } 20 \% \text { TE and } 20 \% \text { TT) }\end{array}$ \\
\hline
\end{tabular}

\section{Chan 2004}

\section{Study characteristics}

\begin{tabular}{ll}
\hline Methods & Single-blinded, parallel-group randomised controlled surgical trial with 1-year duration of follow-up \\
\hline Participants & Setting: 4 otolaryngology, head and neck surgery clinical centres, USA \\
& Sample size:
\end{tabular}


Chan 2004 (Continued)

- Number randomised: 55 children

- Number completed: 43 children

Participant (baseline) characteristics:

- Age: 3 to 12 years

- Gender: $58 \%$ males, $42 \%$ females

Inclusion criteria: children who had longer than a 6-month history of obstructive symptoms, reported no more than 2 episodes of streptococcal pharyngitis per year, and had physical findings consistent with tonsil hypertrophy

Exclusion criteria: active pharyngitis, prior tonsillar surgery, history of peritonsillar abscess, systemic diseases, suggestion of tonsillar neoplasm, coagulopathy, craniofacial anomaly, those judged unable to convey pain or discomfort to the caregiver

Interventions Intervention group: tonsillectomy (TE) using conventional electrosurgery $(n=28$ ( $n=25$ included in
analyses))

Comparator group: intracapsular tonsillectomy (TT) using low-temperature plasma excision ( $n=27$ ( $n$ $=25$ included in analyses))

Use of additional interventions: unclear how many children actually received concurrent adenoidectomy

Short-term outcomes (14 days): operation time, peri-operative bleeding, episodes of postoperative
bleeding, episodes of dehydration, median number of days until free from pain, median number of
days until analgesics no longer required, median number of days until return to normal diet

Long-term outcomes (3 months and 1 year): recurrence of SDB as a result of tonsil regrowth

Notes Participants lost to follow-up total: $9 \%$ of children; $11 \%$ TE group and $7 \%$ TT group; reasons not de-
scribed

\section{Risk of bias}

\begin{tabular}{|c|c|c|}
\hline Bias & Authors' judgement & Support for judgement \\
\hline $\begin{array}{l}\text { Random sequence genera- } \\
\text { tion (selection bias) }\end{array}$ & Low risk & Quote: "Assignment was conducted by coin toss, in blocks of 6 ( $3: 3$ ratio)" \\
\hline $\begin{array}{l}\text { Allocation concealment } \\
\text { (selection bias) }\end{array}$ & Low risk & $\begin{array}{l}\text { Quote: "The sponsor maintained the randomization schedule and specific as- } \\
\text { signment made immediately following enrolment of each individual patient" }\end{array}$ \\
\hline $\begin{array}{l}\text { Blinding of participants } \\
\text { and personnel (perfor- } \\
\text { mance bias) } \\
\text { All outcomes }\end{array}$ & Unclear risk & $\begin{array}{l}\text { It was stated in the abstract of the manuscript that patients were blinded to } \\
\text { treatment assignment but no further details on blinding were provided }\end{array}$ \\
\hline $\begin{array}{l}\text { Blinding of outcome as- } \\
\text { sessment (detection bias) } \\
\text { All outcomes }\end{array}$ & Unclear risk & $\begin{array}{l}\text { It was stated in the abstract of the manuscript that patients were blinded to } \\
\text { treatment assignment but no further details on blinding were provided }\end{array}$ \\
\hline $\begin{array}{l}\text { Incomplete outcome data } \\
\text { (attrition bias) } \\
\text { All outcomes }\end{array}$ & Unclear risk & $9 \%$ of randomised children not included in analyses \\
\hline $\begin{array}{l}\text { Selective reporting (re- } \\
\text { porting bias) }\end{array}$ & High risk & Data beyond 3 months not reported \\
\hline Other bias & Unclear risk & Baseline characteristics: balanced \\
\hline
\end{tabular}


Chan 2004 (Continued)

ITT analysis: unclear if performed

Formal sample size calculations: performed

Use of co-interventions: unclear how many children in each group received concurrent adenoidectomy

\section{Study characteristics}

\begin{tabular}{ll}
\hline Methods & Double-blinded, parallel-group randomised controlled surgical trial with 6 days of follow-up \\
\hline Participants & Setting: Division of Pediatric Otolaryngology, Lucile Packard Children's Hospital at Stanford and De- \\
partment of Otolaryngology-Head Neck Surgery, Stanford University School of Medicine, USA \\
Sample size: \\
- Number randomised: 128 children (128 children randomised; 27 declined to participate; 101 children \\
received surgery and were included in analyses) \\
Pumber completed: 101 children \\
Participant (baseline) characteristics: \\
- Age: 2 to 10 years \\
Gender: $52 \%$ males, $48 \%$ females \\
Inclusion criteria: children scheduled to have tonsillectomy and adenoidectomy for obstructive sleep \\
apnoea or sleep-disordered breathing \\
Exclusion criteria: history of recurrent or chronic tonsillitis or severe co-morbidities
\end{tabular}

Interventions

Intervention group: traditional tonsillectomy (TE) performed by electrocautery $(n=53(n=49$ received surgery and were included in analyses))

Comparator group: intracapsular tonsillectomy (TT) using coblation ( $n=75$ ( $n=52$ received surgery and were included in analyses))

Use of additional interventions: concurrent adenoidectomy performed in 100\% TE group and 98\% TT group

$35 \%$ of TE group and $29 \%$ of TT group received concurrent tympanostomy tube placement

$2 \%$ of TE group received concurrent frenuloplasty and excision of tongue mucocele

$2 \%$ of TT group received nasal endoscopy with cauterisation and concurrent direct laryngoscopy

Outcomes

Short-term outcomes (6 days): mean peri-operative blood loss, complications and readmissions, postoperative pain, type and frequency of pain medication, presence of nausea or vomiting, proportion of children with poor/fair/good oral intake, mean percentage of normal activity, parental days lost from work

Notes

Participants lost to follow-up total: $21 \%$ (27 declined randomisation; $8 \%$ TE group versus 31\% TT group)

\section{Risk of bias}


Chang 2005 (Continued)

Random sequence genera- Unclear risk Method not described tion (selection bias)

Allocation concealment $\quad$ Unclear risk
(selection bias)

\begin{tabular}{|c|c|c|}
\hline All outcomes & & $\begin{array}{l}\text { Surgeon not blinded to treatment assignment, unclear at what time the sur- } \\
\text { geon was notified of treatment allocation }\end{array}$ \\
\hline
\end{tabular}

\begin{tabular}{|c|c|c|}
\hline $\begin{array}{l}\text { Blinding of outcome as- } \\
\text { sessment (detection bias) } \\
\text { All outcomes }\end{array}$ & Low risk & $\begin{array}{l}\text { Quote: "Both the parents and the nurse practitioner performing the assess- } \\
\text { ments were blinded to the treatment assignment." }\end{array}$ \\
\hline
\end{tabular}

\begin{tabular}{lll}
\hline $\begin{array}{l}\text { Incomplete outcome data } \\
\text { (attrition bias) } \\
\text { All outcomes }\end{array}$ & High risk & $\begin{array}{l}\text { Significant number of randomised children (21\%) not included in analyses; } \\
4 / 53(8 \%) \text { declined to participate in tonsillectomy group versus 23/75 (31\%) in } \\
\text { tonsillotomy group }\end{array}$ \\
\hline $\begin{array}{l}\text { Selective reporting (re- } \\
\text { porting bias) }\end{array}$ & Unclear risk & $\begin{array}{l}\text { No protocol available; insufficient information to permit a judgement of low or } \\
\text { high risk }\end{array}$ \\
\hline Other bias & Unclear risk & Baseline characteristics: balanced \\
& $\begin{array}{l}\text { ITT analysis: unclear if performed } \\
\text { Sample size calculations: performed }\end{array}$ \\
& $\begin{array}{l}\text { Use of co-interventions: balanced (concurrent adenoidectomy performed in } \\
100 \% \text { TE and } 98 \% \text { TT) }\end{array}$ \\
\hline
\end{tabular}

\section{Chang 2008}

\section{Study characteristics}

\begin{tabular}{ll}
\hline Methods & Double-blinded, parallel-group randomised controlled trial with 6-day duration of follow-up \\
\hline Participants & Setting: single paediatric otolaryngology clinic, Stanford, California, USA \\
Sample size: & Number randomised: 69 children (102 screened for eligibility, 12 did not meet inclusion criteria, 21 \\
- Nurents refused randomisation) \\
Participant (baseline) characteristics: \\
- Age: 2 to 16 years \\
- Gender: $52 \%$ males, $48 \%$ females \\
Inclusion criteria: scheduled for tonsillectomy and adenoidectomy for OSA/SDB; no further diagnostic \\
criteria provided \\
Exclusion criteria: significant comorbidities, significant history of recurrent/chronic tonsillitis \\
Intervention group: tonsillectomy (TE) using coblation ( $n=35)$ \\
Comparator group: tonsillotomy (TT) using coblation ( $\mathrm{n}=34)$
\end{tabular}


Chang 2008 (Continued)

Use of additional interventions: curette adenoidectomy - proportion unclear

Outcomes Short-term outcomes (6 days): postoperative pain (child and parent perception), analgesia use, presence of nausea/vomiting, return to normal diet, return to normal activity, days of missed work for parents and complications or readmissions

Notes Participants lost to follow-up total: $0 \%$

\section{Risk of bias}

\begin{tabular}{|c|c|c|}
\hline Bias & Authors' judgement & Support for judgement \\
\hline $\begin{array}{l}\text { Random sequence genera- } \\
\text { tion (selection bias) }\end{array}$ & Unclear risk & Quote: "randomly assigned to treatment groups" - no method given \\
\hline $\begin{array}{l}\text { Allocation concealment } \\
\text { (selection bias) }\end{array}$ & Unclear risk & Method not described \\
\hline $\begin{array}{l}\text { Blinding of participants } \\
\text { and personnel (perfor- } \\
\text { mance bias) } \\
\text { All outcomes }\end{array}$ & Low risk & $\begin{array}{l}\text { Quote: "Both the parents and the nurse practitioner who performed the as- } \\
\text { sessments were blinded" }\end{array}$ \\
\hline $\begin{array}{l}\text { Blinding of outcome as- } \\
\text { sessment (detection bias) } \\
\text { All outcomes }\end{array}$ & Low risk & $\begin{array}{l}\text { Quote: "Both the parents and the nurse practitioner who performed the as- } \\
\text { sessments were blinded" }\end{array}$ \\
\hline $\begin{array}{l}\text { Incomplete outcome data } \\
\text { (attrition bias) } \\
\text { All outcomes }\end{array}$ & Unclear risk & No statement of dropouts \\
\hline $\begin{array}{l}\text { Selective reporting (re- } \\
\text { porting bias) }\end{array}$ & High risk & $\begin{array}{l}\text { Two outcomes not reported (analgesia required, days parents required off } \\
\text { work) }\end{array}$ \\
\hline \multirow[t]{4}{*}{ Other bias } & Unclear risk & Baseline characteristics: balanced \\
\hline & & ITT analysis: performed \\
\hline & & Formal sample size calculations: performed \\
\hline & & Use of co-interventions: not stated across groups \\
\hline
\end{tabular}

Coticchia 2006

\section{Study characteristics}

\begin{tabular}{ll}
\hline Methods & $\begin{array}{l}\text { Non-blinded (open-label), parallel-group randomised controlled surgical trial with 1-year duration of } \\
\text { follow-up }\end{array}$
\end{tabular}

Participants

Setting: 4 otolaryngology, head and neck surgery clinical centres, USA

\section{Sample size:}

- Number randomised: 27 children (23 children received surgery and were included in analyses)

- Number completed: 23 children

\section{Participant (baseline) characteristics:}


Coticchia 2006 (Continued)

\section{- Age: 4 to 15 years \\ - Gender: $61 \%$ males, $39 \%$ females}

Inclusion criteria: children with mild to moderate OSAS based on polysomnography with a BMI below 30

Exclusion criteria: prior surgery for upper airway obstruction, active respiratory infection, chronic lung disease, Down syndrome, speech, swallowing or neurological disorders, craniofacial abnormalities, other comorbidities such as cor pulmonale

Interventions

Intervention group: tonsillectomy (TE) performed by electrocautery with concurrent adenoidectomy ( $n=$ unknown $(n=10$ received surgery and were included in analyses $))$

Comparator group: temperature-controlled radiofrequency tonsil reduction (TT) with concurrent adenoidectomy ( $n=$ unknown ( $n=13$ received surgery and were included in analyses))

Use of additional interventions: all children received adenoidectomy

Outcomes Short-term outcomes ( 7 days): peri-operative complications, postoperative bleeding requiring admission, postoperative dehydration requiring admission

Long-term outcomes (1, 2, 3, 6 and 12 months): severity of obstructive symptoms (RDI using polysomnography at 3 months only), postoperative pain, return to normal diet

Notes

Participants lost to follow-up total: 4/27 children (15\%); no further information provided

\section{Risk of bias}

\begin{tabular}{lll}
\hline Bias & Authors' judgement & Support for judgement \\
\hline $\begin{array}{l}\text { Random sequence genera- } \\
\text { tion (selection bias) }\end{array}$ & Unclear risk & Method not described \\
\hline $\begin{array}{l}\text { Allocation concealment } \\
\text { (selection bias) }\end{array}$ & Unclear risk & Method not described \\
\hline $\begin{array}{l}\text { Blinding of participants } \\
\text { and personnel (perfor- } \\
\text { mance bias) } \\
\text { All outcomes }\end{array}$ & High risk & Not blinded \\
\hline
\end{tabular}

Blinding of outcome assessment (detection bias)

High risk

Not blinded, except for the polysomnography findings

All outcomes

\begin{tabular}{lll}
\hline $\begin{array}{l}\text { Incomplete outcome data } \\
\text { (attrition bias) } \\
\text { All outcomes }\end{array}$ & Unclear risk & $15 \%(4 / 27)$ of randomised children not included in analyses \\
\hline $\begin{array}{l}\text { Selective reporting (re- } \\
\text { porting bias) }\end{array}$ & Unclear risk & $\begin{array}{l}\text { No protocol available; insufficient information to permit a judgement of low or } \\
\text { high risk }\end{array}$ \\
\hline Other bias & Unclear risk & Baseline characteristics: balanced \\
& ITT analysis: unclear if performed \\
& Formal sample size calculations: not performed \\
& Use of co-interventions: similar across groups (all received adenoidectomy)
\end{tabular}


Dai 2014

\section{Study characteristics}

\begin{tabular}{ll}
\hline Methods & Non-blinded, parallel-group randomised controlled surgical trial with 3-month duration of follow-up \\
\hline Participants & Setting: general hospital, China \\
Sample size: & Number randomised: 57 children \\
- Number completed: 57 children \\
Participant (baseline) characteristics: \\
- Age: 2 to 12 years \\
- Gender: $67 \%$ males, $33 \%$ females \\
Inclusion criteria: positive polysomnography for OSAHS (AHI > 5/hour and/or Al >1/hour, lowest oxy- \\
gen saturation < $92 \%$ ), adenoid hypertrophy (A/N ratio $\geq 0.71$ on nasopharyngeal lateral radiographs), \\
tonsil hypertrophy on physical exam (bilateral tonsils beyond velopharyngeal bow - Grade III), absence \\
of CRS (paranasal sinus computed tomography) \\
Exclusion criteria: chronic sinusitis, allergic rhinitis, recurrent acute tonsillitis, chronic respiratory dis- \\
ease, nephritis, systemic allergic disease and URTI in 2 weeks prior to surgery
\end{tabular}

Interventions

Intervention group: tonsillectomy (TE) by low-temperature plasma radiofrequency ablation $(\mathrm{n}=20)$

Comparator group: tonsillotomy (TT) by low-temperature plasma radiofrequency ablation $(\mathrm{n}=37)$

Use of additional interventions: not stated

Outcomes

Short-term outcomes (1 and 3 months): humoral immunity (serum levels of immunoglobulins A, G and $\mathrm{M}$ ), cellular immunity (serum levels of $\mathrm{T}$ cells $\mathrm{CD} 3+/ \mathrm{CD} 4+/ \mathrm{CD} 8+$ )

Notes Participants analysed: not stated

\section{Risk of bias}

\begin{tabular}{|c|c|c|}
\hline Bias & Authors' judgement & Support for judgement \\
\hline $\begin{array}{l}\text { Random sequence genera- } \\
\text { tion (selection bias) }\end{array}$ & Unclear risk & Quote: "randomly divided" - no method given \\
\hline $\begin{array}{l}\text { Allocation concealment } \\
\text { (selection bias) }\end{array}$ & Unclear risk & Method not described \\
\hline $\begin{array}{l}\text { Blinding of participants } \\
\text { and personnel (perfor- } \\
\text { mance bias) } \\
\text { All outcomes }\end{array}$ & High risk & Not blinded \\
\hline $\begin{array}{l}\text { Blinding of outcome as- } \\
\text { sessment (detection bias) } \\
\text { All outcomes }\end{array}$ & High risk & Not blinded \\
\hline $\begin{array}{l}\text { Incomplete outcome data } \\
\text { (attrition bias) } \\
\text { All outcomes }\end{array}$ & High risk & $\begin{array}{l}\text { Not clear if there was any loss of data due to no statement of data numbers } \\
\text { analysed }\end{array}$ \\
\hline
\end{tabular}


Dai 2014 (Continued)

Selective reporting (re- Unclear risk No protocol available; insufficient information to permit a judgement of low or porting bias) high risk

Other bias

High risk

Baseline characteristics: not balanced for gender (M 67\%:F 33\%) or group size (35\% TE:64\% TT)

ITT analysis: performed

Formal sample size calculations: not performed

Use of co-interventions: not stated across groups

\section{Densert 2001}

\section{Study characteristics}

\begin{tabular}{|c|c|}
\hline Methods & Single-blinded, parallel-group randomised controlled surgical trial with 2-year duration of follow-up \\
\hline \multirow[t]{8}{*}{ Participants } & Setting: ENT clinic, Halmstad, Sweden \\
\hline & Sample size: \\
\hline & - Number randomised: 43 children \\
\hline & - Number completed: 41 children \\
\hline & Participant (baseline) characteristics: \\
\hline & - Age: 2 to 9 years \\
\hline & - Gender: $42 \%$ males, $58 \%$ females \\
\hline & $\begin{array}{l}\text { Inclusion criteria: children were included in the study on the basis of symptoms of OSAS. Snoring and } \\
\text { apnoea were the most frequently reported symptoms. Dysfunctional problems such as reluctance to } \\
\text { eat, daytime sleepiness hyperactivity, irritability and aggression were also reported as frequent occur- } \\
\text { rences. The patient history was obtained from the parents and a thorough physical examination of the } \\
\text { children was performed. When the symptoms of OSAS persisted after } 3 \text { to } 4 \text { months the patients were } \\
\text { scheduled for surgery, the hypertrophic tonsils being the probable cause of the symptoms } \\
\text { Exclusion criteria: tonsil problems caused by infections, anatomic or neurological conditions, allergy }\end{array}$ \\
\hline
\end{tabular}

Interventions

Intervention group: tonsillectomy $(\mathrm{TE})$ by blunt dissection ( $\mathrm{n}=$ unknown)

Comparator group: tonsillotomy (TT) by $\mathrm{CO}_{2}$ laser ( $\mathrm{n}=$ unknown)

Use of additional interventions: all patients had previously received adenoidectomy

Outcomes Short-term outcomes (1 day): surgical time, intraoperative bleeding, postoperative bleeding, postoperative pain

Long-term outcomes (3 months, 2 years): OSDB symptoms, frequency of infections (throat and catarrhal)

$\begin{array}{ll}\text { Notes } & \text { Participants lost to short-term (3-month) follow-up: } 0 \% \\ & \text { Participants lost to long-term (2-year) follow-up: } 5 \% \text { (1 per group) }\end{array}$

\section{Risk of bias}

Bias Authors' judgement Support for judgement


Densert 2001 (Continued)

Random sequence genera- Low risk Quote: "On the day of surgery, the patients were randomized into one of two tion (selection bias) groups to undergo either a standard TE or a TT using a CO2 laser. The patients were randomized in blocks of $10 "$

\begin{tabular}{lll}
\hline $\begin{array}{l}\text { Allocation concealment } \\
\text { (selection bias) }\end{array}$ & Unclear risk & Method not described \\
\hline $\begin{array}{l}\text { Blinding of participants } \\
\text { and personnel (perfor- }\end{array}$ & High risk & Patients and personnel not blinded \\
mance bias) & & \\
All outcomes & &
\end{tabular}

\begin{tabular}{|c|c|c|}
\hline $\begin{array}{l}\text { Blinding of outcome as- } \\
\text { sessment (detection bias) } \\
\text { All outcomes }\end{array}$ & Low risk & $\begin{array}{l}\text { Quote: "The patient data were blinded and evaluated by a researcher and a } \\
\text { statistician who did not have any direct communication with or knowledge of } \\
\text { the patients" }\end{array}$ \\
\hline $\begin{array}{l}\text { Incomplete outcome data } \\
\text { (attrition bias) } \\
\text { All outcomes }\end{array}$ & Unclear risk & $\begin{array}{l}\text { No protocol available; insufficient information to permit a judgement of low or } \\
\text { high risk }\end{array}$ \\
\hline $\begin{array}{l}\text { Selective reporting (re- } \\
\text { porting bias) }\end{array}$ & High risk & Number of participants randomised to each group not stated \\
\hline \multirow[t]{4}{*}{ Other bias } & Unclear risk & Baseline characteristics: balanced \\
\hline & & ITT analysis: unclear if performed \\
\hline & & Formal sample size calculations: not performed \\
\hline & & $\begin{array}{l}\text { Use of co-interventions: balanced across groups (all had previously received } \\
\text { adenoidectomy) }\end{array}$ \\
\hline
\end{tabular}

\section{Derkay 2006}

\section{Study characteristics}

Methods Double-blinded, parallel-group randomised controlled surgical trial with 1 month of follow-up

\section{Participants}

Setting: Department of Otolaryngology - Head and Neck Surgery, Eastern Virginia Medical School, USA

\section{Sample size:}

- Number randomised: unclear how many children were randomised

- Number completed: 300 children

\section{Participant (baseline) characteristics:}

- Age: 2 years and older

- Gender: $45 \%$ males, $55 \%$ females

Inclusion criteria: children with solely symptomatic adenotonsillar hyperplasia

Exclusion criteria: history of recurrent tonsillitis, craniofacial syndrome, haematologic disorder, severe developmental disorder or severe co-morbidities 
Derkay 2006 (Continued)

Use of additional interventions: concurrent adenoidectomy was performed whenever it was clinically indicated; unclear how many children received concurrent adenoidectomy

Outcomes

Short-term outcomes (14 days): time to normal activity, intraoperative blood loss, postoperative bleeding events (first 24 hours and delayed), return visits to the emergency department for treatment of dehydration, operative time for tonsillectomy alone, total surgical time, total time in operating room, postoperative morbidity including child's pain level using the FACES pain scale, dosing of pain medication, time to return to normal diet

Long-term outcomes (1 month): disease-specific quality of life, presence of eschar, residual tonsil tissue, surgery-related voice changes

Notes

Participants lost to follow-up total: 300 children completed the study, however unclear how many children were randomised

\section{Risk of bias}

\begin{tabular}{|c|c|c|}
\hline Bias & Authors' judgement & Support for judgement \\
\hline $\begin{array}{l}\text { Random sequence genera- } \\
\text { tion (selection bias) }\end{array}$ & Low risk & Randomisation using a random-number generator \\
\hline $\begin{array}{l}\text { Allocation concealment } \\
\text { (selection bias) }\end{array}$ & Low risk & $\begin{array}{l}\text { Quote: "The patient and his or her family or guardians were blinded as to the } \\
\text { technique utilized, and the operating surgeon was notified of the patient's } \\
\text { group status immediately prior to surgery." }\end{array}$ \\
\hline $\begin{array}{l}\text { Blinding of participants } \\
\text { and personnel (perfor- } \\
\text { mance bias) } \\
\text { All outcomes }\end{array}$ & Low risk & $\begin{array}{l}\text { Quote: "The patient and his or her family or guardians were blinded as to the } \\
\text { technique utilized, and the operating surgeon was notified of the patient's } \\
\text { group status immediately prior to surgery." }\end{array}$ \\
\hline $\begin{array}{l}\text { Blinding of outcome as- } \\
\text { sessment (detection bias) } \\
\text { All outcomes }\end{array}$ & Low risk & $\begin{array}{l}\text { Quote: "The patient and his or her family or guardians were blinded as to the } \\
\text { technique utilized. Nurses in the postanesthesia care unit (PACU) were blind- } \\
\text { ed as to the surgical technique. An office visit was performed one month after } \\
\text { surgery by an attending physician other than the surgeon of record." }\end{array}$ \\
\hline $\begin{array}{l}\text { Incomplete outcome data } \\
\text { (attrition bias) } \\
\text { All outcomes }\end{array}$ & Unclear risk & $\begin{array}{l}\text { Quote: "Three hundred patients completed the study, } 150 \text { in the microdebrid- } \\
\text { er group and } 150 \text { in the electrocautery group." } \\
\text { Unclear how many children were randomised. Baseline characteristics were, } \\
\text { however, balanced. }\end{array}$ \\
\hline $\begin{array}{l}\text { Selective reporting (re- } \\
\text { porting bias) }\end{array}$ & Unclear risk & $\begin{array}{l}\text { No protocol available; insufficient information to permit a judgement of low or } \\
\text { high risk }\end{array}$ \\
\hline Other bias & Unclear risk & $\begin{array}{l}\text { Baseline characteristics: balanced } \\
\text { ITT analysis: performed } \\
\text { Formal sample size calculations: performed } \\
\text { Use of co-interventions: unclear how many children in each group received } \\
\text { concurrent adenoidectomy }\end{array}$ \\
\hline
\end{tabular}

\section{Study characteristics}


Ericsson 2009 (Continued)

Methods Non-blinded, parallel-group randomised controlled surgical trial with 2-year duration of follow-up

Setting: 1 university clinic, 2 county council hospitals, Sweden
Sample size:
- Number randomiced: 118 randomised (36 declined participation, 4 excluded due to randomisation
error, 7 excluded due to exclusion criteria, 71 children included in study)
- Number completed: 67 children
Participant (baseline) characteristics:
- Age: 4.5 to 5.5 years
- Gender: $58 \%$ males, $42 \%$ females
Inclusion criteria: tonsil hypertrophy and sleep disordered breathing with or without recurrent tonsil-
litis as determined by otolaryngologist and listed for tonsil surgery
Exclusion criteria: antibiotics for throat infection in past 3 months, prior treatment for peritonsillitis,
record of small tonsils, complicating disease requiring special care, inability to speak Swedish, obesity
and bleeding disorder

Interventions Intervention group: cold knife tonsillectomy (TE) with blunt dissection $(\mathrm{n}=32)$

Comparator group: radiofrequency tonsillotomy (TT) of protruding part of tonsils, removed to region parallel to tonsillar pillars $(n=35)$

Use of additional interventions: $80 \%$ had concurrent adenoidectomy; TE $78 \%$, TT $80 \%$

\begin{abstract}
Outcomes
Short-term outcomes (6 months): postoperative pain, postoperative bleeding, analgesic use, return to normal diet, return to normal activity, disease-specific quality of life (OSA-18), behaviour (Child Behaviour Checklist, $\mathrm{CBCL}$ ), general health (questionnaire), oSDB symptom recurrence, infection rate

Long-term (2 years): disease-specific quality of life (OSA-18), behaviour (Child Behaviour Checklist, $\mathrm{CBCL}$ ), general health (questionnaire), oSDB symptom recurrence, infection rate, dentofacial morphology and growth
\end{abstract}

Notes

Participants lost pre-trial total: $40 \%$ pre-trial dropout (method of Zelen; 36 declined participation, 4 excluded due to randomisation error, 7 excluded due to exclusion criteria)

Participants lost to short-term follow-up: $6 \%$ dropout before 6 months (3 spontaneous recovery and 1 declined surgery).

Participants lost to long-term follow-up: 4\% dropout at 2 years (3 did not attend ENT examination)

\title{
Risk of bias
}

\begin{tabular}{lll}
\hline Bias & Authors' judgement & Support for judgement \\
\hline $\begin{array}{ll}\text { Random sequence genera- } \\
\text { tion (selection bias) }\end{array}$ & Low risk & $\begin{array}{l}\text { Quote: "The children were initially randomized from the existing ordinary wait- } \\
\text { ing list for tonsil surgery either to tonsillotomy using radiofrequency technique } \\
\text { or to regular Tonsillectomy (TE), according the method of Zelen" }\end{array}$
\end{tabular}

$\begin{array}{ll}\begin{array}{l}\text { Allocation concealment } \\ \text { (selection bias) }\end{array} & \text { Low risk }\end{array} \quad \begin{aligned} & \text { Quote: "The randomization procedure was implemented using a computer } \\ & \text { generated sequentially numbered list. An independent person drew from this } \\ & \text { list and assigned even numbers to TT and odd numbers to TE." }\end{aligned}$

Blinding of participants High risk $\quad$ Not blinded
and personnel (perfor-
mance bias)
All outcomes


Ericsson 2009 (Continued)
Blinding of outcome as-
High risk
Not blinded sessment (detection bias)

All outcomes

$\begin{array}{ll}\begin{array}{l}\text { Incomplete outcome data } \\ \text { (attrition bias) }\end{array} & \text { High risk } \\ \text { All outcomes } & \begin{array}{l}40 \% \text { pre-trial dropout (method of Zelen; } 36 \text { declined participation, } 4 \text { excluded } \\ \text { due to randomisation error, } 7 \text { excluded due to exclusion criteria) }\end{array} \\ & 6 \% \text { loss to short-term ( } 6 \text { months) follow-up } \\ & 4 \% \text { loss to long-term ( } 2 \text { year) follow-up }\end{array}$

\begin{tabular}{lll}
\hline $\begin{array}{l}\text { Selective reporting (re- } \\
\text { porting bias) }\end{array}$ & High risk & 11-item questionnaire not fully reported \\
\hline Other bias & Unclear risk & $\begin{array}{l}\text { Baseline characteristics: not balanced for gender in tonsillectomy group (M } \\
69 \%: F 31 \%)\end{array}$ \\
& ITT analysis: performed \\
& Formal sample size calculations: performed \\
& $\begin{array}{l}\text { Use of co-interventions: similar across groups (concurrent adenoidectomy per- } \\
\text { formed in } 78 \% \text { TE, 80\% TT) }\end{array}$
\end{tabular}

Hultcrantz 1999

\section{Study characteristics}

Methods

Participants
Non-blinded, parallel-group randomised controlled surgical trial with 6-year duration of follow-up

Setting: ENT clinic, university hospital, Uppsala, Sweden

\section{Sample size:}

- Number randomised: 50 randomised (6 declined participation, 3 excluded, 41 children included in study)

- Number completed: 41 children

\section{Participant (baseline) characteristics:}

- Age: 3.5 to 8 years

- Gender: $37 \%$ female, $63 \%$ male

Inclusion criteria: children on the waiting list for tonsil surgery due to obstructive problems: snoring and/or sleep apnoea, mouth breathing and/or eating problems. Verified tonsil hyperplasia.

Exclusion criteria: preference for the other surgical technique, preference for non-surgical treatment, throat infection
Intervention group: traditional (total) blunt dissection tonsillectomy (TE) ( $n=20)$

Comparator group: intracapsular partial tonsillectomy (tonsillotomy TT) using $\mathrm{CO}_{2}$ laser technique (n $=21)$

Use of additional interventions: concurrent adenoidectomy performed in $15 \%$ of children
Short-term outcomes (10 days): postoperative pain, time in operating theatre, duration of surgery, peri-operative blood loss, general condition and alertness, resumption of drinking and eating, analgesic drug use, weight 
Hultcrantz 1999 (Continued)

Long-term outcomes (1 year and 6 years): recurrence of OSDB symptoms, hospitalisation

Notes Participants lost pre-trial total: 18\% pre-trial dropout (method of Zelen; 6 declined participation, 3 excluded due to exclusion criteria)

Participants lost to follow-up: $0 \%$

\section{Risk of bias}

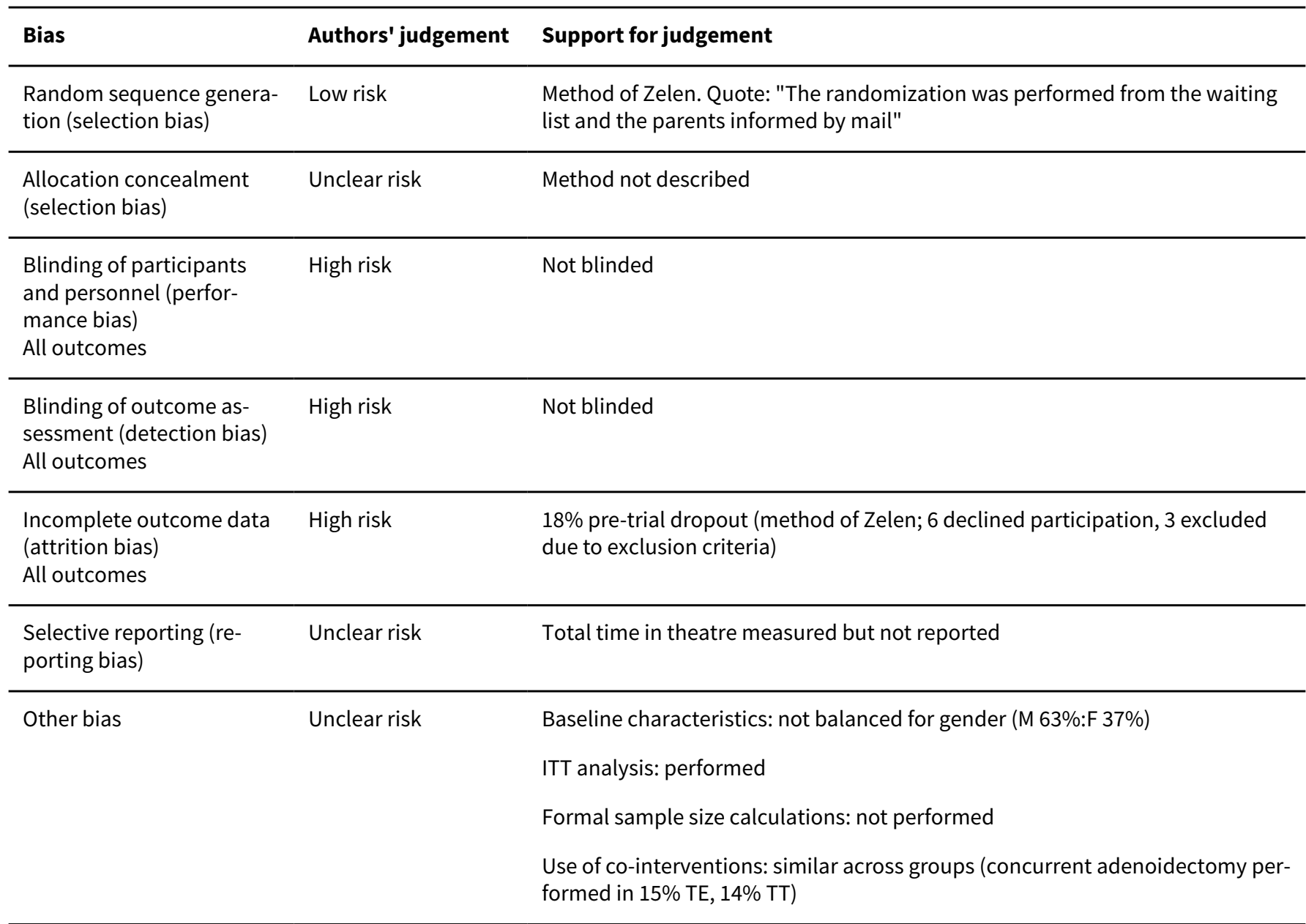

Hultcrantz 2004

\section{Study characteristics}

$\begin{array}{ll}\text { Nethods } & \begin{array}{l}\text { Non-blinded (open-label), parallel-group randomised controlled surgical trial with 3-year duration of } \\ \text { follow-up }\end{array}\end{array}$

Participants Setting: 3 otolaryngology clinics (1 university clinic and 2 otolaryngology clinics at local hospitals) in Sweden

\section{Sample size:}

- Number randomised: 150 randomised (22 declined participation, 12 excluded due to exclusion criteria, 116 children included in study)

- Number completed: 92 children 
Hultcrantz 2004 (Continued)

\section{Participant (baseline) characteristics:}

- Age: 5 to 15 years

- Gender: $49 \%$ males, $51 \%$ females

Inclusion criteria: children on the waiting list for tonsillectomy because of obstructive problems due to tonsil hypertrophy with or without recurrent tonsillitis (approximately $60 \%$ of children in both groups had more than one episode of tonsil infection)

Exclusion criteria: children who had had peri-tonsillitis, those with small tonsils and those who no longer fulfilled the criteria for surgery

Interventions

Intervention group: tonsillectomy (TE) by cold knife and blunt dissection $(n=43)$

Comparator group: tonsillotomy (TT) using radiofrequency technique $(n=49)$

Use of additional interventions: concurrent adenoidectomy performed in $49 \%$ of children

\section{Outcomes}

Short-term outcomes (10 days): intraoperative blood loss, postoperative bleeding events, postoperative infections, weight, anxiety, postoperative pain, dietary intake, snoring

Long-term outcomes (1 year): general health, snoring, eating difficulties, infections using the Qu1 questionnaire and the Child Behaviour Checklist $(\mathrm{CBCL})$, reoperation rates, tonsil regrowth, parental satisfaction

Long-term outcomes ( 3 years): generic health-related quality of life using the Glasgow Children's Benefit Inventory (GCBI), snoring, eating difficulties, number of ENT infections using the Qu1 questionnaire, reoperation rates, tonsil regrowth, parental satisfaction

Notes

Participants lost pre-trial total: $22 \%$ pre-trial dropout (method of Zelen; 22 declined participation, 11 excluded due to exclusion criteria)

Participants lost to short-term follow-up: $21 \%$ dropout (24 spontaneous recovery so not operated on)

Participants lost to long-term follow-up: $0 \%$ dropout at 1 and 3 years

\section{Risk of bias}

\begin{tabular}{lll}
\hline Bias & Authors' judgement & Support for judgement \\
\hline $\begin{array}{l}\text { Random sequence genera- } \\
\text { tion (selection bias) }\end{array}$ & Low risk & $\begin{array}{l}\text { Quote: "The randomization was performed according to a modification of Ze- } \\
\text { len's method" }\end{array}$ \\
\hline $\begin{array}{l}\text { Allocation concealment } \\
\text { (selection bias) }\end{array}$ & Unclear risk & Method not described \\
\hline $\begin{array}{l}\text { Blinding of participants } \\
\text { and personnel (perfor- } \\
\text { mance bias) } \\
\text { All outcomes }\end{array}$ & High risk & Not blinded \\
\hline
\end{tabular}

Blinding of outcome assessment (detection bias)

All outcomes

High risk Not blinded

Incomplete outcome data High risk (attrition bias)

All outcomes

\author{
$22 \%$ pre-trial dropout (method of Zelen; 22 declined participation, 12 excluded \\ due to exclusion criteria) \\ $21 \%$ loss to short-term (10 days) follow-up due to spontaneous recovery pre- \\ surgery
}


Hultcrantz 2004 (Continued)

$0 \%$ loss to long-term (2-year) follow-up

Selective reporting (re- Unclear risk No protocol available; insufficient information to permit a judgement of low or porting bias) high risk

Other bias Unclear risk Baseline characteristics: not balanced for gender in tonsillotomy group ( $\mathrm{M}$ 39\%:F 61\%)

Unclear whether ITT analysis was performed

Formal sample size calculations: performed

Use of co-interventions: similar across groups; concurrent adenoidectomy performed in 44\% TE and 53\% TT

Kordeluk 2016

\section{Study characteristics}

\begin{tabular}{ll}
\hline Methods & Double-blinded, parallel-group randomised controlled trial with 6-month duration of follow-up \\
\hline Participants & Setting: Soroka University Medical Center (SUMC), tertiary hospital, Southern Israel \\
Sample size: & Number randomised: 100 children randomised, 92 included in the postoperative analysis \\
- Number completed: 92 children \\
Participant (baseline) characteristics: \\
- Age: 2 to 10 years \\
- Gender: $63 \%$ boys, $37 \%$ girls \\
Inclusion criteria: clinical history of OSDB (snoring and apnoea) and if physical exam showed tonsil \\
size to be +3 according to Brodsky grading or more (extending past halfway between the anterior pillar \\
and the uvula) with enlarged adenoids as seen either by endoscopy or X-ray \\
Exclusion criteria: patients with a history of recurrent tonsillitis and peritonsillar abscess, where a par- \\
tial tonsillectomy may not be appropriate in addition. Patients with craniofacial abnormalities or neu- \\
romuscular disorders.
\end{tabular}

Interventions Intervention group: standard tonsillectomy (TE) using electrocautery $(\mathrm{n}=34)$

Comparator group: partial intracapsular tonsillectomy (TT) using laser $(n=30)$ or microdebrider $(n=$ 28); $(n=58)$

Use of additional interventions: concurrent adenoidectomy performed in all participants

Outcomes Short-term outcomes (24 hours): inflammation (CRP, WBC, NEU, IL-6 and TNF-alpha) and bleeding

Short-term outcomes (1 week): postoperative pain, swallowing, analgesic use and snoring

Long-term outcomes (3 to 6 months): respiratory events during sleep (Apnoea-Hypopnea Index, AHI)

Notes

Participants lost to short-term follow-up total: $8 \%$

Participants lost to long-term follow-up total: $73 \%$

\section{Risk of bias}


Kordeluk 2016 (Continued)

\begin{tabular}{|c|c|c|}
\hline Bias & Authors' judgement & Support for judgement \\
\hline $\begin{array}{l}\text { Random sequence genera- } \\
\text { tion (selection bias) }\end{array}$ & Low risk & $\begin{array}{l}\text { Quote: "The randomization was performed into three groups in four strata of } \\
\text { age 2-4, 4-6, 6-8, 8-10" }\end{array}$ \\
\hline $\begin{array}{l}\text { Allocation concealment } \\
\text { (selection bias) }\end{array}$ & Unclear risk & $\begin{array}{l}\text { Quote: "We conducted a randomized controlled trial (RCT)"; no further details } \\
\text { provided }\end{array}$ \\
\hline $\begin{array}{l}\text { Blinding of participants } \\
\text { and personnel (perfor- } \\
\text { mance bias) } \\
\text { All outcomes }\end{array}$ & Low risk & $\begin{array}{l}\text { Quote: "The study was double-blind; the patients and caregivers did not know } \\
\text { before surgery until the first appointment ( } 7 \text { days after surgery) what type of } \\
\text { surgery would be performed" }\end{array}$ \\
\hline $\begin{array}{l}\text { Blinding of outcome as- } \\
\text { sessment (detection bias) } \\
\text { All outcomes }\end{array}$ & Low risk & $\begin{array}{l}\text { Quote: "the lab technicians performing the testing were not aware of the } \\
\text { group assignment" }\end{array}$ \\
\hline $\begin{array}{l}\text { Incomplete outcome data } \\
\text { (attrition bias) } \\
\text { All outcomes }\end{array}$ & Unclear risk & $\begin{array}{l}8 \% \text { loss to follow-up } \\
73 \% \text { loss to follow-up for polysomnography data }\end{array}$ \\
\hline $\begin{array}{l}\text { Selective reporting (re- } \\
\text { porting bias) }\end{array}$ & Low risk & Clinical Trials Registration \#NCT01319058 \\
\hline Other bias & Low risk & $\begin{array}{l}\text { Baseline characteristics: balanced } \\
\text { ITT analysis: performed } \\
\text { Formal sample size calculations: performed } \\
\text { Use of co-interventions: balanced, all children received concurrent adenoidec- } \\
\text { tomy }\end{array}$ \\
\hline
\end{tabular}

Korkmaz 2008

\section{Study characteristics}

Methods Non-blinded, parallel-group randomised controlled surgical trial with 2-year duration of follow-up

Participants

Setting: secondary care hospital, Trabzon, Turkey

Sample size:

- Number randomised: 104 randomised (96 consented, 81 included in study)

- Number completed: 68 children

Participant (baseline) characteristics:

- Age: 2 to 14 years

- Gender: quoted for the 81 who were analysed; $60 \%$ males, $40 \%$ females

Inclusion criteria: children diagnosed with obstructive tonsilla palatina; obstructive problems due to the tonsillar palatina hypertrophy were based on the history provided by the child's caregiver (snoring, apnoea, restless sleep, frequent awakenings and bed wetting). Diagnosis of the obstructive tonsils were confirmed by the physician by physical examination (tonsils occupying more than $75 \%$ of the space between anterior pillars). 
Korkmaz 2008 (Continued)

Exclusion criteria: patients with documented recurrent tonsillitis disease, patients with a history of acute tonsillitis in the previous 3 weeks, patients with active infection, patients with additional health problems

\begin{tabular}{ll}
\hline Interventions & Intervention group: classical dissection tonsillectomy $(T E)(n=41)$ \\
Comparator group: intracapsular partial tonsillectomy $(T T)(n=40)$ \\
Use of additional interventions: adenoidectomy where required, no figure quoted
\end{tabular}

Outcomes

Short-term outcomes (10 days): postoperative pain, operation time, intraoperative blood loss, postoperative nausea, postoperative otalgia, postoperative infection, postoperative haemorrhage, postoperative quality of life (VAS), postoperative daily activity (VAS)

Long-term outcome (2 years): tonsil re-growth

Notes

Participants lost pre-trial total: $8 \%$ pre-trial dropout (method of Zelen; 8 declined participation)

Participants lost to short-term follow-up total: $16 \%$ excluded from the analysis

Participants lost to long-term follow-up: $29 \%$ completed the 2-year follow-up

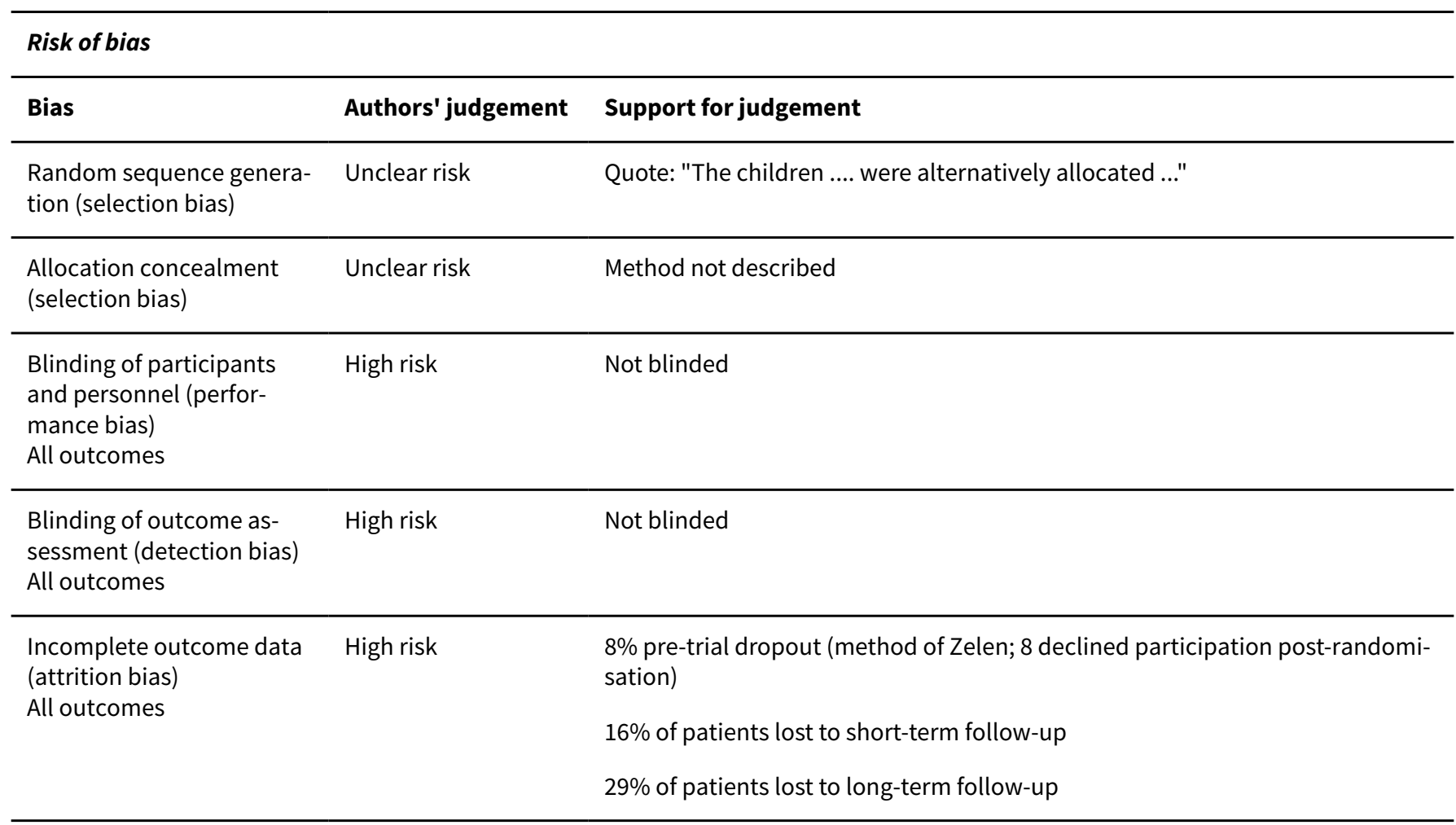

\begin{tabular}{|c|c|c|}
\hline $\begin{array}{l}\text { Selective reporting (re- } \\
\text { porting bias) }\end{array}$ & High risk & $\begin{array}{l}\text { No mention of demographics for the } 96 \text { consented, only the } 81 \text { analysed } \\
\text { No mention of vomiting in the results } \\
\text { VAS scores seemed to be combined but are meant to refer to quality of life and } \\
\text { daily activity - not reported separately }\end{array}$ \\
\hline Other bias & High risk & $\begin{array}{l}\text { Baseline characteristics: not balanced for gender in tonsillectomy group (M } \\
69 \%: F 31 \% \text { ) } \\
\text { ITT analysis: not performed } \\
\text { Formal sample size calculations: not performed }\end{array}$ \\
\hline
\end{tabular}




\section{Study characteristics}

\begin{tabular}{|c|c|c|}
\hline Methods & \multicolumn{2}{|c|}{ Non-blinded, parallel-group randomised controlled surgical trial with 6-month duration of follow-up } \\
\hline Participants & \multicolumn{2}{|c|}{$\begin{array}{l}\text { Setting: Center Hospital Dalian, China } \\
\text { Sample size: } \\
\text { - Number randomised: } 160 \text { children } \\
\text { - Number completed: } 147 \text { children } \\
\text { Participant (baseline) characteristics: } \\
\text { - Age: } 2 \text { to } 13 \text { years } \\
\text { - Gender: } 56 \% \text { males, } 44 \% \text { females } \\
\text { Inclusion criteria: diagnosis of OSAHS according to the Urumqi } 2007 \text { criteria produced by the Chinese } \\
\text { Otolaryngology Research Team } \\
\text { Exclusion criteria: not stated }\end{array}$} \\
\hline Interventions & \multicolumn{2}{|c|}{$\begin{array}{l}\text { Intervention group: tonsillectomy (TE) using coblation }(n=80) \\
\text { Comparator group: tonsillotomy (TT) using coblation }(n=80) \\
\text { Use of additional interventions: concurrent adenoidectomy in all participants }\end{array}$} \\
\hline Outcomes & \multicolumn{2}{|c|}{$\begin{array}{l}\text { Short-term outcomes ( } \mathbf{1} \text { week and } \mathbf{3} \text { months): sleep monitoring resu } \\
\text { lowest oxygen saturation and mean oxygen saturation), postoperative } \\
\text { apeutic effects (e.g. postoperative bleeding) } \\
\text { Medium-term outcomes ( } 6 \text { months): recurrence of oSDB symptoms }\end{array}$} \\
\hline Notes & \multicolumn{2}{|c|}{ Participants lost to medium-term follow-up (6 months) total: $8 \%$ (10\% TE, $6 \% \mathrm{TT}$ ) } \\
\hline Risk of bias & & \\
\hline Bias & Authors' judgement & Support for judgement \\
\hline $\begin{array}{l}\text { Random sequence genera- } \\
\text { tion (selection bias) }\end{array}$ & Unclear risk & Method not described \\
\hline $\begin{array}{l}\text { Allocation concealment } \\
\text { (selection bias) }\end{array}$ & Unclear risk & Method not described \\
\hline $\begin{array}{l}\text { Blinding of participants } \\
\text { and personnel (perfor- } \\
\text { mance bias) } \\
\text { All outcomes }\end{array}$ & High risk & Not blinded \\
\hline $\begin{array}{l}\text { Blinding of outcome as- } \\
\text { sessment (detection bias) } \\
\text { All outcomes }\end{array}$ & High risk & Not blinded \\
\hline
\end{tabular}


Li 2013 (Continued)

Incomplete outcome data High risk $\quad 8 \%$ patients lost to follow-up
(attrition bias)

All outcomes

$\begin{array}{ll}\begin{array}{l}\text { Selective reporting (re- } \\ \text { porting bias) }\end{array} & \begin{array}{l}\text { No protocol available; insufficient information to permit a judgement of low or } \\ \text { high risk }\end{array}\end{array}$

\begin{tabular}{ll}
\hline Other bias & Unclear risk \\
& Formal sample size calculations: not performed \\
ITT analysis: unclear & Use of co-interventions: similar across groups (concurrent adenoidectomy per- \\
formed in $100 \%$ TE, $100 \%$ TT)
\end{tabular}

Lundeborg 2009

\section{Study characteristics}

$\begin{array}{ll}\text { Methods } & \begin{array}{l}\text { Non-blinded (open-label), parallel-group randomised controlled surgical trial with 6-month duration of } \\ \text { follow-up }\end{array}\end{array}$

Participants

Setting: secondary care hospital; three clinics in the south-east region Sweden

\section{Sample size:}

- Number randomised: 118 children randomised (37 parents declined participation, 4 excluded due to randomisation error, 10 excluded due to exclusion criteria, 67 children included in study)

- Number completed: 65 children

\section{Participant (baseline) characteristics:}

- Age: 4 to 6 years

- Gender: $58 \%$ males, $42 \%$ females

Inclusion criteria: children with adenotonsillar hypertrophy and obstructive problems, on the waiting lists for surgery. The decision about surgery was made together with the parents after a clinical examination, with findings consistent with a case history including heavy snoring and/or recurrent tonsillitis. No sleep studies were performed. The families were invited to participate in the research project after the parents received written information about the study and the surgery their child would undergo. Exclusion criteria: treated tonsillitis within 3 months prior to the planned operation, spontaneous recovery from an earlier obstruction, concomitant disease, non-Swedish speaker

Comparator group: tonsillotomy (TT) using high-frequency radiosurgery $(n=34)$

Use of additional interventions: concurrent adenoidectomy performed in 79\% of children. The 14 children who did not have an adenoidectomy were evaluated at surgery to have small, not obstructive adenoids; 7 of them had earlier undergone an adenoidectomy.

Concurrent tympanostomy tube placement because of otitis media with effusion (OME) performed in $9 \%$ of children

\section{Outcomes}

Short-term outcome (6 months): oral motor function (using the Nordic Orofacial Test-Screening; NOTS), phonology (using a Swedish Phonology Test), perceptual and acoustic measures of vocal function 
Lundeborg 2009 (Continued)

Notes
Participants lost pre-trial total: 43\% pre-trial dropout (method of Zelen; 37 declined participation, 4 excluded due to randomisation error, 10 excluded due to exclusion criteria)

Participants lost to short-term follow-up: $5 \%$ at 6 months

\section{Risk of bias}

\begin{tabular}{lll}
\hline Bias & Authors' judgement & Support for judgement \\
\hline $\begin{array}{ll}\text { Random sequence genera- } \\
\text { tion (selection bias) }\end{array}$ & Low risk & $\begin{array}{l}\text { Quote: "The families were invited to participate in the research project after } \\
\text { the parents received written information about the study and the surgery their } \\
\text { child would undergo" } \\
\text { Quote: "randomised... according to the method of Zelen..." }\end{array}$ \\
\hline
\end{tabular}

\begin{tabular}{lll}
\hline $\begin{array}{l}\text { Allocation concealment } \\
\text { (selection bias) }\end{array}$ & Unclear risk & Method not described \\
\hline $\begin{array}{l}\text { Blinding of participants } \\
\text { and personnel (perfor- } \\
\text { mance bias) }\end{array}$ & High risk & Not blinded \\
All outcomes & \\
\hline
\end{tabular}

\section{Blinding of outcome as- High risk} sessment (detection bias)

All outcomes
Quote: "Preferably, the evaluations would have been double-blinded. However, in conjunction with tonsillar problems, a complete blinded assessment is not possible since the NOT-S requires visualization of the oral cavity including the tonsil area"

\begin{tabular}{lll}
\hline $\begin{array}{l}\text { Incomplete outcome data } \\
\text { (attrition bias) } \\
\text { All outcomes }\end{array}$ & High risk & $\begin{array}{l}\text { 43\% pre-trial dropout (method of Zelen; } 37 \text { declined participation, } 4 \text { excluded } \\
\text { due to randomisation error, } 10 \text { excluded due to exclusion criteria) }\end{array}$ \\
\hline $\begin{array}{l}\text { Selective reporting (re- } \\
\text { porting bias) }\end{array}$ & High risk & $\begin{array}{l}\text { Quote: "The results are presented as prevalence of symptoms in the TE and TT } \\
\text { groups (combined) and in controls." }\end{array}$ \\
\hline $\begin{array}{l}\text { Other bias } \\
\text { Unclear risk }\end{array}$ & $\begin{array}{l}\text { Baseline characteristics: not balanced for gender in TE group (67\% M:33\% F) } \\
\text { ITT analysis: performed }\end{array}$ \\
& $\begin{array}{l}\text { Formal sample size calculations: not performed } \\
\text { Use of co-interventions: similar across groups, concurrent adenoidectomy per- } \\
\text { formed in } 76 \% \text { TE group and } 82 \% \text { TT group, concurrent tympanostomy tube } \\
\text { placement performed in } 9 \% \text { TE group and 9\% TT group }\end{array}$
\end{tabular}

Park 2007

\section{Study characteristics}

\begin{tabular}{ll}
\hline Methods & Double-blinded, parallel-group randomised controlled surgical trial with 1-week duration of follow-up \\
\hline Participants & Setting: university paediatric children's hospital, Utah, USA \\
& Sample size: \\
- Number randomised: 40 children \\
- Number completed: 39 children
\end{tabular}


Park 2007 (Continued)

\section{Participant (baseline) characteristics:}

- Age: 2 to 12 years

- Gender: 35\% males, $65 \%$ females

Inclusion criteria: children undergoing adenotonsillectomy for airway obstruction or difficulty breathing who are otherwise healthy

Exclusion criteria: patients with diabetes, cardiac conduction abnormalities, electrolyte abnormalities, liver or kidney insufficiency, hypersensitivity to acetaminophen or hydrocodone, history of chronic pain, pregnancy, patients with chronic tonsillitis

Interventions

Intervention group: total tonsillectomy $(T E)$ with monopolar cautery $(n=21)$

Comparator group: subtotal tonsillectomy (TT) with bipolar cautery $(n=19)$

Use of additional interventions: adenoidectomy in 100\% of participants

Outcomes

Short-term outcomes (1 week): postoperative pain at rest and while eating, intraoperative blood loss, return to normal activity, oral intake, neck, ear and throat pain scales, number of episodes retching and emesis, frequency and analgesic use and rescue medication, presence of fever, time to take $100 \mathrm{~cm}^{3}$ of fluid, quantity of liquids consumed, complications or calls to the physician

\begin{tabular}{ll}
\hline Notes & Participants lost to short-term follow-up total: $0 \%$ \\
Participants lost to long-term follow-up total: $3 \%(5 \% \mathrm{TE}, 0 \% \mathrm{TT})$
\end{tabular}

\section{Risk of bias}

\begin{tabular}{lll}
\hline Bias & Authors' judgement & Support for judgement \\
\hline $\begin{array}{l}\text { Random sequence genera- } \\
\text { tion (selection bias) }\end{array}$ & Low risk & $\begin{array}{l}\text { Quote: "A computer generated number table guided the randomization of the } \\
\text { patients to receive either a subtotal tonsillectomy or total removal of the ton- } \\
\text { sils" }\end{array}$ \\
\hline $\begin{array}{l}\text { Allocation concealment } \\
\text { (selection bias) }\end{array}$ & Unclear risk & Method not described \\
\hline $\begin{array}{l}\text { Blinding of participants } \\
\text { and personnel (perfor- } \\
\text { mance bias) } \\
\text { All outcomes }\end{array}$ & Unclear risk & Quote: "double-blinded clinical trial"; no further details given \\
\hline
\end{tabular}

Blinding of outcome as-
sessment (detection bias) $\quad$ Unclear risk Quote: "double-blinded clinical trial"; no further details given

All outcomes

Incomplete outcome data Unclear risk 1 patient lost to long-term follow-up

(attrition bias)

All outcomes

\begin{tabular}{lll}
\hline $\begin{array}{l}\text { Selective reporting (re- } \\
\text { porting bias) }\end{array}$ & Unclear risk & Analgesic use not reported \\
\hline Other bias & Unclear risk & Baseline characteristics: not balanced for gender in TT group (26\% M:74\% F) \\
& ITT analysis: performed \\
& Formal sample size calculations: not performed
\end{tabular}


Park 2007 (Continued)

Use of co-interventions: balanced across groups (adenoidectomy performed in $100 \%$ TE group and $100 \%$ TT group)

Skoulakis 2007

\section{Study characteristics}

$\begin{array}{ll}\text { Methods } & \begin{array}{l}\text { Non-blinded (open-label), parallel-group randomised controlled surgical trial with 2-year duration of } \\ \text { follow-up }\end{array}\end{array}$

\section{Participants}

Setting: 2 otolaryngology, head and neck surgery clinical centres, Greece

\section{Sample size:}

- Number randomised: 30 children

- Number completed: 30 children

Participant (baseline) characteristics:

- Age: 3 to 12 years

- Gender: $57 \%$ males, $43 \%$ females

Inclusion criteria: children on waiting list for tonsil surgery owing to adenotonsillar enlargement (tonsil size of +3 or greater; filling $>50 \%$ of the oropharynx) and upper airway obstruction (clinically diagnosed with obstructive symptoms) regardless of underlying medical factors (none of them had repeated streptococcal throat infections, but 9 had OME)

Exclusion criteria: none

Intervention group: tonsillectomy (TE) using blunt dissection $(\mathrm{n}=15)$
Comparator group: tonsilloplasty (TT, $75 \%$ to $80 \%$ of the tonsil tissue is dissected by a knife) ( $\mathrm{n}=15)$
Use of additional interventions: all children received concurrent adenoidectomy. 9 children received
concurrent myringotomy because of OME; 33\% TE group and $27 \%$ TT group.

Outcomes

Short-term outcomes (15 days): postoperative pain, mean time in operation room, time to normal diet, intraoperative bleeding, postoperative bleeding

Long-term outcomes (1 year and 2 years): recurrence of oSDB symptoms

\begin{tabular}{lll}
\hline Notes & Participants lost to follow-up total: $0 \%$ \\
\hline Risk of bias & \\
\hline Bias & Authors' judgement & Support for judgement \\
\hline $\begin{array}{l}\text { Random sequence genera- } \\
\text { tion (selection bias) }\end{array}$ & Unclear risk & Method not described \\
\hline $\begin{array}{l}\text { Allocation concealment } \\
\text { (selection bias) }\end{array}$ & Unclear risk & Method not described \\
\hline $\begin{array}{l}\text { Blinding of participants } \\
\text { and personnel (perfor- } \\
\text { mance bias) } \\
\begin{array}{l}\text { All outcomes } \\
\hline\end{array}\end{array}$ & High risk & Not blinded \\
\hline
\end{tabular}


Skoulakis 2007 (Continued)

$\begin{array}{lll}\text { Blinding of outcome as- } & \text { High risk } & \text { Not blinded } \\ \text { sessment (detection bias) } & \end{array}$

All outcomes

Incomplete outcome data Low risk No loss to follow-up
(attrition bias)
All outcomes

\begin{tabular}{|c|c|c|}
\hline $\begin{array}{l}\text { Selective reporting (re- } \\
\text { porting bias) }\end{array}$ & Unclear risk & $\begin{array}{l}\text { No protocol available; insufficient information to permit a judgement of low or } \\
\text { high risk }\end{array}$ \\
\hline \multirow[t]{4}{*}{ Other bias } & Unclear risk & Baseline characteristics: balanced \\
\hline & & ITT analysis performed: unclear \\
\hline & & Formal sample size calculations: not performed \\
\hline & & $\begin{array}{l}\text { Use of co-interventions: balanced. All children received concurrent adenoidec- } \\
\text { tomy. } 9 \text { children received concurrent myringotomy because of OME; } 33 \% \text { TE } \\
\text { group and } 27 \% \text { TT group. }\end{array}$ \\
\hline
\end{tabular}

Sobol 2006

\section{Study characteristics}

\begin{tabular}{|c|c|}
\hline Methods & Single-blinded, parallel-group randomised controlled surgical trial with 10-day duration of follow-up \\
\hline Participants & $\begin{array}{l}\text { Setting: tertiary paediatric hospital, Philadelphia } \\
\text { Sample size: } \\
\text { - Number randomised: } 74 \text { children } \\
\text { - Number completed: } 74 \text { children } \\
\text { Participant (baseline) characteristics: } \\
\text { - Age: } 3 \text { to } 7 \text { years } \\
\text { - Gender: } 68 \% \text { males, } 32 \% \text { females } \\
\text { Inclusion criteria: scheduled for adenotonsillectomy for upper airway obstruction } \\
\text { Exclusion criteria: prior adenotonsillar surgery, non-obstructive indication for tonsillectomy (e.g. } \\
\text { chronic tonsillitis), craniofacial syndrome, mucopolysaccharidoses, impaired ability to express their } \\
\text { degree of pain, haematological disorder/wound healing disorder, necrotising dermatoses }\end{array}$ \\
\hline Interventions & $\begin{array}{l}\text { Intervention group: monopolar electrocautery tonsillectomy }(T E)(n=36) \\
\text { Comparator group: microdebrider tonsillotomy }(T T)(n=38) \\
\text { Use of additional interventions: all patients underwent concurrent microdebrider adenoidectomy }\end{array}$ \\
\hline Outcomes & $\begin{array}{l}\text { Short-term outcomes (10 days): postoperative pain, number of days until analgesia-free, days until } \\
\text { normal diet, days until normal activity, daily analgesia use, surgical time, intraoperative blood loss }\end{array}$ \\
\hline Notes & Participants lost to follow-up total: $0 \%$ \\
\hline Risk of bias & \\
\hline Bias & Authors' judgement Support for judgement \\
\hline
\end{tabular}


Sobol 2006 (Continued)

Random sequence genera- Low risk tion (selection bias)
Quote: "Randomization was implemented with sealed envelopes that were to be opened only on the morning of surgery after consent and before the induction of anesthesia, with the family blinded to this process for the duration of the study. Randomization was balanced across the 2 surgeons (R.F.W. and I.N.J.) but was not otherwise stratified. Children were randomized in blocks of $10^{\prime \prime}$

As per above

(selection bias)

Low risk

Blinding of participants Low risk Participants blinded
and personnel (perfor-
mance bias)

\begin{tabular}{lll}
\hline $\begin{array}{l}\text { Blinding of outcome as- } \\
\text { sessment (detection bias) } \\
\text { All outcomes }\end{array}$ & Low risk & Parent-reported outcomes \\
\hline $\begin{array}{l}\text { Incomplete outcome data } \\
\text { (attrition bias) } \\
\text { All outcomes }\end{array}$ & Low risk & No loss to follow-up \\
\hline $\begin{array}{l}\text { Selective reporting (re- } \\
\text { porting bias) }\end{array}$ & Unclear risk & $\begin{array}{l}\text { No protocol available; insufficient information to permit a judgement of low or } \\
\text { high risk }\end{array}$ \\
\hline $\begin{array}{l}\text { Other bias } \\
\text { Unclear risk }\end{array}$ & $\begin{array}{l}\text { Baseline characteristics: not balanced for gender in TE group (78\% M:22\% F) } \\
\text { ITT analysis: performed } \\
\text { Formal sample size calculation: performed } \\
\end{array}$ & $\begin{array}{l}\text { Use of co-interventions: all children in each group received concurrent ade- } \\
\text { noidectomy }\end{array}$ \\
\hline
\end{tabular}

Zhou 2016

\section{Study characteristics}

\begin{tabular}{ll}
\hline Methods & Single-blinded, parallel-group randomised controlled surgical trial with 6-month duration of follow-up \\
\hline Participants & Setting: acute care hospital, China \\
Sample size: & Number randomised: 100 children \\
- Number completed: 100 children \\
Participant (baseline) characteristics: \\
- Age: 2 to 13 years \\
- Gender: $65 \%$ males, $35 \%$ females \\
Inclusion criteria: AHI $\geq 5$ on polysomnography, OSA-18 class 2 \\
Exclusion criteria: not stated
\end{tabular}

Interventions $\quad$ Intervention group: tonsillectomy $(\mathrm{TE})(\mathrm{n}=50)$


Zhou 2016 (Continued)

Comparator group: partial tonsillectomy $(T T)(n=50)$

Use of additional interventions: concurrent adenoidectomy in all participants

Outcomes

Short-term outcomes ( 6 months): postoperative bleeding, postoperative infection, tonsil regrowth, humoral immunity (serum levels of immunoglobulins $A, G$ and $M$ ) and cellular immunity (serum levels of $T$ cells $C D 3+/ C D 4+/ C D 8+)$

\begin{tabular}{|c|c|c|}
\hline Notes & Participants lost to s & ort-term follow-up total: not stated \\
\hline \multicolumn{3}{|l|}{ Risk of bias } \\
\hline Bias & Authors' judgement & Support for judgement \\
\hline $\begin{array}{l}\text { Random sequence genera- } \\
\text { tion (selection bias) }\end{array}$ & Unclear risk & Quote: "randomly assigned" - no method given \\
\hline $\begin{array}{l}\text { Allocation concealment } \\
\text { (selection bias) }\end{array}$ & Unclear risk & Method not stated \\
\hline $\begin{array}{l}\text { Blinding of participants } \\
\text { and personnel (perfor- } \\
\text { mance bias) } \\
\text { All outcomes }\end{array}$ & Unclear risk & Participants blinded; not stated for personnel \\
\hline $\begin{array}{l}\text { Blinding of outcome as- } \\
\text { sessment (detection bias) } \\
\text { All outcomes }\end{array}$ & Unclear risk & Not stated \\
\hline $\begin{array}{l}\text { Incomplete outcome data } \\
\text { (attrition bias) } \\
\text { All outcomes }\end{array}$ & Unclear risk & Number of dropouts not stated \\
\hline $\begin{array}{l}\text { Selective reporting (re- } \\
\text { porting bias) }\end{array}$ & High risk & Postoperative bleeding, inflammation and dysphagia not reported \\
\hline \multirow[t]{4}{*}{ Other bias } & Unclear risk & $\begin{array}{l}\text { Baseline characteristics: not balanced for gender in TE group ( } 68 \% \mathrm{M}: 32 \% \mathrm{~F} \text { ) or } \\
\text { TT group }(62 \% \mathrm{M}: 38 \% \mathrm{~F})\end{array}$ \\
\hline & & ITT analysis: performed \\
\hline & & Formal sample size calculations: not performed \\
\hline & & $\begin{array}{l}\text { Use of co-interventions: balanced across groups (adenoidectomy performed in } \\
100 \% \text { TE group and 100\% TT group) }\end{array}$ \\
\hline
\end{tabular}

AHI: Apnoea-Hypopnea Index

BMI: body mass index

CBCL: Child Behaviour Checklist

CRP: C-reactive protein

CRS: chronic rhinosinusitis

ENT: ear, nose and throat

F: female

ITT: intention-to-treat

M: male

NEU: neutrophils

OME: otitis media with effusion

OSA(S): obstructive sleep apnoea (syndrome)

OSAHS: obstructive sleep apnoea hypopnoea syndrome 
(o)SDB: (obstructive) sleep-disordered breathing

PSG: polysomnography

RDI: Respiratory Disturbance Index

TE: tonsillectomy

TNF: tumour necrosis factor

TT: tonsillotomy

URTI: upper respiratory tract infection

VAS: visual analogue scale

WBC: white blood cells

Characteristics of excluded studies [ordered by study ID]

\section{Study Reason for exclusion}

Babademez $2011 \quad$ INTERVENTION

Patients randomised to 3 types of tonsillotomy; no tonsillectomy group

Bitar 2008 INTERVENTION

Adenoidectomy was performed in $85.71 \%$ of Group 1 and in $68.18 \%$ of Group 2 (> $10 \%$ difference)

Cantarella $2012 \quad$ PARTICIPANTS

No randomisation; groups were split to receive tonsillectomy/tonsillotomy according to presence/absence of recurrent tonsillitis

Cao $2018 \quad$ INTERVENTION
Patients randomised to 2 types of tonsillectomy; no tonsillotomy group

Esteller $2016 \quad$ ALLOCATION

Not a randomised controlled trial

Gabr $2014 \quad$ PARTICIPANTS

Children undergoing tonsillectomy or tonsillotomy for any indication without further specification

\begin{tabular}{ll}
\hline Hagerdorn 2005 & ALLOCATION \\
Not a randomised controlled trial \\
\hline
\end{tabular}

Oubaid Ahmed $2018 \quad$ ALLOCATION

Tonsil unit of randomisation (right tonsil tonsillectomy, left tonsil tonsillotomy)

\begin{tabular}{ll}
\hline Pfaar 2007 & PARTICIPANTS \\
& $2 \%$ over the age of 16 \\
\hline Pruegsanusak 2010 & INTERVENTION \\
& $\begin{array}{l}\text { Adenoidectomy performed in } 65 \% \text { of tonsillectomy group and } 45 \% \text { of tonsillotomy group (> } 10 \% \\
\text { difference) }\end{array}$ \\
& Myringotomy performed in $0 \%$ tonsillectomy group and $15 \%$ tonsillotomy group $(>10 \%$ difference) \\
\hline Vlastos 2008 & ALLOCATION \\
\hline
\end{tabular}




\begin{tabular}{ll}
\hline Study & Reason for exclusion \\
\hline Wireklint 2012 & PARTICIPANTS \\
& Young adults, 16 to 25 years old \\
\hline
\end{tabular}

Characteristics of ongoing studies [ordered by study ID]

\section{NCT01676181}

\begin{tabular}{ll}
\hline Study name & 'ATT compared with ATE in OSAS children' \\
\hline Methods & Parallel, double-blind randomised controlled trial \\
\hline Participants & $\begin{array}{l}\text { Children aged } 2 \text { to } 6 \text { years with tonsil hypertrophy and moderate to severe OSA confirmed by noc- } \\
\text { turnal polysomnography (Apnea-Hypopnea Index (AHI) } 5 \text { to 30) and clinical symptoms (apnoea, } \\
\text { snoring, disturbed sleep) }\end{array}$ \\
\hline Interventions & $\begin{array}{l}\text { Intervention: adenotonsillectomy (total removal of tonsils and adenoids with cold steel) } \\
\text { Comparator: adenotonsillotomy (partial removal of tonsils with coblation and total removal of } \\
\text { adenoids with cold steel) }\end{array}$ \\
\hline Outcomes & $\begin{array}{l}\text { Primary outcome measure: change in polysomnographic parameter AHI (Apnea-Hypopnoea Index) } \\
\text { Other outcome measures: peri- and postoperative bleeding, changes in polysomnographic para- } \\
\text { meters other than AHI, postoperative pain, re-operation rates and DNA analysis of blood and tonsil } \\
\text { tissue }\end{array}$ \\
\hline Starting date & $\begin{array}{l}\text { November 2011 } \\
\text { Contact information }\end{array}$ \\
\hline Dotes & $\begin{array}{l}\text { Sweden Friberg, Associate Professor, Senior Surgeon, Karolinska University Hospital, Stockholm, } \\
\text { https:/clinicaltrials.gov/ct2/show/NCT01676181 }\end{array}$ \\
\hline
\end{tabular}

ATE: adenotonsillectomy

ATT: adenotonsillotomy

SDQ: Strengths and Difficulties Questionnaire

\section{DATA AND ANALYSES}

\section{Comparison 1. Tonsillectomy versus tonsillotomy}

\begin{tabular}{llllll}
\hline Outcome or subgroup title & $\begin{array}{l}\text { No. of } \\
\text { studies }\end{array}$ & $\begin{array}{l}\text { No. of } \\
\text { partici- } \\
\text { pants }\end{array}$ & Statistical method & Effect size \\
\hline 1.1 Peri-operative blood loss & 8 & 610 & Mean Difference (IV, Random, 95\% CI) & $14.06[1.91,26.21]$ \\
\hline $\begin{array}{l}1.2 \text { Peri-operative blood loss (sensi- } \\
\text { tivity analysis) }\end{array}$ & 3 & 196 & Mean Difference (IV, Random, 95\% Cl) & $18.71[-30.45,67.87]$ \\
\hline
\end{tabular}




\begin{tabular}{|c|c|c|c|c|}
\hline Outcome or subgroup title & $\begin{array}{l}\text { No. of } \\
\text { studies }\end{array}$ & $\begin{array}{l}\text { No. of } \\
\text { partici- } \\
\text { pants }\end{array}$ & Statistical method & Effect size \\
\hline $\begin{array}{l}1.3 \text { Need for medical intervention } \\
\text { within } 7 \text { days }\end{array}$ & 16 & 1416 & Risk Ratio (M-H, Fixed, 95\% Cl) & $1.75[1.06,2.91]$ \\
\hline $\begin{array}{l}1.4 \text { Need for medical intervention } \\
\text { within } 7 \text { days (sensitivity analysis) }\end{array}$ & 10 & 864 & Risk Ratio (M-H, Fixed, 95\% Cl) & $1.57[0.86,2.87]$ \\
\hline 1.5 Behaviour (CBCL 6 months) & 1 & 67 & Mean Difference (IV, Fixed, 95\% CI) & $-6.00[-12.98,0.98]$ \\
\hline 1.6 Behaviour (CBCL 24 months) & 1 & 67 & Mean Difference (IV, Fixed, 95\% CI) & $-0.30[-8.95,8.35]$ \\
\hline $\begin{array}{l}1.7 \text { Measures of respiratory events } \\
\text { during sleep (AHI } 6 \text { months) }\end{array}$ & 1 & 25 & Mean Difference (IV, Fixed, 95\% CI) & $-0.58[-5.43,4.27]$ \\
\hline $\begin{array}{l}\text { 1.8 Recurrence of SDB symptoms ( } 6 \\
\text { months) }\end{array}$ & 3 & 186 & Risk Ratio (M-H, Fixed, 95\% Cl) & $0.26[0.03,2.22]$ \\
\hline $\begin{array}{l}1.9 \text { Recurrence of SDB symptoms ( } 6 \\
\text { months sensitivity analysis) }\end{array}$ & 1 & 100 & Risk Ratio (M-H, Fixed, 95\% Cl) & $0.20[0.01,4.06]$ \\
\hline $\begin{array}{l}1.10 \text { Recurrence of SDB symptoms } \\
\text { (12 months) }\end{array}$ & 4 & 206 & Risk Ratio (M-H, Fixed, 95\% Cl) & $0.35[0.04,3.23]$ \\
\hline $\begin{array}{l}1.11 \text { Recurrence of SDB symptoms } \\
\text { (12 months sensitivity analysis) }\end{array}$ & 2 & 73 & Risk Ratio (M-H, Fixed, 95\% Cl) & $0.35[0.01,8.11]$ \\
\hline $\begin{array}{l}1.12 \text { Recurrence of SDB symptoms } \\
\text { ( } 24 \text { months) }\end{array}$ & 1 & 65 & Risk Ratio (M-H, Fixed, 95\% Cl) & $0.21[0.01,4.13]$ \\
\hline 1.13 Reoperation rates (12 months) & 2 & 166 & Risk Ratio (M-H, Fixed, 95\% Cl) & $0.32[0.08,1.28]$ \\
\hline 1.14 Reoperation rates (18 months) & 1 & 41 & Risk Ratio (M-H, Fixed, 95\% Cl) & $0.35[0.02,8.10]$ \\
\hline $\begin{array}{l}1.15 \text { Incidence of throat infection ( } 6 \\
\text { months) }\end{array}$ & 1 & 67 & Risk Ratio (M-H, Fixed, 95\% Cl) & $0.55[0.11,2.79]$ \\
\hline $\begin{array}{l}1.16 \text { Incidence of throat infection ( } 12 \\
\text { months) }\end{array}$ & 2 & 174 & Risk Ratio (M-H, Fixed, 95\% Cl) & $0.56[0.19,1.65]$ \\
\hline $\begin{array}{l}1.17 \text { Incidence of throat infection ( } 24 \\
\text { months) }\end{array}$ & 1 & 65 & Risk Ratio (M-H, Fixed, 95\% Cl) & $0.13[0.02,0.97]$ \\
\hline 1.18 Duration of surgery & 8 & 566 & Mean Difference (IV, Fixed, 95\% CI) & $-0.99[-1.97,-0.02]$ \\
\hline $\begin{array}{l}1.19 \text { Duration of surgery (sensitivity } \\
\text { analysis) }\end{array}$ & 4 & 251 & Mean Difference (IV, Random, 95\% CI) & $-2.59[-7.72,2.53]$ \\
\hline $\begin{array}{l}1.20 \text { Severity of postoperative pain } \\
\text { ( } 24 \text { hours) }\end{array}$ & 4 & 368 & Mean Difference (IV, Fixed, 95\% CI) & $1.09[0.88,1.29]$ \\
\hline $\begin{array}{l}1.21 \text { Severity of postoperative pain } \\
\text { ( } 24 \text { hours sensitivity analysis) }\end{array}$ & 2 & 109 & Mean Difference (IV, Fixed, 95\% CI) & $0.46[-0.39,1.31]$ \\
\hline $\begin{array}{l}1.22 \text { Severity of postoperative pain ( } 2 \\
\text { to } 3 \text { days) }\end{array}$ & 3 & 301 & Mean Difference (IV, Random, 95\% CI) & $0.93[-0.14,2.00]$ \\
\hline
\end{tabular}




\begin{tabular}{|c|c|c|c|c|}
\hline Outcome or subgroup title & $\begin{array}{l}\text { No. of } \\
\text { studies }\end{array}$ & $\begin{array}{l}\text { No. of } \\
\text { partici- } \\
\text { pants }\end{array}$ & Statistical method & Effect size \\
\hline $\begin{array}{l}1.23 \text { Severity of postoperative pain ( } 2 \\
\text { to } 3 \text { days sensitivity analysis) }\end{array}$ & 1 & 40 & Mean Difference (IV, Fixed, 95\% CI) & $-0.60[-1.78,0.58]$ \\
\hline $\begin{array}{l}1.24 \text { Severity of postoperative pain ( } 4 \\
\text { to } 7 \text { days) }\end{array}$ & 4 & 370 & Mean Difference (IV, Random, 95\% CI) & $1.07[-0.40,2.53]$ \\
\hline $\begin{array}{l}1.25 \text { Severity of postoperative pain ( } 4 \\
\text { to } 7 \text { days sensitivity analysis) }\end{array}$ & 2 & 109 & Mean Difference (IV, Random, 95\% CI) & $0.87[-0.89,2.64]$ \\
\hline $\begin{array}{l}1.26 \text { Days until analgesics no longer } \\
\text { required }\end{array}$ & 3 & 267 & Mean Difference (IV, Random, 95\% CI) & $2.78[1.92,3.64]$ \\
\hline $\begin{array}{l}1.27 \text { Days until analgesics no longer } \\
\text { required (sensitivity analysis) }\end{array}$ & 1 & 74 & Mean Difference (IV, Fixed, 95\% CI) & $1.30[-0.17,2.77]$ \\
\hline 1.28 Return to normal diet & 2 & 175 & Mean Difference (IV, Random, 95\% CI) & $2.60[1.16,4.04]$ \\
\hline $\begin{array}{l}1.29 \text { Return to normal diet (sensitivity } \\
\text { analysis) }\end{array}$ & 1 & 74 & Mean Difference (IV, Fixed, 95\% CI) & $1.70[0.37,3.03]$ \\
\hline 1.30 Return to normal activity & 3 & 248 & Mean Difference (IV, Random, 95\% CI) & $3.84[0.23,7.44]$ \\
\hline $\begin{array}{l}1.31 \text { Return to normal activity (sensi- } \\
\text { tivity analysis) }\end{array}$ & 2 & 156 & Mean Difference (IV, Random, 95\% CI) & $4.24[-1.30,9.78]$ \\
\hline
\end{tabular}

\section{Analysis 1.1. Comparison 1: Tonsillectomy versus tonsillotomy, Outcome 1: Peri-operative blood loss}

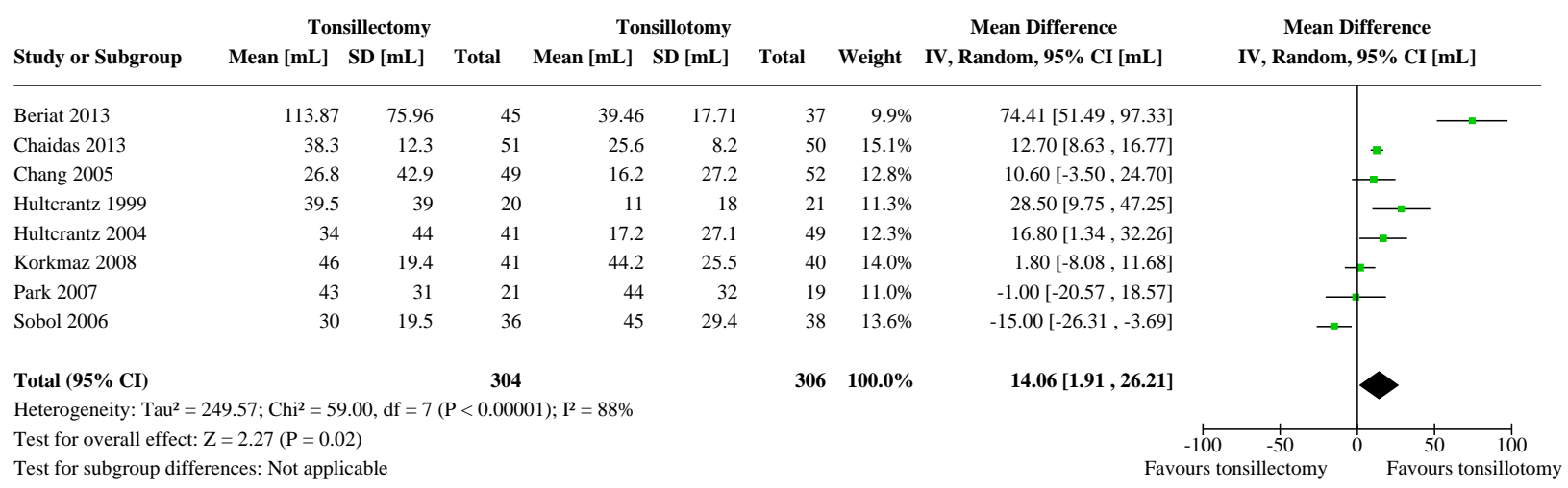




\section{Analysis 1.2. Comparison 1: Tonsillectomy versus tonsillotomy, Outcome 2: Peri-operative blood loss (sensitivity analysis)}

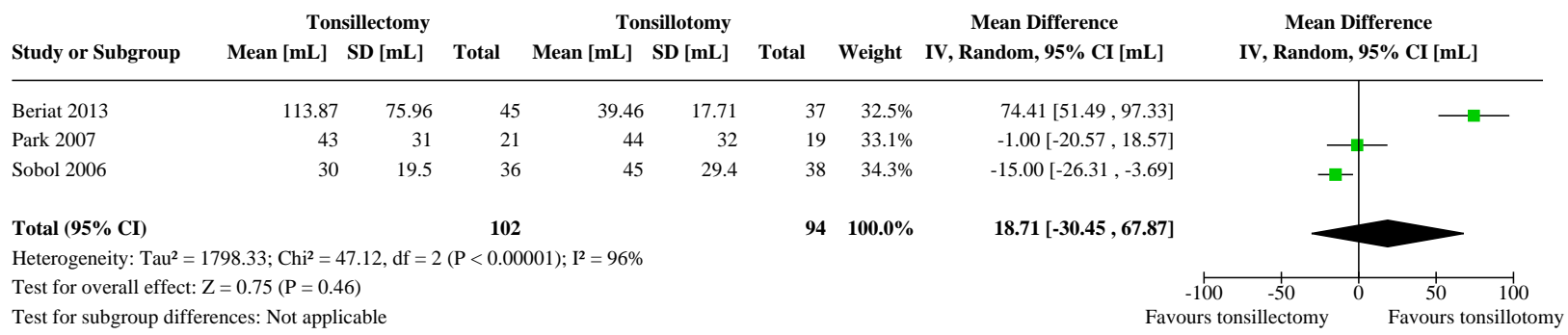

\section{Analysis 1.3. Comparison 1: Tonsillectomy versus tonsillotomy, Outcome 3: Need for medical intervention within 7 days}

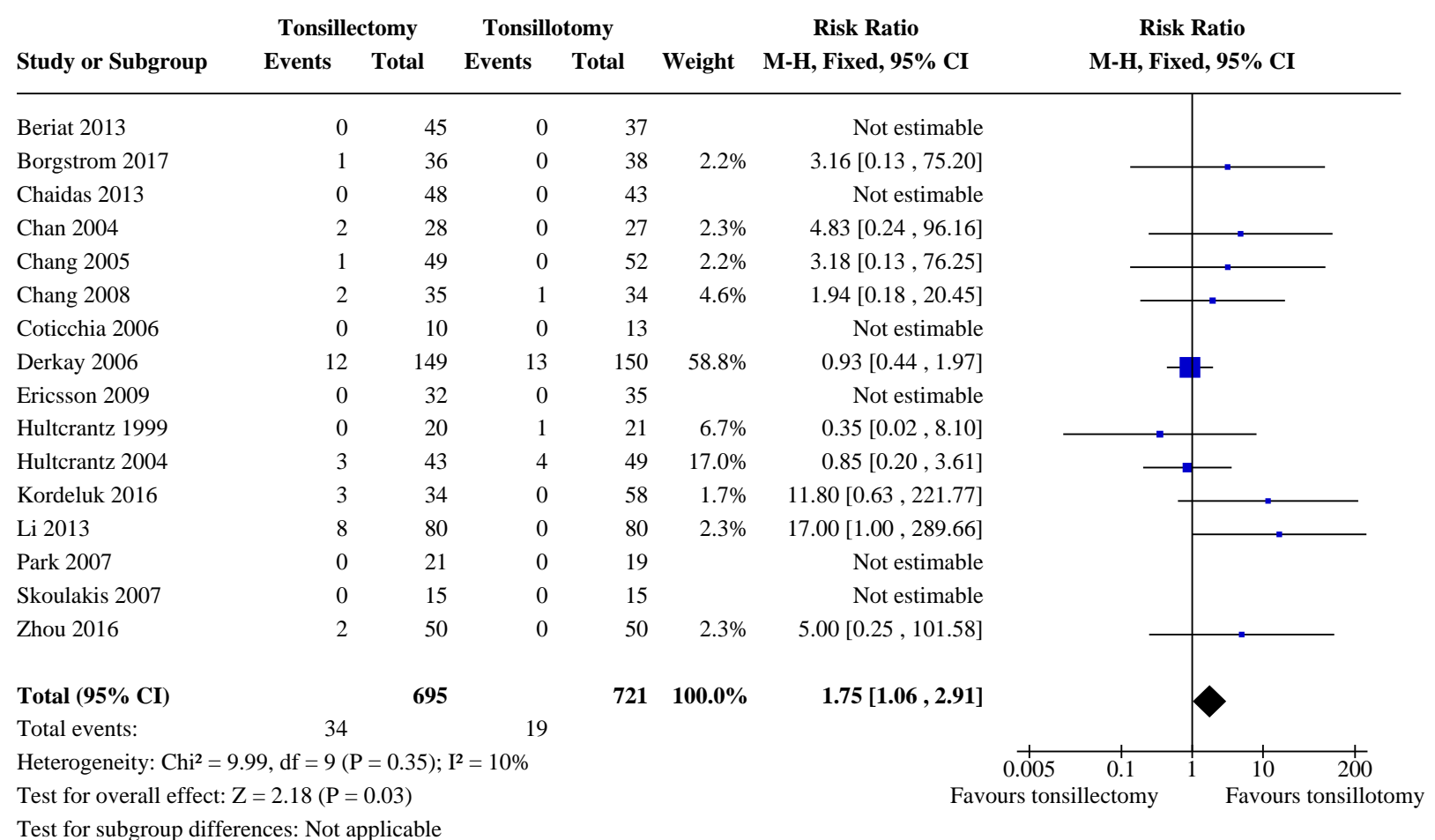


Analysis 1.4. Comparison 1: Tonsillectomy versus tonsillotomy, Outcome 4: Need for medical intervention within 7 days (sensitivity analysis)

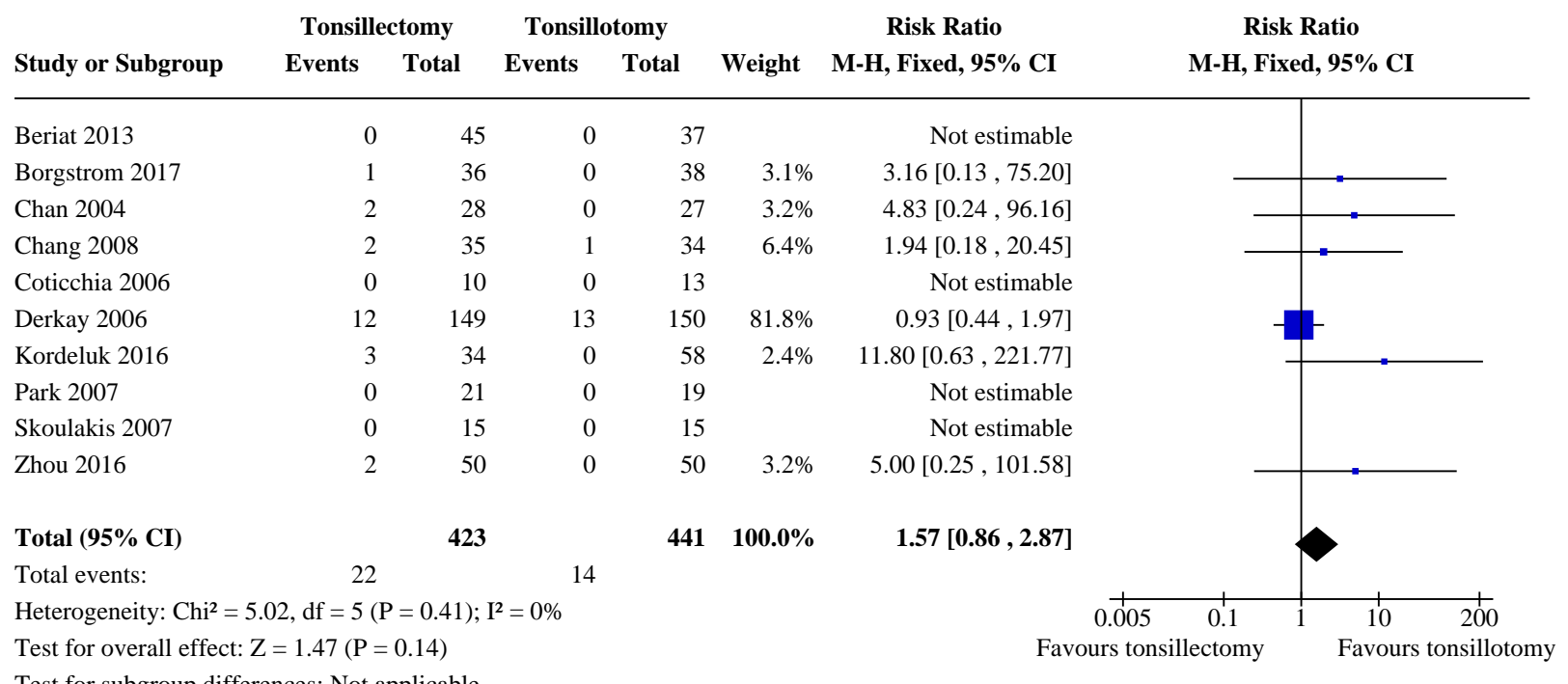

Analysis 1.5. Comparison 1: Tonsillectomy versus tonsillotomy, Outcome 5: Behaviour (CBCL 6 months)

\begin{tabular}{|c|c|c|c|c|c|c|c|c|}
\hline & \multicolumn{3}{|c|}{ Tonsillectomy } & \multicolumn{2}{|c|}{ Tonsillotomy } & \multirow{2}{*}{\multicolumn{2}{|c|}{ Mean Difference }} & Mean Difference \\
\hline Study or Subgroup & Mean & SD & Total & Mean & SD & & & IV, Fixed, 95\% C \\
\hline
\end{tabular}

\begin{tabular}{lllllllll}
\hline Ericsson 2009 & 13.5 & 9.8 & 32 & 19.5 & 18.4 & 35 & $100.0 \%$ & $-6.00[-12.98,0.98]$
\end{tabular}

Total $(95 \%$ CI)

32

$35 \mathbf{1 0 0 . 0 \%}$

$-6.00[-12.98,0.98]$

Test for overall effect: $\mathrm{Z}=1.69(\mathrm{P}=0.09)$

Test for subgroup differences: Not applicable

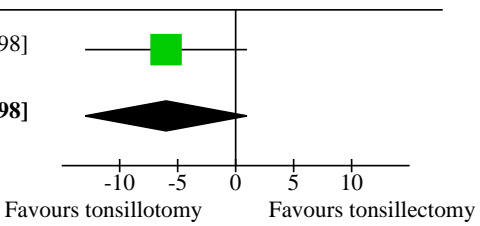

Analysis 1.6. Comparison 1: Tonsillectomy versus tonsillotomy, Outcome 6: Behaviour (CBCL 24 months)

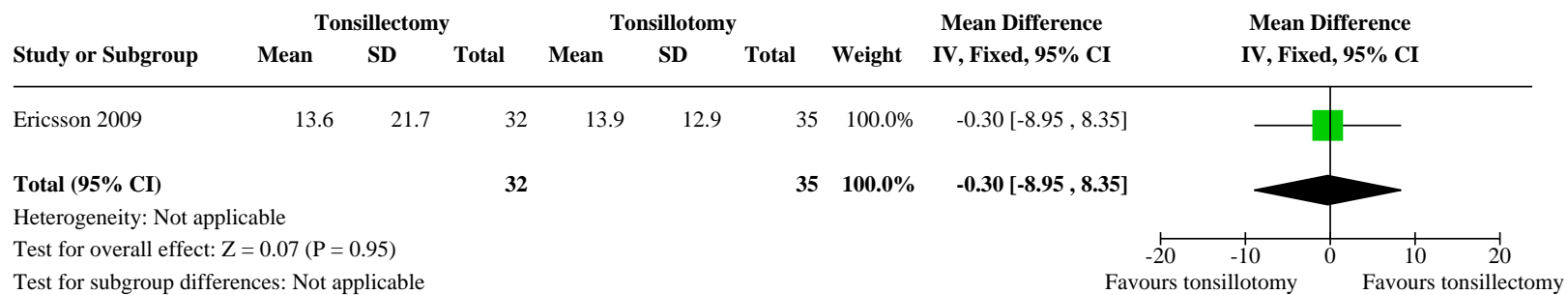


Analysis 1.7. Comparison 1: Tonsillectomy versus tonsillotomy, Outcome 7: Measures of respiratory events during sleep (AHI 6 months)

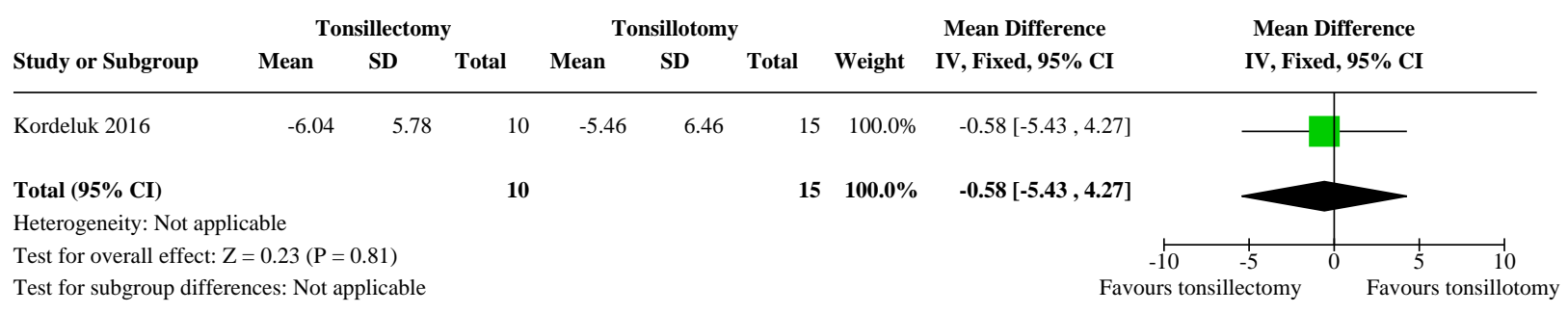

\section{Analysis 1.8. Comparison 1: Tonsillectomy versus tonsillotomy, Outcome 8: Recurrence of SDB symptoms (6 months)}

\begin{tabular}{|c|c|c|c|c|c|c|c|}
\hline & Tonsil & tomy & Tons & tomy & & Risk Ratio & Risk Ratio \\
\hline Study or Subgroup & Events & Total & Events & Total & Weight & M-H, Fixed, $95 \%$ CI & M-H, Fixed, $95 \%$ CI \\
\hline
\end{tabular}

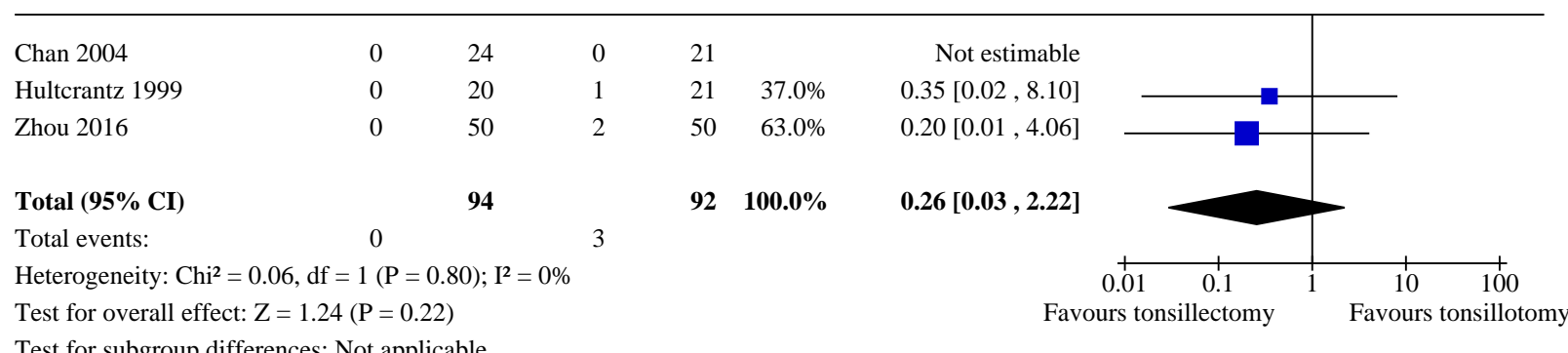

Test for subgroup differences: Not applicable

Analysis 1.9. Comparison 1: Tonsillectomy versus tonsillotomy, Outcome 9: Recurrence of SDB symptoms (6 months sensitivity analysis)

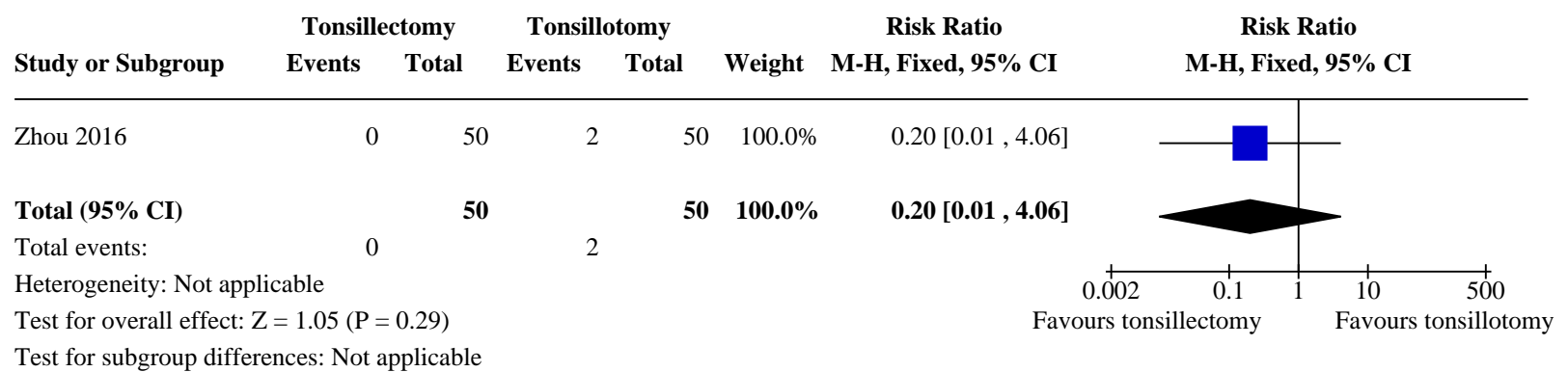




\section{Analysis 1.10. Comparison 1: Tonsillectomy versus tonsillotomy, Outcome 10: Recurrence of SDB symptoms (12 months)}

\begin{tabular}{lccccccc} 
& \multicolumn{2}{c}{ Tonsillectomy } & \multicolumn{2}{c}{ Tonsillotomy } & \multicolumn{2}{c}{ Risk Ratio } & Risk Ratio \\
Study or Subgroup & Events & Total & Events & Total & Weight & M-H, Fixed, 95\% CI & M-H, Fixed, 95\% CI
\end{tabular}

\begin{tabular}{llllllr}
\hline Chan 2004 & 0 & 21 & 1 & 22 & $50.0 \%$ & $0.35[0.01,8.11]$ \\
Hultcrantz 1999 & 0 & 20 & 1 & 21 & $50.0 \%$ & $0.35[0.02,8.10]$ \\
Hultcrantz 2004 & 0 & 43 & 0 & 49 & & Not estimable \\
Skoulakis 2007 & 0 & 15 & 0 & 15 & & Not estimable
\end{tabular}

Total $(95 \%$ CI $)$

99

$107 \quad 100.0 \%$

$0.35[0.04,3.23]$

Total events:

0

2

Heterogeneity: $\mathrm{Chi}^{2}=0.00, \mathrm{df}=1(\mathrm{P}=1.00) ; \mathrm{I}^{2}=0 \%$

Test for overall effect: $\mathrm{Z}=0.93(\mathrm{P}=0.35)$

Test for subgroup differences: Not applicable

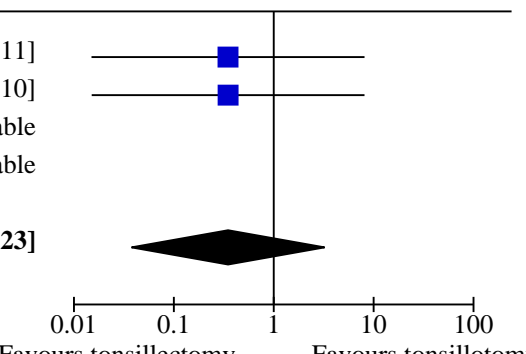

Favours tonsillectomy $\quad$ Favours tonsillotomy

\section{Analysis 1.11. Comparison 1: Tonsillectomy versus tonsillotomy, Outcome 11: Recurrence of SDB symptoms (12 months sensitivity analysis)}

\begin{tabular}{|c|c|c|c|c|c|}
\hline & Tonsillectomy & Tonsillotomy & & Risk Ratio & Risk Ratio \\
\hline Study or Subgroup & Events & Events & Weight & M-H, Fixed, 95\% CI & M-H, Fixed, $95 \%$ CI \\
\hline
\end{tabular}

\begin{tabular}{|c|c|c|c|c|c|c|c|}
\hline Chan 2004 & 0 & 21 & 1 & 22 & $100.0 \%$ & $0.35[0.01,8.11]$ & \\
\hline Skoulakis 2007 & 0 & 15 & 0 & 15 & & Not estimable & \\
\hline Total $(95 \%$ CI $)$ & & 36 & & 37 & $100.0 \%$ & $0.35[0.01,8.11]$ & \\
\hline Total events: & 0 & & 1 & & & & \\
\hline Heterogeneity: $\mathrm{N}$ & & & & & & $0.01 \quad 0.1$ & 100 \\
\hline Test for overall & $\mathrm{P}=$ & & & & & Favours tonsillectomy & Favours tonsillotomy \\
\hline
\end{tabular}

Test for subgroup differences: Not applicable

\section{Analysis 1.12. Comparison 1: Tonsillectomy versus tonsillotomy, Outcome 12: Recurrence of SDB symptoms (24 months)}

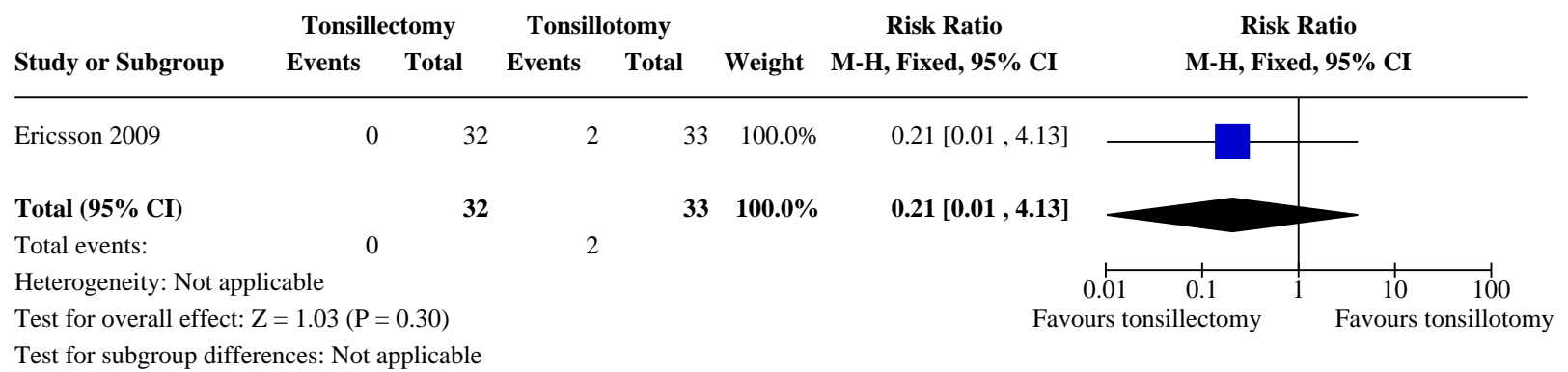


Analysis 1.13. Comparison 1: Tonsillectomy versus tonsillotomy, Outcome 13: Reoperation rates (12 months)

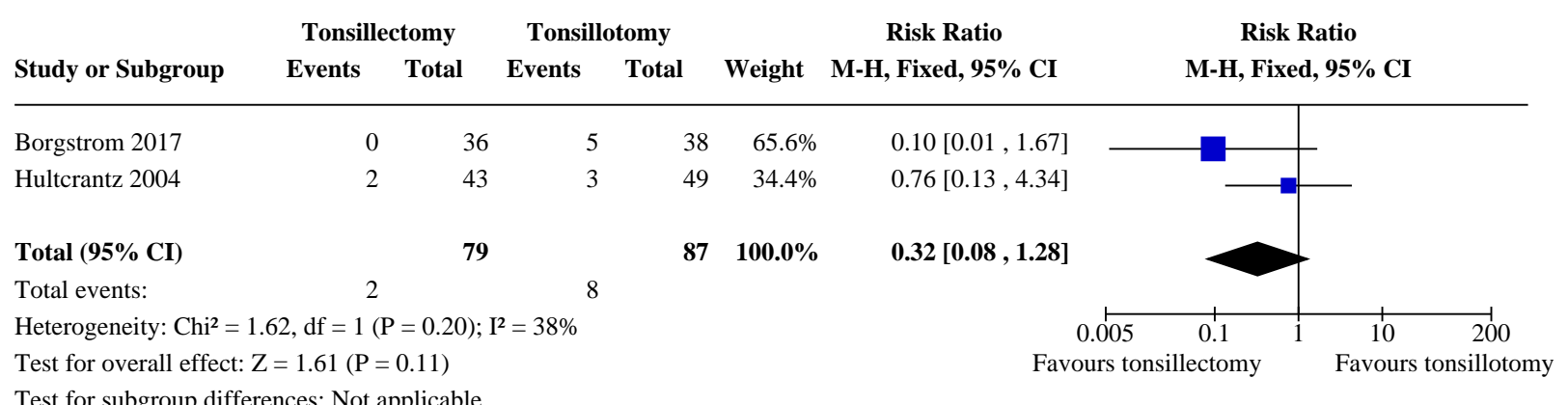

Analysis 1.14. Comparison 1: Tonsillectomy versus tonsillotomy, Outcome 14: Reoperation rates (18 months)

\begin{tabular}{|c|c|c|c|c|}
\hline & Ton & ctomy & Tons & tomy \\
\hline r Subaroun & Events & Total & Events & Tota \\
\hline
\end{tabular}

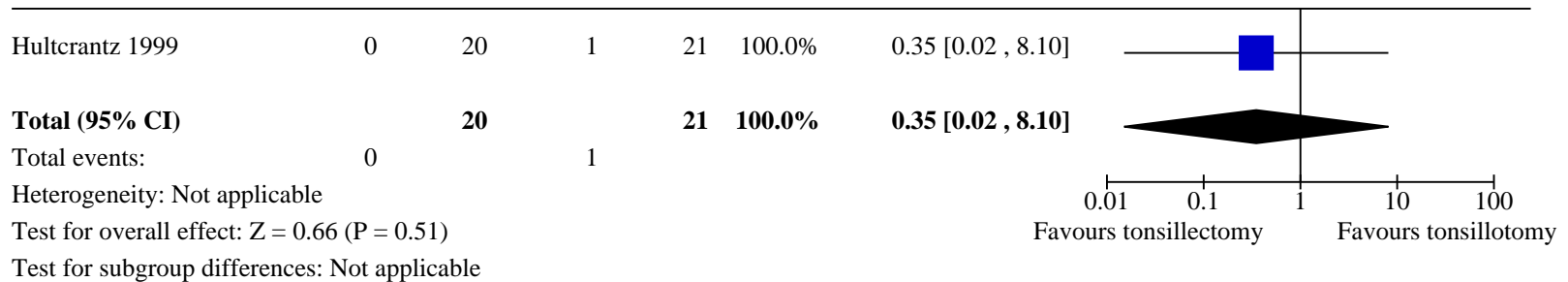

Analysis 1.15. Comparison 1: Tonsillectomy versus tonsillotomy, Outcome 15: Incidence of throat infection (6 months)

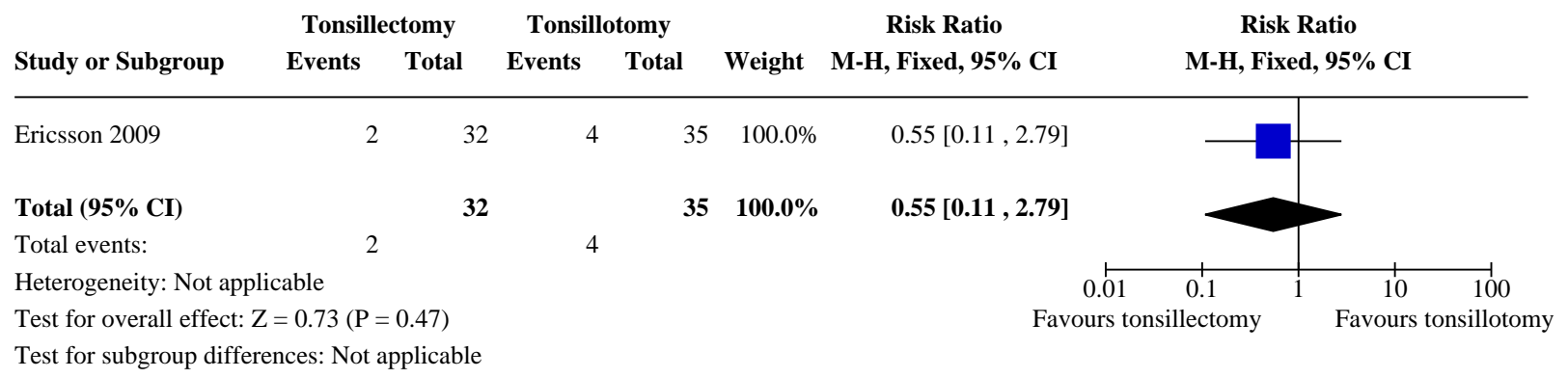


Analysis 1.16. Comparison 1: Tonsillectomy versus tonsillotomy, Outcome 16: Incidence of throat infection (12 months)

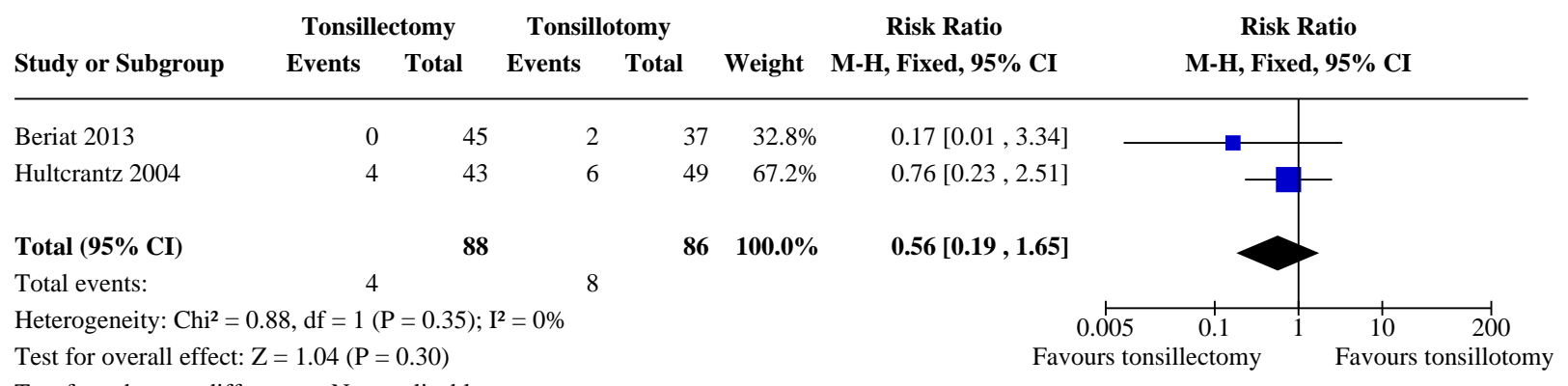

Analysis 1.17. Comparison 1: Tonsillectomy versus tonsillotomy, Outcome 17: Incidence of throat infection (24 months)

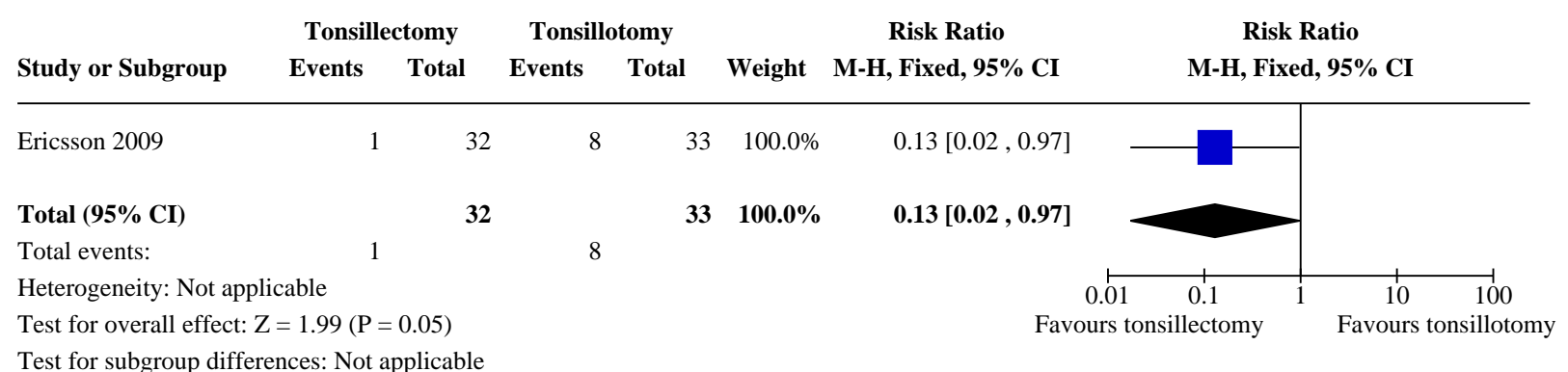

\section{Analysis 1.18. Comparison 1: Tonsillectomy versus tonsillotomy, Outcome 18: Duration of surgery}

\begin{tabular}{|c|c|c|c|c|c|c|c|c|c|c|}
\hline \multirow[b]{2}{*}{ Study or Subgroup } & \multicolumn{2}{|c|}{ Tonsillectomy } & \multicolumn{4}{|c|}{ Tonsillotomy } & \multicolumn{2}{|r|}{ Mean Difference } & \multirow{2}{*}{\multicolumn{2}{|c|}{$\begin{array}{c}\text { Mean Difference } \\
\text { IV, Fixed, 95\% CI [minutes] }\end{array}$}} \\
\hline & Mean [minutes] & SD [minutes] & Total & Mean [minutes] & SD [minutes] & Total & Weight & IV, Fixed, 95\% CI [minutes] & & \\
\hline Beriat 2013 & 29.53 & 7.27 & 45 & 24.76 & 10.04 & 37 & $6.3 \%$ & $4.77[0.90,8.64]$ & & - \\
\hline Chaidas 2013 & 20.4 & 3.8 & 51 & 19.9 & 3.6 & 50 & $45.6 \%$ & $0.50[-0.94,1.94]$ & & - \\
\hline Chan 2004 & 11.2 & 8.7 & 28 & 19.5 & 10.9 & 27 & $3.5 \%$ & $-8.30[-13.52,-3.08]$ & & \\
\hline Hultcrantz 1999 & 27.5 & 13 & 20 & 24.5 & 14 & 21 & $1.4 \%$ & $3.00[-5.27,11.27]$ & & \\
\hline Hultcrantz 2004 & 26.5 & 8.4 & 43 & 28.3 & 8.9 & 49 & $7.6 \%$ & $-1.80[-5.34,1.74]$ & & - \\
\hline Korkmaz 2008 & 22.3 & 7.9 & 41 & 21.3 & 9.4 & 40 & $6.6 \%$ & $1.00[-2.79,4.79]$ & & 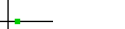 \\
\hline Park 2007 & 24 & 10 & 21 & 27 & 8 & 19 & $3.0 \%$ & $-3.00[-8.59,2.59]$ & & - \\
\hline Sobol 2006 & 16.6 & 4 & 36 & 20.9 & 4.4 & 38 & $25.9 \%$ & $-4.30[-6.21,-2.39]$ & $\rightarrow-$ & \\
\hline Total $(95 \%$ CI) & & & 285 & & & 281 & $100.0 \%$ & $-0.99[-1.97,-0.02]$ & & \\
\hline \multicolumn{11}{|c|}{ Heterogeneity: $\mathrm{Chi}^{2}=34.27, \mathrm{df}=7(\mathrm{P}<0.0001) ; \mathrm{I}^{2}=80 \%$} \\
\hline Test for overall effect & $=2.00(\mathrm{P}=0.05)$ & & & & & & & & -10 & $\frac{1}{5}$ \\
\hline
\end{tabular}

\section{Analysis 1.19. Comparison 1: Tonsillectomy versus tonsillotomy,}

Outcome 19: Duration of surgery (sensitivity analysis)

\begin{tabular}{|c|c|c|c|c|c|c|c|c|c|c|}
\hline Study or Subgroup & $\begin{array}{r}\text { Tons } \\
\text { Mean [minutes] }\end{array}$ & \multicolumn{2}{|c|}{ Tonsillectomy } & $\begin{array}{r}\text { Ton } \\
\text { Mean [minutes] }\end{array}$ & Tonsillotomy & Total & Weight & $\begin{array}{c}\text { Mean Difference } \\
\text { IV, Random, 95\% CI [minutes] }\end{array}$ & \multicolumn{2}{|c|}{$\begin{array}{c}\text { Mean Difference } \\
\text { IV, Random, 95\% CI [minutes] }\end{array}$} \\
\hline Beriat 2013 & 29.53 & 7.27 & 45 & 24.76 & 10.04 & 37 & $25.8 \%$ & $4.77[0.90,8.64]$ & & $\longrightarrow$ \\
\hline Chan 2004 & 11.2 & 8.7 & 28 & 19.5 & 10.9 & 27 & $23.0 \%$ & $-8.30[-13.52,-3.08]$ & & \\
\hline Park 2007 & 24 & 10 & 21 & 27 & 8 & 19 & $22.2 \%$ & $-3.00[-8.59,2.59]$ & & - \\
\hline Sobol 2006 & 16.6 & 4 & 36 & 20.9 & 4.4 & 38 & $29.0 \%$ & $-4.30[-6.21,-2.39]$ & - & \\
\hline Total $(95 \%$ CI) & & & 130 & & & 121 & $100.0 \%$ & $-2.59[-7.72,2.53]$ & & \\
\hline \multicolumn{11}{|c|}{ Heterogeneity: $\mathrm{Tau}^{2}=22.65 ; \mathrm{Ch}^{2}=21.20, \mathrm{df}=3(\mathrm{P}<0.0001) ; \mathrm{I}^{2}=86 \%$} \\
\hline Test for overall effect: & $=0.99(P=0.32)$ & & & & & & & Favo & $\begin{array}{ll}-10 & -5 \\
& -5\end{array}$ & $\begin{array}{cc}5 & 10 \\
& \end{array}$ \\
\hline
\end{tabular}


Analysis 1.20. Comparison 1: Tonsillectomy versus tonsillotomy, Outcome 20: Severity of postoperative pain (24 hours)

\begin{tabular}{|c|c|c|c|c|c|c|c|c|c|}
\hline & \multicolumn{3}{|c|}{ Tonsillectomy } & \multicolumn{3}{|c|}{ Tonsillotomy } & \multicolumn{2}{|r|}{ Mean Difference } & Mean Difference \\
\hline Study or Subgroup & Mean & SD & Total & Mean & SD & Total & Weight & d, $95 \%$ CI & $6 \mathbf{C I}$ \\
\hline
\end{tabular}

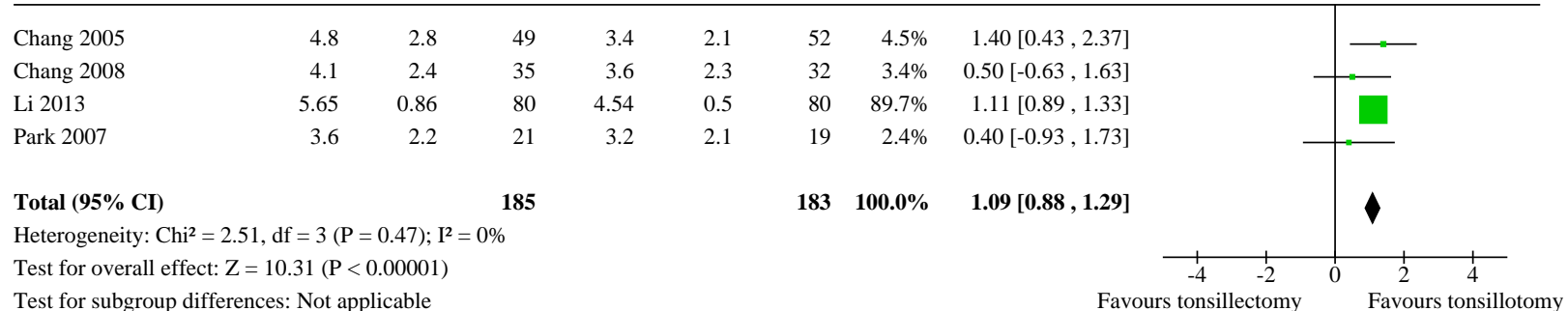

Test for subgroup differences: Not applicable

Analysis 1.21. Comparison 1: Tonsillectomy versus tonsillotomy, Outcome 21: Severity of postoperative pain (24 hours sensitivity analysis)

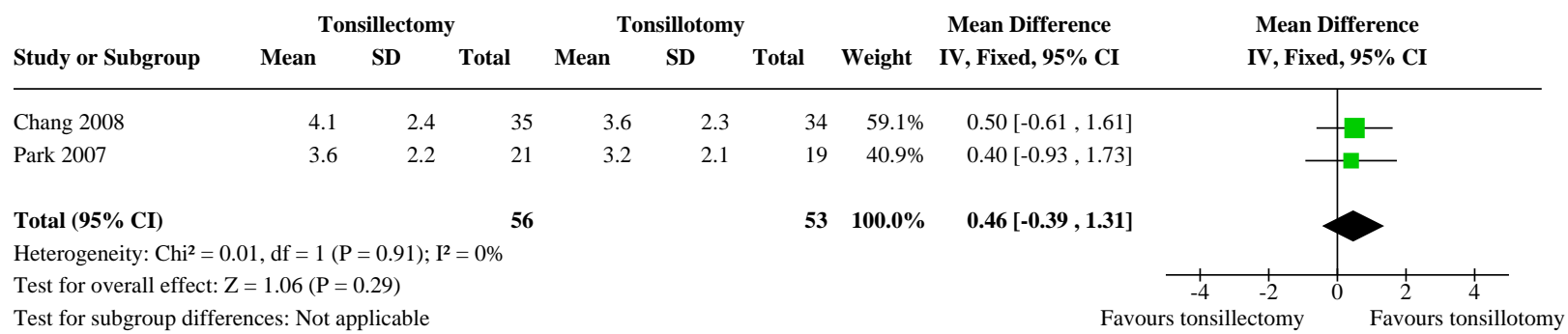

\section{Analysis 1.22. Comparison 1: Tonsillectomy versus tonsillotomy,} Outcome 22: Severity of postoperative pain ( 2 to 3 days)

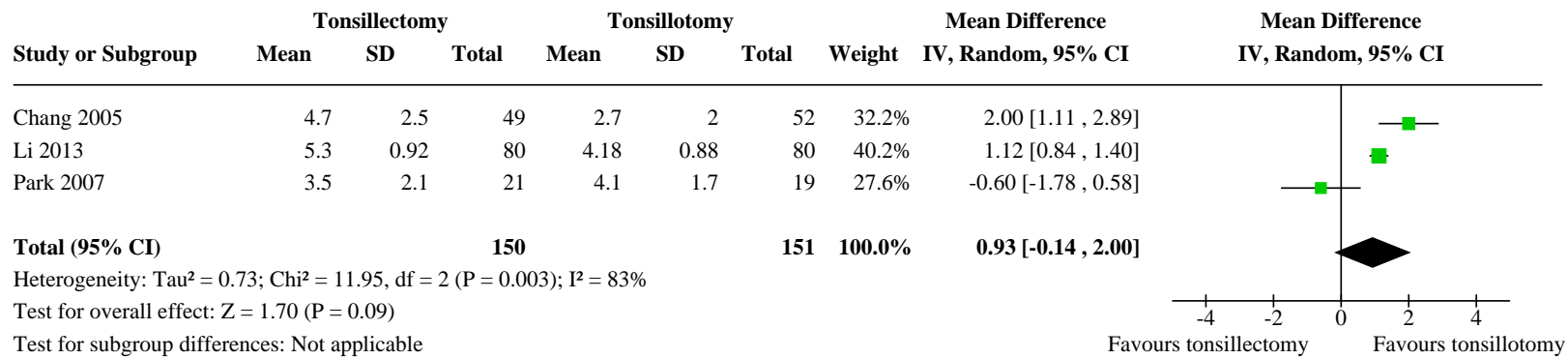

\section{Analysis 1.23. Comparison 1: Tonsillectomy versus tonsillotomy, Outcome} 23: Severity of postoperative pain ( 2 to 3 days sensitivity analysis)

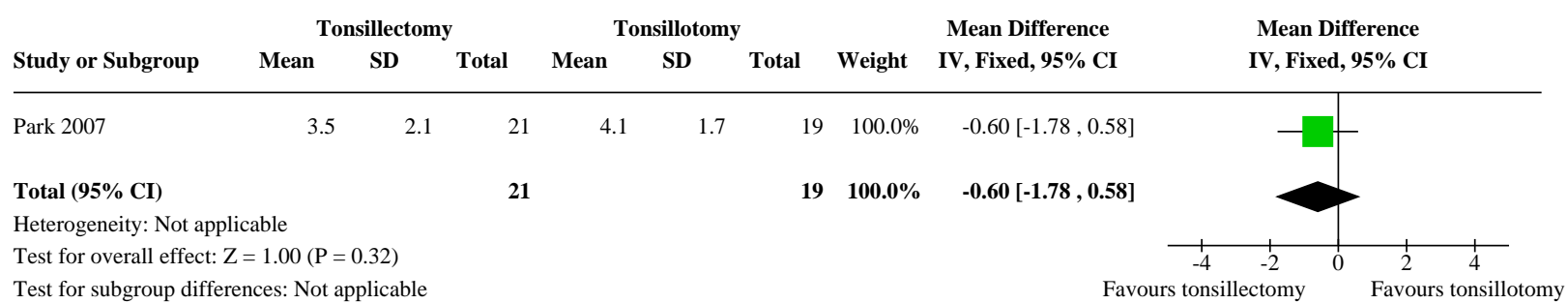


Analysis 1.24. Comparison 1: Tonsillectomy versus tonsillotomy, Outcome 24: Severity of postoperative pain (4 to 7 days)

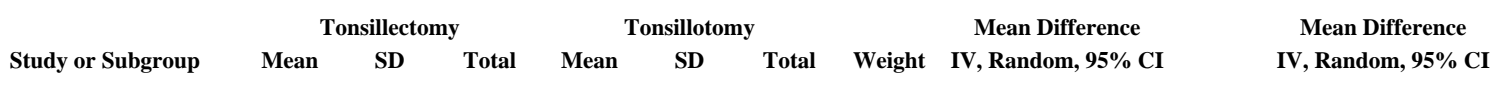

\begin{tabular}{|c|c|c|c|c|c|c|c|c|}
\hline Chang 2005 & 4.5 & 2.3 & 49 & 1.9 & 1.7 & 52 & $25.6 \%$ & $2.60[1.81,3.39]$ \\
\hline Chang 2008 & 3.7 & 3.1 & 35 & 1.9 & 2.1 & 34 & $23.1 \%$ & $1.80[0.55,3.05]$ \\
\hline Li 2013 & 2.86 & 1.04 & 80 & 2.92 & 1.22 & 80 & $27.3 \%$ & $-0.06[-0.41,0.29]$ \\
\hline Park 2007 & 3.4 & 1.7 & 21 & 3.4 & 1.8 & 19 & $24.0 \%$ & $0.00[-1.09,1.09]$ \\
\hline Total $(95 \%$ CI $)$ & & & 185 & & & 185 & $100.0 \%$ & $1.07[-0.40,2.53]$ \\
\hline
\end{tabular}

Heterogeneity: $\mathrm{Tau}^{2}=2.01 ; \mathrm{Chi}^{2}=41.51, \mathrm{df}=3(\mathrm{P}<0.00001) ; \mathrm{I}^{2}=93 \%$

Test for overall effect: $\mathrm{Z}=1.43(\mathrm{P}=0.15)$

Test for subgroup differences: Not applicable

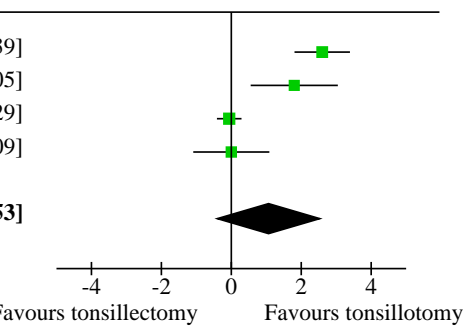

Analysis 1.25. Comparison 1: Tonsillectomy versus tonsillotomy, Outcome 25: Severity of postoperative pain ( 4 to 7 days sensitivity analysis)

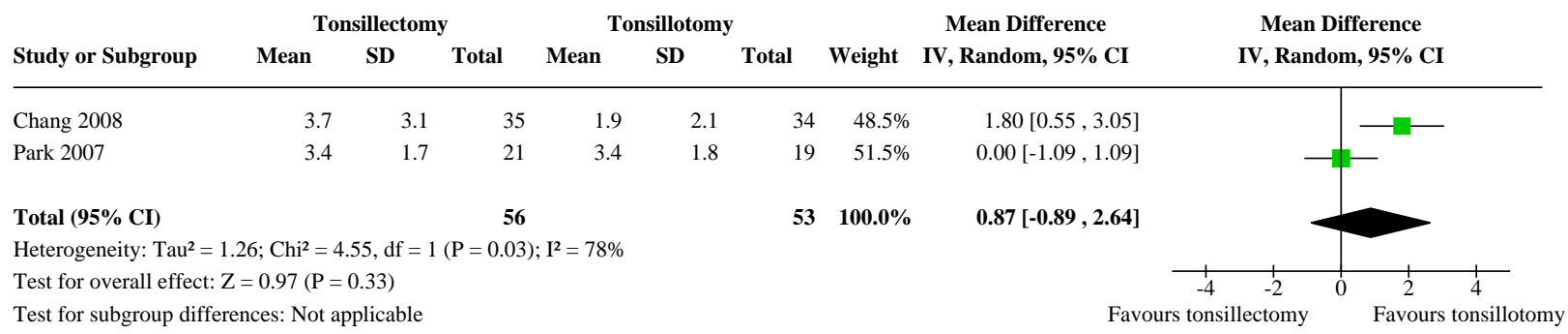

Analysis 1.26. Comparison 1: Tonsillectomy versus tonsillotomy, Outcome 26: Days until analgesics no longer required

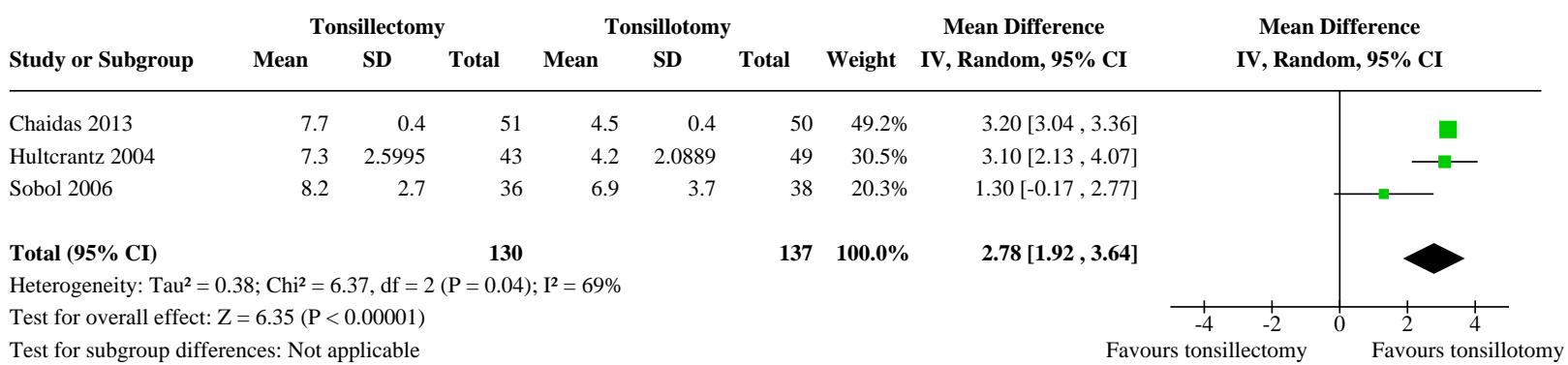

Test for subgroup differences: Not applicable

Analysis 1.27. Comparison 1: Tonsillectomy versus tonsillotomy, Outcome 27: Days until analgesics no longer required (sensitivity analysis)

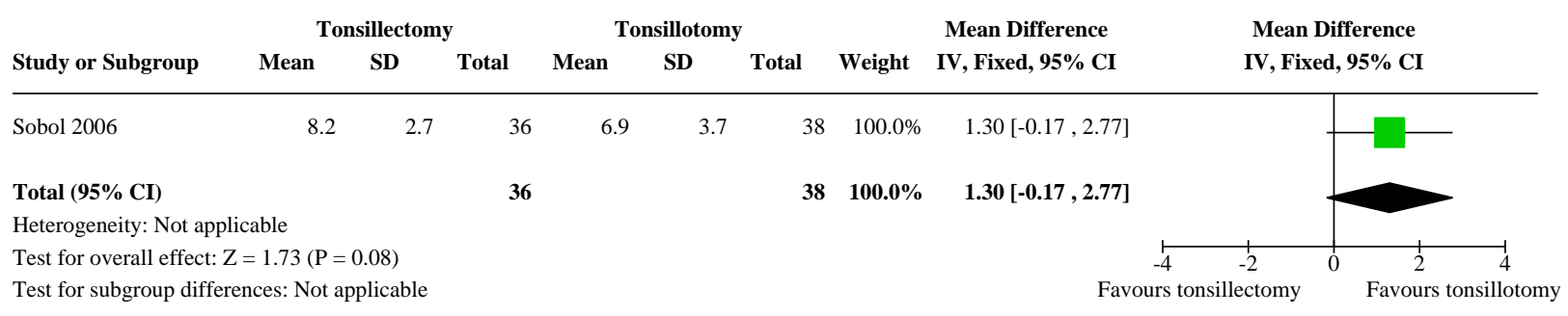


Analysis 1.28. Comparison 1: Tonsillectomy versus tonsillotomy, Outcome 28: Return to normal diet

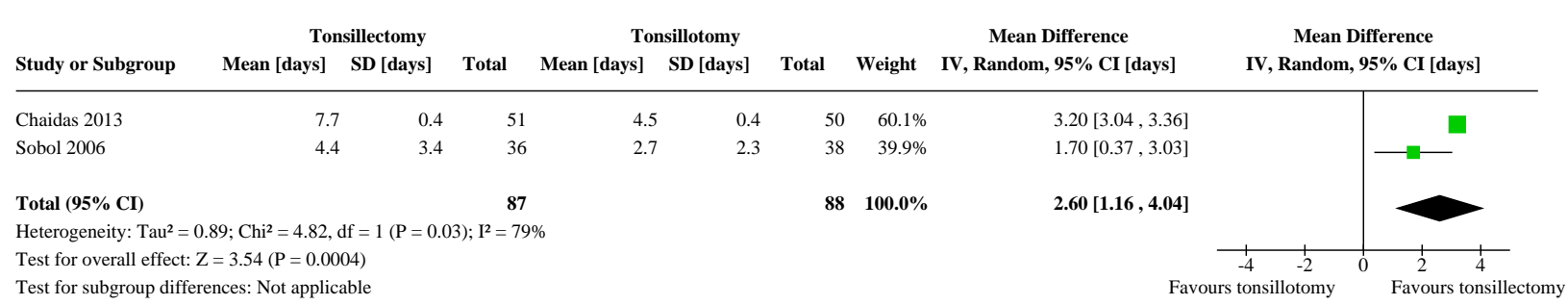

Analysis 1.29. Comparison 1: Tonsillectomy versus tonsillotomy, Outcome 29: Return to normal diet (sensitivity analysis)

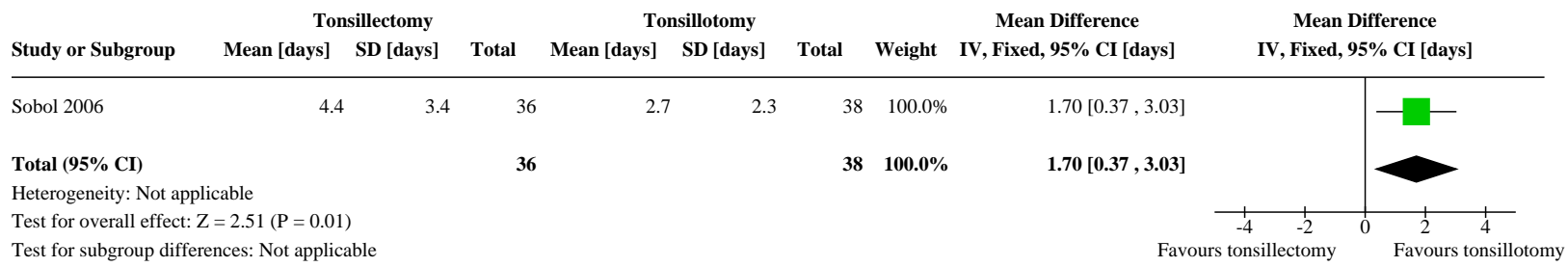

Analysis 1.30. Comparison 1: Tonsillectomy versus tonsillotomy, Outcome 30: Return to normal activity

\begin{tabular}{|c|c|c|c|c|c|c|c|c|c|c|}
\hline \multirow[b]{2}{*}{ Study or Subgroup } & \multicolumn{2}{|c|}{ Tonsillectomy } & \multicolumn{4}{|c|}{ Tonsillotomy } & \multirow[b]{2}{*}{ Weight } & Mean Difference & \multicolumn{2}{|c|}{ Mean Difference } \\
\hline & Mean [days] & SD [days] & Total & Mean [days] & SD [days] & Total & & IV, Random, 95\% CI [days] & IV, Random, & $95 \%$ CI [days] \\
\hline Beriat 2013 & 12.27 & 2.4 & 45 & 5.22 & 1.11 & 37 & $33.7 \%$ & $7.05[6.26,7.84]$ & & - \\
\hline Hultcrantz 2004 & 9 & 2.9244 & 43 & 6 & 2.7852 & 49 & $33.1 \%$ & $3.00[1.83,4.17]$ & & - \\
\hline Sobol 2006 & 3.8 & 3 & 36 & 2.4 & 1.8 & 38 & $33.2 \%$ & $1.40[0.27,2.53]$ & & - \\
\hline Total $(95 \%$ CI) & & & 124 & & & 124 & $100.0 \%$ & $3.84[0.23,7.44]$ & & \\
\hline \multicolumn{11}{|c|}{ Heterogeneity: $\mathrm{Tau}^{2}=9.87 ; \mathrm{Chi}^{2}=74.81, \mathrm{df}=2(\mathrm{P}<0.00001) ; \mathrm{I}^{2}=97 \%$} \\
\hline Test for overall effect & $=2.09(\mathrm{P}=0.04)$ & & & & & & & & $\begin{array}{cc}1 & 1 \\
-4 & -2\end{array}$ & $\begin{array}{lll} & 1 & 1 \\
0 & 2 & 4\end{array}$ \\
\hline Test for subgroup diff & nces: Not applica & & & & & & & Favo & onsillectomy & Favou \\
\hline
\end{tabular}

\section{Analysis 1.31. Comparison 1: Tonsillectomy versus tonsillotomy, Outcome 31: Return to normal activity (sensitivity analysis)}

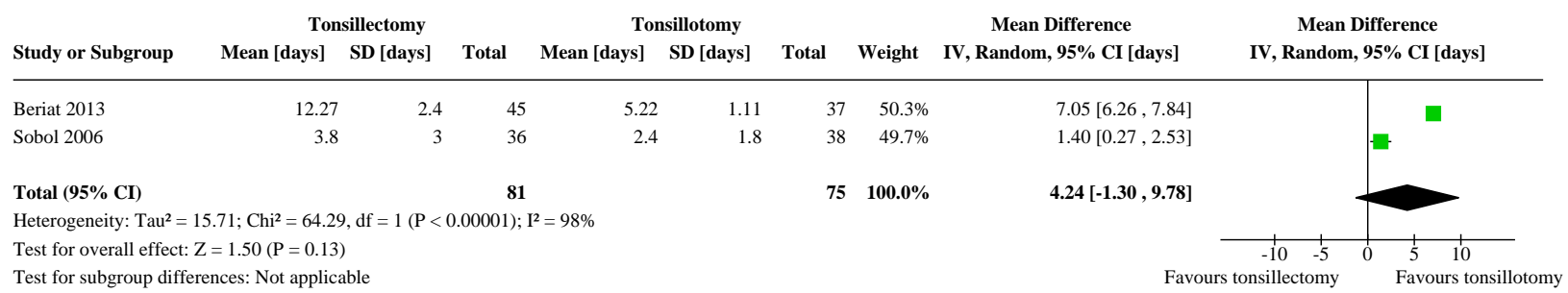

\section{ADDITIONAL TABLES}


Table 1. Overview of interventions

\begin{tabular}{|c|c|c|c|c|}
\hline \multirow[t]{2}{*}{ Study } & \multirow[t]{2}{*}{ Country } & \multicolumn{2}{|c|}{ Surgical technique } & \multirow{2}{*}{$\begin{array}{l}\text { Concurrent } \\
\text { adenoidecto- } \\
\text { my (\%) }\end{array}$} \\
\hline & & Tonsillectomy & Tonsillotomy & \\
\hline Dai 2014 & China & Coblation & Coblation & Not stated \\
\hline Li 2013 & China & Coblation & Coblation & 100 \\
\hline Zhou 2016 & China & Not stated & Not stated & 100 \\
\hline Chaidas 2013 & Greece & Blunt dissection & Blunt dissection & 100 \\
\hline Skoulakis 2007 & Greece & Blunt dissection & Blunt dissection & 100 \\
\hline Kordeluk 2016 & Israel & Electrocautery & $\mathrm{CO}_{2}$ laser/microdebrider & 100 \\
\hline Bitar 2016 & Lebanon & Electrocautery & Microdebrider & Not stated \\
\hline Borgstrom 2017 & Sweden & Blunt dissection & Coblation & 100 \\
\hline Densert 2001 & Sweden & Blunt dissection & $\mathrm{CO}_{2}$ laser & (100 previously) \\
\hline Ericsson 2009 & Sweden & Blunt dissection & Radiofrequency & 80 \\
\hline Hultcrantz 1999 & Sweden & Blunt dissection & $\mathrm{CO}_{2}$ laser & 15 \\
\hline Hultcrantz 2004 & Sweden & Blunt dissection & Radiofrequency & 49 \\
\hline Lundeborg 2009 & Sweden & Blunt dissection & Radiofrequency & $\begin{array}{l}79 \text { (10 previous- } \\
\text { ly) }\end{array}$ \\
\hline Beriat 2013 & Turkey & Blunt dissection & Microdebrider & Not stated \\
\hline Korkmaz 2008 & Turkey & Blunt dissection & Blunt dissection & Not stated \\
\hline Chan 2004 & USA & Electrocautery & Coblation & Not stated \\
\hline Chang 2005 & USA & Electrocautery & Coblation & 99 \\
\hline Chang 2008 & USA & Coblation & Coblation & Not stated \\
\hline Coticchia 2006 & USA & Electrocautery & Radiofrequency & 100 \\
\hline Derkay 2006 & USA & Electrocautery & Microdebrider & Not stated \\
\hline Park 2007 & USA & Electrocautery & Electrocautery & 100 \\
\hline Sobol 2006 & USA & Electrocautery & Microdebrider & 100 \\
\hline
\end{tabular}

Table 2. Primary outcomes

Study PRIMARY OUTCOMES


Table 2. Primary outcomes (Continued) $\begin{array}{ll}\text { Clinical effectiveness expressed as: } & \begin{array}{l}\text { Peri- and postoperative morbidity and compli- } \\ \text { cations expressed as: }\end{array}\end{array}$

\begin{tabular}{|c|c|c|c|c|}
\hline \multicolumn{3}{|c|}{$\begin{array}{l}\text { Disease-specific quality of life } \\
\text { (OSA-18) }\end{array}$} & \multirow{2}{*}{$\begin{array}{l}\text { Peri-opera- } \\
\text { tive } \\
\text { blood loss }\end{array}$} & \multirow{2}{*}{$\begin{array}{l}\text { Postoperative complications } \\
\text { requiring medical intervention } \\
\text { with or without hospitalisation }\end{array}$} \\
\hline $\mathbf{S}$ & $\mathbf{M}$ & $\mathbf{L}$ & & \\
\hline & & & $x$ & $x$ \\
\hline
\end{tabular}

Beriat 2013

Bitar 2016

\begin{tabular}{llll}
\hline Borgstrom 2017 & $\mathrm{X}$ & $\mathrm{X}$ \\
\hline Chaidas 2013 & $\mathrm{X}$ & $\mathrm{X}$ \\
\hline Chan 2004 & $\mathrm{X}$ & $\mathrm{x}$ \\
\hline Chang 2005 & $\mathrm{X}$ & $\mathrm{x}$ \\
\hline Chang 2008 & & $\mathrm{x}$ \\
\hline Coticchia 2006 & $\mathrm{x}$ \\
\hline
\end{tabular}

Dai 2014

\begin{tabular}{|c|c|c|c|c|}
\hline Densert 2001 & $x$ & $x$ & & $x$ \\
\hline Derkay 2006 & $x$ & & & $x$ \\
\hline Ericsson 2009 & $x$ & $x$ & & $x$ \\
\hline Hultcrantz 1999 & & & $x$ & $x$ \\
\hline Hultcrantz 2004 & & & $x$ & $x$ \\
\hline Kordeluk 2016 & & & & $x$ \\
\hline Korkmaz 2008 & & & $x$ & \\
\hline Li 2013 & & & & $x$ \\
\hline \multicolumn{5}{|l|}{ Lundeborg 2009} \\
\hline Park 2007 & & & $x$ & $x$ \\
\hline Skoulakis 2007 & & & $x$ & $x$ \\
\hline Sobol 2006 & & & $x$ & \\
\hline Zhou 2016 & & & & $x$ \\
\hline
\end{tabular}




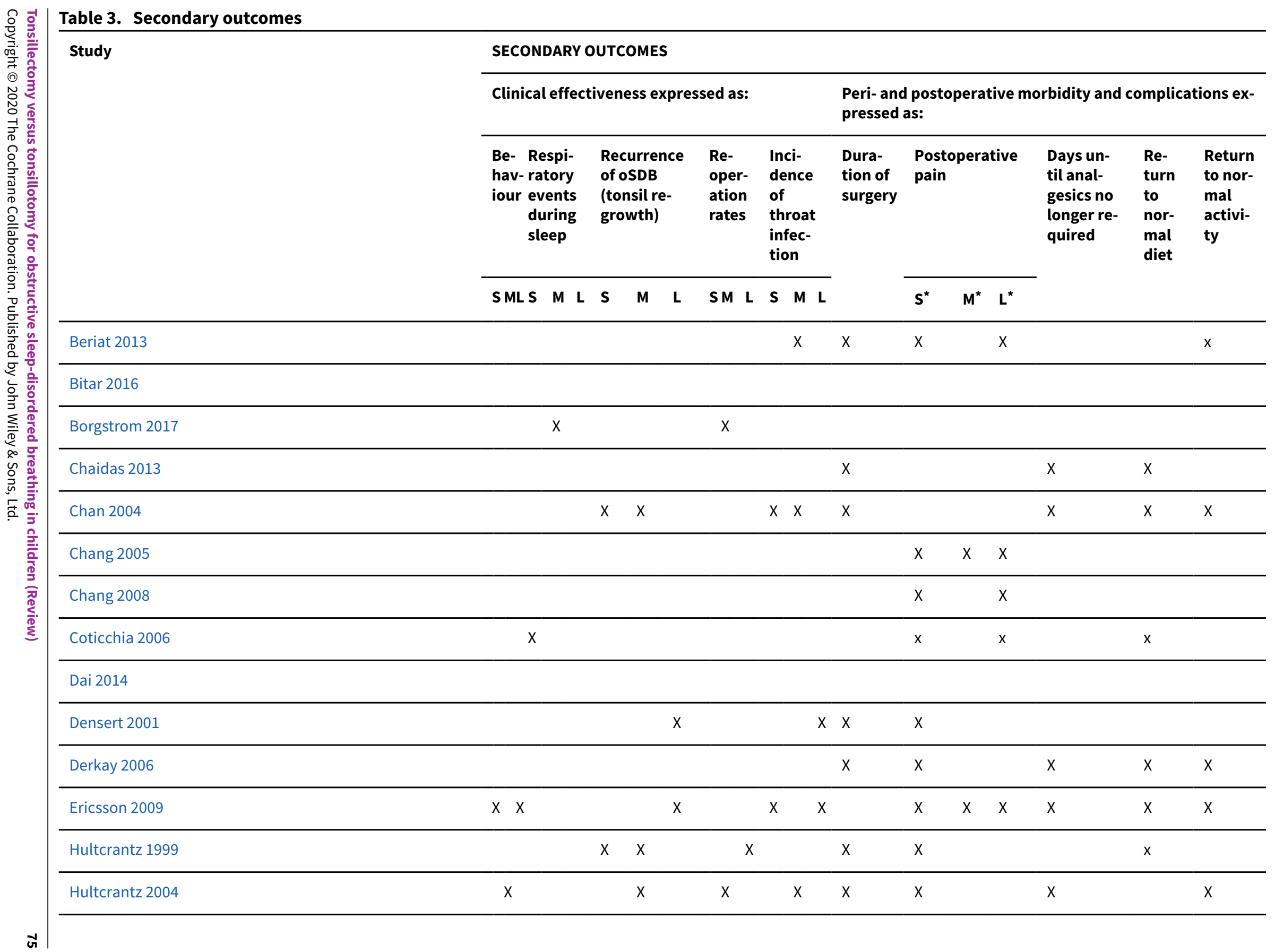




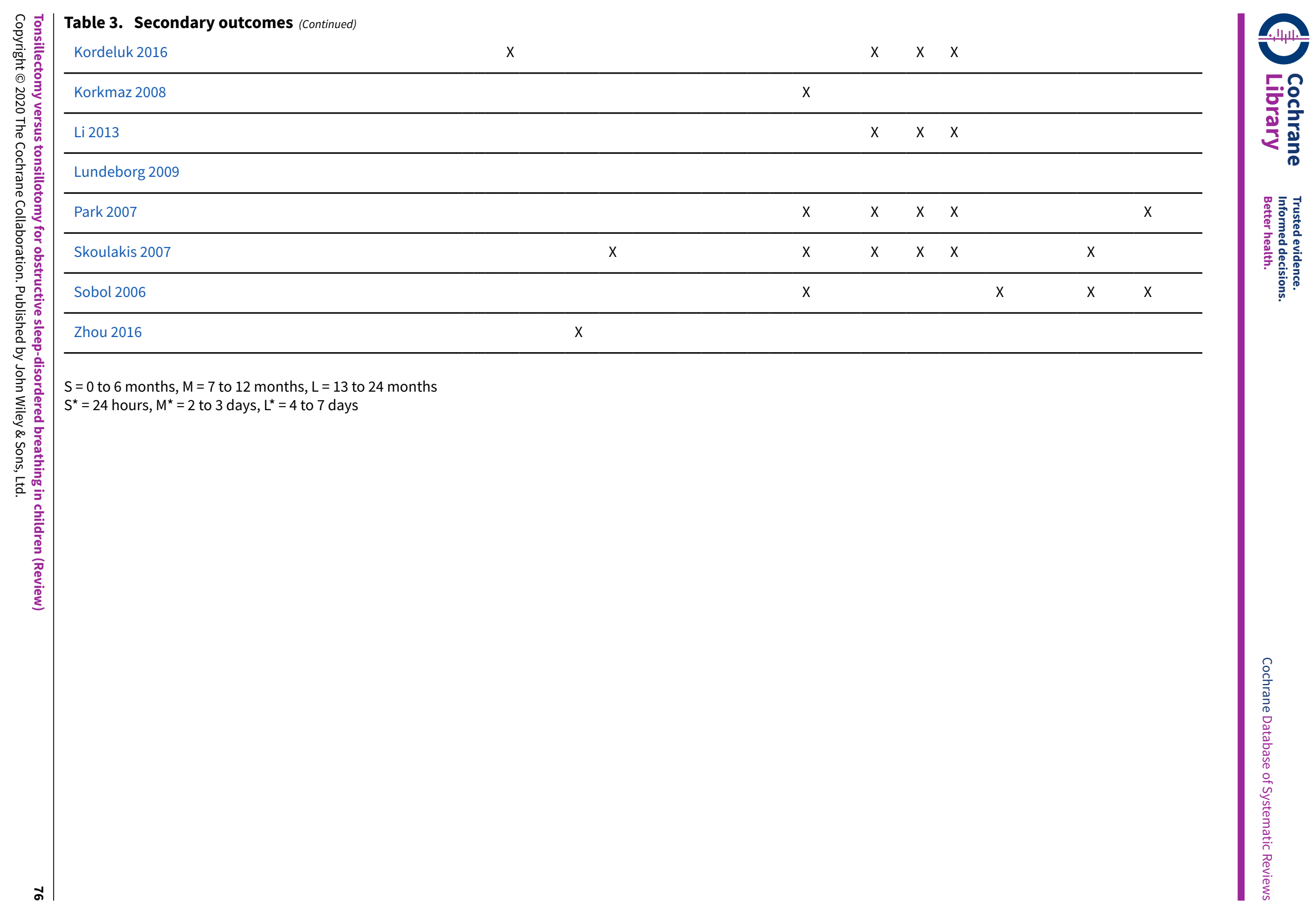


Table 4. Reporting of short-term pain (24 hours)

\begin{tabular}{|c|c|c|c|c|c|c|}
\hline Study & Scale used ${ }^{\star}$ & $\begin{array}{l}\text { Person } \\
\text { reporting }\end{array}$ & Data reported & $\begin{array}{l}\text { Meta- } \\
\text { analysis? }\end{array}$ & \multicolumn{2}{|l|}{ Results } \\
\hline \multirow[t]{2}{*}{$\begin{array}{l}\text { Beriat } \\
2013\end{array}$} & $\begin{array}{l}\text { Modified } \\
\text { Hannallah } \\
\text { Pain Score } \\
\text { (MHPS) }\end{array}$ & $\begin{array}{l}\text { Anaesthe- } \\
\text { siologist }\end{array}$ & Mean and SD & $\mathrm{N}$ & \multicolumn{2}{|c|}{$\begin{array}{l}\text { Pain scores lower in tonsillotomy group at } 2 \text { hours } \\
\text { (mean } 0.51, \text { SD } 0.93 \text { ) than tonsillectomy group } \\
\text { (mean 1.34, SD 1.18), } \mathrm{P}<0.0005\end{array}$} \\
\hline & 10-point VAS & Staff & Mean graphically & $\mathrm{N}$ & \multicolumn{2}{|c|}{$\begin{array}{l}\text { Pain scores lower in tonsillotomy group at } 22 \\
\text { hours than tonsillectomy group, } P<0.0005\end{array}$} \\
\hline \multirow[t]{2}{*}{$\begin{array}{l}\text { Chang } \\
2005\end{array}$} & \multirow[t]{2}{*}{$\begin{array}{l}\text { Wong-Bak- } \\
\text { er FACES 10- } \\
\text { point VAS }\end{array}$} & Child & $\begin{array}{l}\text { Mean and SD graphi- } \\
\text { cally }\end{array}$ & $\mathrm{N}$ & \multicolumn{2}{|c|}{$\begin{array}{l}\text { Pain scores lower in tonsillotomy group (mean } \\
2.5, \mathrm{SD} 2.5 \text { ) than tonsillectomy group (mean } 4.6 \text {, } \\
\text { SD 3.3), } \mathrm{P}<0.005\end{array}$} \\
\hline & & Parent & $\begin{array}{l}\text { Mean and SD graphi- } \\
\text { cally }\end{array}$ & Y & \multicolumn{2}{|l|}{ See Analysis 1.20} \\
\hline \multirow[t]{2}{*}{$\begin{array}{l}\text { Chang } \\
2008\end{array}$} & \multirow[t]{2}{*}{$\begin{array}{l}\text { Wong-Bak- } \\
\text { er FACES 10- } \\
\text { point VAS }\end{array}$} & Child & Mean only & $\mathrm{N}$ & \multicolumn{2}{|c|}{$\begin{array}{l}\text { No evidence of a difference in pain scores be- } \\
\text { tween the groups (mean score of } 2.8 \text { in both } \\
\text { groups) }\end{array}$} \\
\hline & & Parent & $\begin{array}{l}\text { Mean and SD graphi- } \\
\text { cally }\end{array}$ & $\mathrm{Y}$ & \multicolumn{2}{|l|}{ See Analysis 1.20} \\
\hline \multirow[t]{3}{*}{$\begin{array}{l}\text { Densert } \\
2001\end{array}$} & \multirow[t]{3}{*}{ 5-point VAS } & Child & $\begin{array}{l}\text { Mean rank. Did not re- } \\
\text { port the number of } \\
\text { children randomised } \\
\text { to each arm }\end{array}$ & $\mathrm{N}$ & \multirow[t]{3}{*}{$\begin{array}{l}\text { "statistically significant reduction } \\
\text { in pain after tonsillotomy com- } \\
\text { pared to tonsillectomy" }\end{array}$} & $\begin{array}{l}\text { Mean rank } \\
11.0 \text { ver- } \\
\text { sus } 17.3, P \\
=0.03\end{array}$ \\
\hline & & Parent & & & & $\begin{array}{l}\text { Mean rank } \\
11.1 \text { ver- } \\
\text { sus } 17.1, \mathrm{P} \\
=0.046\end{array}$ \\
\hline & & Staff & & & & $\begin{array}{l}\text { Mean rank } \\
10.7 \text { ver- } \\
\text { sus } 18.0, P \\
=0.015\end{array}$ \\
\hline $\begin{array}{l}\text { Derkay } \\
2006\end{array}$ & $\begin{array}{l}\text { Wong-Bak- } \\
\text { er FACES 10- } \\
\text { point VAS }\end{array}$ & Parent & Median and IQR & $\mathrm{N}$ & \multicolumn{2}{|c|}{ Median pain score 3 (IQR 2 to 4 ) in both groups } \\
\hline $\begin{array}{l}\text { Ericsson } \\
2009\end{array}$ & 5-point VAS & Parent & $\begin{array}{l}\text { Median and IQR } \\
\text { graphically (data not } \\
\text { normally distributed) }\end{array}$ & $\mathrm{N}$ & \multicolumn{2}{|c|}{$\begin{array}{l}\text { The median pain score was lower in children who } \\
\text { had undergone tonsillotomy compared to ton- } \\
\text { sillectomy; } 2 \text { (IQR } 2 \text { to } 3 \text { ) versus } 3 \text { (IQR } 3 \text { to } 4 \text { ), P } \\
0.01\end{array}$} \\
\hline $\begin{array}{l}\text { Hultcrantz } \\
1999\end{array}$ & 10-point VAS & Child & $\begin{array}{l}\text { Distribution of hourly } \\
\text { scores graphically }\end{array}$ & $\mathrm{N}$ & \multicolumn{2}{|c|}{$\begin{array}{l}\text { "the postoperative mean pain score was signifi- } \\
\text { cantly lower for the first } 24 \mathrm{~h} \text { for the TT children } \\
\text { than the TE children" }\end{array}$} \\
\hline $\begin{array}{l}\text { Hultcrantz } \\
2004\end{array}$ & 6-point VAS & Child & $\begin{array}{l}\text { Hourly distribution of } \\
\text { scores graphically }\end{array}$ & $\mathrm{N}$ & \multicolumn{2}{|c|}{$\begin{array}{l}\text { "there was a significant difference between the TT } \\
\text { and the TE group at } 2,5 \text {, and } 8 \text { hours after surgery } \\
(P<0.05) "\end{array}$} \\
\hline
\end{tabular}


Table 4. Reporting of short-term pain (24 hours) (Continued)

\begin{tabular}{llllll} 
& 7-point VAS & Parent & No data reported & N & - \\
\cline { 2 - 6 } & 7-point VAS & Staff & No data reported & N & - \\
\hline Li 2013 & 5-point VAS & Parent & Mean and SD & Y & See Analysis 1.20 \\
\hline Park 2007 & $\begin{array}{l}\text { Wong Bak- } \\
\text { er FACES 10- } \\
\text { point VAS }\end{array}$ & Parent & $\begin{array}{l}\text { Mean and SD graphi- } \\
\text { cally }\end{array}$ & Y & See Analysis 1.20 \\
\hline $\begin{array}{l}\text { Skoulakis } \\
2007\end{array}$ & $\begin{array}{l}\text { 10-point VAS } \\
\text { Parent }\end{array}$ & Mean graphically & $\mathrm{N}$ & $\begin{array}{l}\text { "on average, the pain scores were significant- } \\
\text { ly lower (about 50\%) for the tonsillotomy group } \\
\text { than for the tonsillectomy group (P<0.01)" }\end{array}$ \\
\hline
\end{tabular}

IQR: interquartile range

SD: standard deviation

$\mathrm{TE}$ : tonsillectomy

TT: tonsillotomy

VAS: visual analogue scale

Table 5. Reporting of medium-term pain ( 2 to 3 days)

\begin{tabular}{|c|c|c|c|c|c|}
\hline Study & Scale used* & $\begin{array}{l}\text { Person } \\
\text { Report- } \\
\text { ing }\end{array}$ & Data Reported & $\begin{array}{l}\text { Meta- } \\
\text { analysis? }\end{array}$ & Results \\
\hline \multirow[t]{2}{*}{$\begin{array}{l}\text { Chang } \\
2005\end{array}$} & $\begin{array}{l}\text { Wong-Bak- } \\
\text { er FACES 10- } \\
\text { point VAS }\end{array}$ & Child & $\begin{array}{l}\text { Mean and SD } \\
\text { graphically }\end{array}$ & $\mathrm{N}$ & $\begin{array}{l}\text { Pain scores lower in tonsillotomy group (mean 1.9, } \\
\text { SD 2) than tonsillectomy (mean } 4.3, \text { SD 2.5), } P< \\
0.005\end{array}$ \\
\hline & & Parent & & $Y$ & See Analysis 1.22 \\
\hline $\begin{array}{l}\text { Ericsson } \\
2009\end{array}$ & 5-point VAS & Parent & $\begin{array}{l}\text { Median and IQR } \\
\text { graphically (data } \\
\text { not normally dis- } \\
\text { tributed) }\end{array}$ & $\mathrm{N}$ & $\begin{array}{l}\text { The median pain score was lower in children who } \\
\text { had undergone tonsillotomy compared to tonsil- } \\
\text { lectomy; } \\
2 \text { (IQR } 1 \text { to } 2 \text { ) versus } 3 \text { (IQR } 2 \text { to 3), P < } 0.0001\end{array}$ \\
\hline Li 2013 & 5-point VAS & Parent & Mean and SD & $Y$ & See Analysis 1.22 \\
\hline Park 2007 & $\begin{array}{l}\text { Wong Bak- } \\
\text { er FACES 10- } \\
\text { point VAS }\end{array}$ & Parent & $\begin{array}{l}\text { Mean and SD } \\
\text { graphically }\end{array}$ & $Y$ & See Analysis 1.22 \\
\hline $\begin{array}{l}\text { Skoulakis } \\
2007\end{array}$ & 10-point VAS & Parent & Mean graphically & $\mathrm{N}$ & $\begin{array}{l}\text { "on average, the pain scores were significantly low- } \\
\text { er (about } 50 \%) \text { for the tonsillotomy group than for } \\
\text { the tonsillectomy group }(\mathrm{P}<0.01) \text { " }\end{array}$ \\
\hline
\end{tabular}

IQR: interquartile range

SD: standard deviation

VAS: visual analogue scale 
Table 6. Reporting of long-term pain (4 to 7 days)

\begin{tabular}{|c|c|c|c|c|c|}
\hline Study & Scale used* & $\begin{array}{l}\text { Person } \\
\text { reporting }\end{array}$ & Data reported & $\begin{array}{l}\text { Meta- } \\
\text { analysis? }\end{array}$ & Results \\
\hline $\begin{array}{l}\text { Beriat } \\
2013\end{array}$ & 10-point VAS & Staff & Not reported & $\mathrm{N}$ & $\begin{array}{l}\text { Pain scores lower in tonsillotomy group than tonsil- } \\
\text { lectomy group }(P<0.05)\end{array}$ \\
\hline \multirow[t]{2}{*}{$\begin{array}{l}\text { Chang } \\
2005\end{array}$} & \multirow[t]{2}{*}{$\begin{array}{l}\text { Wong-Bak- } \\
\text { er FACES } 10- \\
\text { point VAS }\end{array}$} & Child & $\begin{array}{l}\text { Mean and SD } \\
\text { graphically }\end{array}$ & $\mathrm{N}$ & $\begin{array}{l}\text { Pain scores lower in tonsillotomy group (mean } 1.5 \text {, } \\
\text { SD 1.5) than tonsillectomy (mean 3.8, SD } 2.5 \text { ), } \mathrm{P}< \\
0.005\end{array}$ \\
\hline & & Parent & & $Y$ & See Analysis 1.24 \\
\hline \multirow[t]{2}{*}{$\begin{array}{l}\text { Chang } \\
2008\end{array}$} & \multirow{2}{*}{$\begin{array}{l}\text { Wong Bak- } \\
\text { er FACES } 10- \\
\text { point VAS }\end{array}$} & Child & Mean only & $\mathrm{N}$ & $\begin{array}{l}\text { Pain scores lower in tonsillotomy group than tonsil- } \\
\text { lectomy (mean } 1.7 \text { versus } 3.2 ; \mathrm{P}<0.05 ; \mathrm{Cl} 0.3 \text { to } 2.7 \text { ) }\end{array}$ \\
\hline & & Parent & $\begin{array}{l}\text { Mean and SD } \\
\text { graphically }\end{array}$ & $\mathrm{Y}$ & See Analysis 1.24 \\
\hline $\begin{array}{l}\text { Ericsson } \\
2009\end{array}$ & 5-point VAS & Parent & $\begin{array}{l}\text { Median and IQR } \\
\text { graphically (data } \\
\text { not normally dis- } \\
\text { tributed) }\end{array}$ & $\mathrm{N}$ & $\begin{array}{l}\text { The median pain score was lower in children who } \\
\text { had undergone tonsillotomy compared to tonsillec- } \\
\text { tomy; } 2 \text { (IQR } 1 \text { to } 2 \text { ) versus } 3 \text { (IQR } 2 \text { to } 3 \text { ), } P<0.0001\end{array}$ \\
\hline Li 2013 & 5-point VAS & Parent & Mean and SD & $Y$ & See Analysis 1.24 \\
\hline Park 2007 & $\begin{array}{l}\text { Wong Bak- } \\
\text { er FACES 10- } \\
\text { point VAS }\end{array}$ & Parent & $\begin{array}{l}\text { Mean and SD } \\
\text { graphically }\end{array}$ & $\mathrm{Y}$ & See Analysis 1.24 \\
\hline $\begin{array}{l}\text { Skoulakis } \\
2007\end{array}$ & 10-point VAS & Parent & Mean graphically & $\mathrm{N}$ & $\begin{array}{l}\text { "on average, the pain scores were significantly lower } \\
\text { (about } 50 \%) \text { for the tonsillotomy group than for the } \\
\text { tonsillectomy group }(\mathrm{P}<0.01) \text { " }\end{array}$ \\
\hline
\end{tabular}

$\mathrm{Cl}$ : confidence interval

IQR: interquartile range

SD: standard deviation

VAS: visual analogue scale

\section{AP PE N DICES}

\section{Appendix 1. Search strategies}

\begin{tabular}{|c|c|c|}
\hline CENTRAL (CRS) & MEDLINE (Ovid) & EMBASE (Ovid) \\
\hline 1 MESH DESCRIPTOR Sleep Apnea & 1. Sleep Apnea Syndromes/ & 1. Sleep Apnea Syndromes/ \\
\hline SETVI IAL. I AR & 2. exp Sleep Apnea, Obstructive/ & 2. exp Sleep Apnea, Obstructive/ \\
\hline $\begin{array}{l}2 \text { MESH DESCRIPTOR Sleep Apnea, } \\
\text { Obstructive EXPLODE ALL AND }\end{array}$ & 3. exp Snoring/ & 3. hypertrophy/ \\
\hline CENTRAL:TARGET & 4. exp Airway Obstruction/ & 4. exp Airway Obstruction/ \\
\hline $\begin{array}{l}3 \text { MESH DESCRIPTOR Snoring EX- } \\
\text { PLODE ALL AND CENTRAL:TARGET }\end{array}$ & 5. Hypertrophy/ & $\begin{array}{l}\text { 5. (sleep* adj3 (apnea* or hypopnea* or ap- } \\
\text { neahypopnea* or apnoea* or hypopnoea* or } \\
\text { apnoeic)).ab,ti. }\end{array}$ \\
\hline
\end{tabular}


(Continued)

4 MESH DESCRIPTOR Airway Obstruction EXPLODE ALL AND CENTRAL:TARGET

5 MESH DESCRIPTOR Hypertrophy AND CENTRAL:TARGET

6 (sleep* and (apnea* or hypopnea* or apneahypopnea* or apnoea* or hypopnoea* or apnoeic) ):AB,EH,KW,KY,MC,MH,TI,TO AND CENTRAL:TARGET

7 (sleep* NEAR3 disorder $^{\star}$ NEAR3 breath* ${ }^{\star}$ ):AB,EH,KW,KY,MC,MH,TI,TO AND CENTRAL:TARGET

8 (OSA or OSAS or OSAHS or SDB or SRBD or OSDB or SAHS ):AB,EH,KW,KY,MC,MH,TI,TO AND CENTRAL:TARGET

9 ((hypertroph* or hyperplasia or obstructive or obstruction) and (tonsil ${ }^{*}$ or adenoid ${ }^{*}$ or adenotonsil $\left.\left.^{\star}\right)\right): A B, E H, K W, K Y, M C, M H, T I, T O$ AND CENTRAL:TARGET

10 ((nasal near obstruct $\left.{ }^{\star}\right)$ or (airway near obstruct ${ }^{\star}$ ) or (obstruct near symptom*)):AB,EH,KW,KY,MC,MH,TI,TO AND CENTRAL:TARGET

11 (snoring):AB,EH,KW,KY,MC,MH,TI,TO AND CENTRAL:TARGET

12 ((nighttime or sleep* or "night time") and (((breath* or airway $\left.{ }^{\star}\right)$ and (obstruct* or restric $\left.\left.{ }^{\star}\right)\right)$ or (mouth near/3 breath*))):AB,E$\mathrm{H}, \mathrm{KW}, \mathrm{KY}, \mathrm{MC}, \mathrm{MH}, \mathrm{TI}, \mathrm{TO}$ AND CENTRAL:TARGET

13 \#1 OR \#2 OR \#3 OR \#4 OR \#5 OR \#6 OR \#7 OR \#8 OR \#9 OR \#10 OR \#11 OR \#12

14 (tonsillotom* or adenotonsillotom * or tonsilotom* or PITA or Tonsilloplast* or tonsiloplast * or adenotonsilloplast $\left.{ }^{\star}\right): A B, E-$ $\mathrm{H}, \mathrm{KW}, \mathrm{KY}, \mathrm{MC}, \mathrm{MH}, \mathrm{TI}, \mathrm{TO}$ AND CENTRAL:TARGET

15 MESH DESCRIPTOR Tonsillectomy EXPLODE ALL AND CENTRAL:TARGET

16 (tonsillectom* or tonsilectom ${ }^{\star}$ or adenotonsillectom ${ }^{\star}$ or $\mathrm{TE}$ ):AB,EH, KW, KY,MC,MH,TI,TO AND CENTRAL:TARGET
6. (sleep* adj5 (apnea* or hypopnea* or apneahypopnea* or apnoea* or hypopnoea* or apnoeic)).ab,ti.

7. (sleep ${ }^{\star}$ adj3 disorder* $\operatorname{adj}^{3}$ breath $\left.^{\star}\right)$.ab,ti.

8. (OSA or OSAS or OSAHS or SDB or SRBD or OSDB or SAHS).ab,ti.

9. ((hypertroph* or hyperplasia or obstructive or obstruction) and (tonsil ${ }^{\star}$ or adenoid ${ }^{*}$ or adenotonsil*)).ab,ti.

10. ((nasal adj6 obstruction) or (airway adj6 obstruct $^{\star}$ ) or (obstruct adj6 symptom*)).ab,ti.

11. snoring.ab,ti.

12. ((nighttime or sleep* or "night time") and (((breath ${ }^{\star}$ or airway $\left.^{\star}\right)$ and (obstruct ${ }^{\star}$ or restric $\left.\left.^{\star}\right)\right)$ or (mouth adj3 breath*))).ab,ti.

13. 1 or 2 or 3 or 4 or 5 or 6 or 7 or 8 or 9 or 10 or 11 or 12

14. (tonsillotom * or adenotonsillotom ${ }^{\star}$ or tonsilotom ${ }^{\star}$ or PITA or Tonsilloplast* ${ }^{\star}$ or tonsiloplast* or adenotonsilloplast* ${ }^{\star}$.ab,ti.

\section{5. exp Tonsillectomy/}

16. (tonsillectom ${ }^{\star}$ or tonsilectom ${ }^{\star}$ or adenotonsillectom* ${ }^{\star}$ or TE).ab,ti.

17. exp Palatine Tonsil/su [Surgery]

18. exp Palatine Tonsil/

19. exp Adenoids/

20. (tonsil ${ }^{\star}$ or adenotonsil $\left.{ }^{\star}\right) \cdot a b$, ti.

\subsection{8 or 19 or 20}

22. exp Surgical Procedures, Operative/

23. (surg* or laser $^{\star}$ or extract* or resect $^{\star}$ or excis $^{\star}$ or operat ${ }^{\star}$ or dissect ${ }^{\star}$ or remov ${ }^{\star}$ or coblat* or ablat*).ab,ti.

\section{22 or 23}

25. 21 and 24

26. 15 or 16 or 17 or 25

27. (intracapsular or partial ${ }^{\star}$ or subtotal or "sub total" or sub-total or TT or TP or subcapsular or "sub capsular" or sub-capsular or MT or ET).ab,ti.

28. 26 and 27

29. 14 or 28

30. 13 and 29
6. (sleep ${ }^{\star}$ adj3 disorder ${ }^{\star}$ adj3 breath).ab,ti.

7. (OSA or OSAS or OSAHS or SDB or SRBD or OSDB or SAHS).ab,ti.

8. ((hypertroph* or hyperplasia or obstructive or obstruction) and (tonsil ${ }^{\star}$ or adenoid ${ }^{\star}$ or adenotonsil $\left.\left.^{\star}\right)\right) \cdot a b, t i$.

9. ((nasal adj6 obstruction) or (airway adj6 obstruct $^{\star}$ ) or (obstruct adj6 symptom*)).ab,ti.

10. ((nighttime or sleep* or "night time") adj3 (((breath* or airway $\left.^{\star}\right)$ adj5 (obstruct* ${ }^{*}$ or restric $\left.\left.^{\star}\right)\right)$ or (mouth adj3 breath $\left.\left.{ }^{\star}\right)\right)$ ).ab,ti.

11.1 or 2 or 3 or 4 or 5 or 6 or 7 or 8 or 9 or 10

12. (tonsillotom* or adenotonsillotom* or tonsilotom* or PITA or Tonsilloplast* or tonsiloplast ${ }^{\star}$ or adenotonsilloplast* ${ }^{\star}$.tw.

13. (tonsillectom* or tonsilectom* or adenotonsillectom* or TE).tw.

14. exp *tonsillectomy/

15. exp Palatine Tonsil/su [Surgery]

16. exp Palatine Tonsil/

17. exp adenoid/

18. (tonsil $^{\star}$ or adenotonsil $\left.{ }^{\star}\right)$.tw

19. 16 or 17 or 18

20. exp Surgical Procedures, Operative/

21. surg $^{\star}$ or laser ${ }^{\star}$ or extract ${ }^{\star}$ or resect ${ }^{\star}$ or excis $^{\star}$ or operat $^{\star}$ or dissect $^{\star}$ or remov ${ }^{\star}$ or coblat $^{\star}$ or ablat $\left.{ }^{\star}\right)$.tw.

22. 20 or 21

23. 19 and 22

24. 13 or 14 or 15 or 23

25. (intracapsular or partial* or subtotal or "sub total" or sub-total or TT or TP or subcapsular or "sub capsular" or sub-capsular or MT or ET).tw.

26. 24 and 25

27. 12 or 26

28. 11 and 27 
(Continued)

17 MESH DESCRIPTOR Palatine Tonsil EXPLODE ALL WITH QUALIFIERS SU AND CEN-

TRAL:TARGET

18 MESH DESCRIPTOR Palatine Tonsil EXPLODE ALL AND CENTRAL:TARGET

19 (tonsil $^{*}$ or adenotonsil ${ }^{*}$ ):AB,E$\mathrm{H}, \mathrm{KW}, \mathrm{KY}, \mathrm{MC}, \mathrm{MH}, \mathrm{TI}, \mathrm{TO}$ AND CENTRAL:TARGET

\section{$20 \# 18$ OR \#19}

21 MESH DESCRIPTOR Surgical Procedures, Operative EXPLODE ALL AND CENTRAL:TARGET

22 (surg $^{\star}$ or laser ${ }^{\star}$ or extract* or resect $^{\star}$ or excis* or operat* or dissect* $^{\star}$ or remov* or coblat ${ }^{\star}$ or ablat ${ }^{\star}$ or Microdebride* or debride $^{*}$ ):AB, EH, KW, KY,MC,MH,TI,TO AND CENTRAL:TARGET

\section{$23 \# 21 \mathrm{OR} \# 22$}

\section{4 \#23 AND \#20}

\section{5 \#16 OR \#15 OR \#17 OR \#24}

26 (intracapsular or partial* or subtotal or "sub total" or sub-total or TT or TP or subcapsular or "sub capsular" or sub-capsular or MT or ET ):AB,EH,KW, KY,MC,MH,TI,TO AND CENTRAL:TARGET

27 \#25 AND \#26

$28 \# 14$ OR \#27

29 \#28 AND \#13

\section{Web of Science (Web of Knowl- edge)}

\#1 TOPIC: ((sleep* near/5 (apnea* or hypopnea* or apneahypopnea* or apnoea* or hypopnoea* or apnoeic)))

\#2 TOPIC: ((sleep* ${ }^{*}$ near/3 disorder* near/3 breath $\left.\left.^{\star}\right)\right)$

\#3 TOPIC: ((OSA or OSAS or OSAHS or SDB or SRBD or OSDB or SAHS))

\#4 TOPIC: (((hypertroph* or hyperplasia or obstructive or obstruction) and (tonsil* or adenoid* or adenotonsil $\left.\left.{ }^{\star}\right)\right)$ )

ICTRP

ClinicalTrials.gov

\section{via www.who.int/ictrp}

sleep AND disorder * AND breath* AND tonsil * OR sleep AND apnea* AND tonsil* OR sleep AND apnoea* AND tonsil ${ }^{\star}$ OR sleep AND hypopnea* AND tonsil ${ }^{\star}$ OR sleep AND hypopnoea* AND tonsil ${ }^{\star}$

\section{via CRS}

1 sleep* and (apnea* or hypopnea* or apneahypopnea* or apnoea* or hypopnoea* or apnoeic) AND CENTRAL:TARGET

2 OSA or OSAS or OSAHS or SDB or SRBD or OSDB or SAHS AND CENTRAL:TARGET

\section{via CT.gov (Expert Search)}

(sleep AND (apnea OR hypopnea OR apneahypopnea OR apnoea OR hypopnoea OR apnoeic OR (disordered AND breathing))) AND (tonsillectomy OR adenotonsillectomy)

\section{Via CRS}

1 sleep* and (apnea* or hypopnea* or apneahypopnea* or apnoea* or hypopnoea* or apnoeic) AND INSEGMENT

2 OSA or OSAS or OSAHS or SDB or SRBD or OSDB or SAHS AND INSEGMENT 
(Continued)

\#5 TOPIC: ((nasal near obstruct $\left.{ }^{\star}\right)$ or (airway near obstruct ${ }^{\star}$ ) or (obstruct near symptom $\left.{ }^{\star}\right)$ )

\#6 TOPIC: ((snoring))

\#7 TOPIC: ((((nighttime or sleep* or "night time") and (((breath* or airway $\left.^{\star}\right)$ and (obstruct ${ }^{\star}$ or restric $\left.\left.{ }^{\star}\right)\right)$ or (mouth near/3 breath $\left.\left.\left.{ }^{\star}\right)\right)\right)$ ))

\#8 \#7 OR \#6 OR \#5 OR \#4 OR \#3 OR \#2 OR \#1

\#9 TOPIC: ((tonsillectom* or tonsilectom* or adenotonsillectom $\left.{ }^{\star}\right)$ )

\#10 TOPIC: ((()tonsil ${ }^{\star}$ or adenotonsil $\left.{ }^{\star}\right)$ near/5 (surg $^{\star}$ or laser ${ }^{\star}$ or extract $^{\star}$ or resect ${ }^{\star}$ or excis ${ }^{\star}$ or operat* or dissect ${ }^{\star}$ or remov ${ }^{\star}$ or coblat* or ablat $\left.\left.{ }^{\star}\right)\right)$ ))

\section{\#11 \#10 OR \#9}

\#12 TOPIC: ((intracapsular or partial* or subtotal or "sub total" or sub-total or TT or TP or subcapsular or "sub capsular" or sub-capsular or MT or ET))

\#13 \#12 AND \#11

\#14 TOPIC: ((tonsillotom* or adenotonsillotom * or tonsilotom * or PITA or Tonsilloplast* or tonsiloplast $^{\star}$ or adenotonsilloplast $\left.{ }^{\star}\right)$ )

\#15 \#14 OR \#13

\#16 \#15 AND \#8
3 sleep* near3 disorder* near3 breath ${ }^{\star}$ AND CENTRAL:TARGET

4 (hypertroph* or hyperplasia or obstructive or obstruction) and (tonsil ${ }^{\star}$ or adenoid $^{*}$ or adenotonsil*) AND CENTRAL:TARGET

5 (nasal near obstruct ${ }^{\star}$ ) or (airway near obstruct $^{\star}$ ) or (obstruct near symptom*) AND CENTRAL:TARGET

\section{6 snoring AND CENTRAL:TARGET}

7 (nighttime or sleep* or "night time") and (((breath* or airway $\left.{ }^{\star}\right)$ and (obstruct ${ }^{\star}$ or restric $\left.\left.^{\star}\right)\right)$ or (mouth near3 breath*)) AND CENTRAL:TARGET

$8 \# 1$ or \#2 or \#3 or \#4 or \#6 or \#7 or \#5 AND CENTRAL:TARGET

9 tonsillotom * or adenotonsillotom * or tonsilotom ${ }^{\star}$ or PITA or Tonsilloplast* or tonsiloplast* or adenotonsilloplast* AND CENTRAL:TARGET

10 tonsillectom ${ }^{\star}$ or tonsilectom* or adenotonsillectom ${ }^{\star}$ or TE AND CENTRAL:TARGET

11 tonsil ${ }^{*}$ or adenotonsil ${ }^{*}$ AND CENTRAL:TARGET

12 surg $^{\star}$ or laser $^{\star}$ or extract ${ }^{\star}$ or resect ${ }^{\star}$ or excis $^{\star}$ or operat ${ }^{\star}$ or dissect ${ }^{\star}$ or remov* or coblat* or ablat* AND CENTRAL:TARGET

\section{3 \#12 AND \#11 AND CENTRAL:TARGET}

14 \#10 OR \#13 AND CENTRAL:TARGET

15 intracapsular or partial ${ }^{*}$ or subtotal or "sub total" or sub-total or TT or TP or subcapsular or "sub capsular" or sub-capsular or MT or ET AND CENTRAL:TARGET

\section{6 \#14 AND \#15 AND CENTRAL:TARGET}

17 \#9 OR \#16 AND CENTRAL:TARGET

18 \#8 AND \#17 AND CENTRAL:TARGET

19 http $^{\star}:$ SO AND CENTRAL:TARGET

20 \#19 AND \#18

1 sleep* and (apnea* or hypopnea* or apneahypopnea* or apnoea* or hypopnoea* or apnoeic) AND INSEGMENT

2 OSA or OSAS or OSAHS or SDB or SRBD or OSDB or SAHS AND INSEGMENT

3 sleep* near3 disorder* near3 breath* AND INSEGMENT
3 sleep ${ }^{\star}$ near3 disorder ${ }^{\star}$ near3 breath ${ }^{\star}$ AND INSEGMENT

4 (hypertroph* or hyperplasia or obstructive or obstruction) and (tonsil ${ }^{\star}$ or adenoid ${ }^{*}$ or adenotonsil ${ }^{\star}$ ) AND INSEGMENT

5 (nasal near obstruct*) or (airway near obstruct $^{\star}$ ) or (obstruct near symptom*) AND INSEGMENT

6 snoring AND INSEGMENT

7 (nighttime or sleep* or "night time") and (((breath* or airway $\left.^{\star}\right)$ and (obstruct* ${ }^{\star}$ or restric $\left.\left.^{\star}\right)\right)$ or (mouth near3 breath*)) AND INSEGMENT

$8 \# 1$ or \#2 or \#3 or \#4 or \#6 or \#7 or \#5 AND INSEGMENT

9 tonsillotom ${ }^{\star}$ or adenotonsillotom ${ }^{*}$ or tonsilotom* or PITA or Tonsilloplast* or tonsiloplast $^{\star}$ or adenotonsilloplast* AND INSEGMENT

10 tonsillectom ${ }^{\star}$ or tonsilectom * or adenotonsillectom ${ }^{\star}$ or TE AND INSEGMENT

\section{1 tonsil $^{\star}$ or adenotonsil ${ }^{*}$ AND INSEGMENT}

12 surg $^{\star}$ or laser ${ }^{\star}$ or extract ${ }^{*}$ or resect ${ }^{\star}$ or excis $^{\star}$ or operat ${ }^{\star}$ or dissect* or remov* or coblat* or ablat ${ }^{\star}$ AND INSEGMENT

\section{3 \#12 AND \#11 AND INSEGMENT}

\section{4 \#10 OR \#13 AND INSEGMENT}

15 intracapsular or partial ${ }^{*}$ or subtotal or "sub total" or sub-total or TT or TP or subcapsular or "sub capsular" or sub-capsular or MT or ET AND INSEGMENT

16 \#14 AND \#15 AND INSEGMENT

17 \#9 OR \#16 AND INSEGMENT

18 \#8 AND \#17 AND INSEGMENT

19 nct $^{\star}$ :AU AND INSEGMENT

20 \#19 AND \#18

1 sleep* and (apnea* or hypopnea* or apneahypopnea* or apnoea* or hypopnoea* or apnoeic) AND CENTRAL:TARGET

2 OSA or OSAS or OSAHS or SDB or SRBD or OSDB or SAHS AND CENTRAL:TARGET

3 sleep* near3 disorder* near3 breath ${ }^{\star}$ AND CENTRAL:TARGET 
4 (hypertroph* or hyperplasia or obstructive or obstruction) and (tonsil ${ }^{\star}$ or adenoid* or adenotonsil*) AND INSEGMENT

5 (nasal near obstruct*) or (airway near obstruct $^{\star}$ ) or (obstruct near symptom ${ }^{\star}$ ) AND INSEGMENT

6 snoring AND INSEGMENT

7 (nighttime or sleep* or "night time") and (((breath ${ }^{\star}$ or airway $\left.{ }^{\star}\right)$ and (obstruct* or restric $\left.\left.{ }^{\star}\right)\right)$ or (mouth near3 breath $\left.\left.{ }^{\star}\right)\right)$ AND INSEGMENT

$8 \# 1$ or \#2 or \#3 or \#4 or \#6 or \#7 or \#5 AND INSEGMENT

9 tonsillotom ${ }^{*}$ or adenotonsillotom ${ }^{*}$ or tonsilotom* or PITA or Tonsilloplast* or tonsiloplast $^{\star}$ or adenotonsilloplast ${ }^{\star}$ AND INSEGMENT

10 tonsillectom ${ }^{\star}$ or tonsilectom ${ }^{\star}$ or adenotonsillectom* or TE AND INSEGMENT

11 tonsil $^{\star}$ or adenotonsil ${ }^{*}$ AND INSEGMENT

12 surg* $^{\star}$ or laser ${ }^{\star}$ or extract* ${ }^{\star}$ or resect* or excis $^{*}$ or operat ${ }^{\star}$ or dissect* ${ }^{\star}$ or remov ${ }^{*}$ or coblat* $^{\star}$ or ablat* AND INSEGMENT

13 \#12 AND \#11 AND INSEGMENT

\section{4 \#10 OR \#13 AND INSEGMENT}

15 intracapsular or partial ${ }^{\star}$ or subtotal or "sub total" or sub-total or TT or TP or subcapsular or "sub capsular" or sub-capsular or MT or ET AND INSEGMENT

16 \#14 AND \#15 AND INSEGMENT

17 \#9 OR \#16 AND INSEGMENT

18 \#8 AND \#17 AND INSEGMENT

$19 \mathrm{http}^{\star}$ :SO AND INSEGMENT

20 \#18 AND \#19
4 (hypertroph* or hyperplasia or obstructive or obstruction) and (tonsil ${ }^{\star}$ or adenoid* or adenotonsil ${ }^{\star}$ ) AND CENTRAL:TARGET

5 (nasal near obstruct ${ }^{\star}$ ) or (airway near obstruct $^{\star}$ ) or (obstruct near symptom ${ }^{\star}$ ) AND CENTRAL:TARGET

\section{6 snoring AND CENTRAL:TARGET}

7 (nighttime or sleep* or "night time") and (((breath ${ }^{\star}$ or airway $\left.{ }^{\star}\right)$ and (obstruct ${ }^{\star}$ or restric $\left.^{\star}\right)$ ) or (mouth near3 breath $\left.\left.{ }^{\star}\right)\right)$ AND CENTRAL:TARGET

8 \#1 or \#2 or \#3 or \#4 or \#6 or \#7 or \#5 AND CENTRAL:TARGET

9 tonsillotom ${ }^{\star}$ or adenotonsillotom ${ }^{*}$ or tonsilotom* or PITA or Tonsilloplast* or tonsiloplast ${ }^{\star}$ or adenotonsilloplast* AND CENTRAL:TARGET

10 tonsillectom ${ }^{\star}$ or tonsilectom ${ }^{\star}$ or adenotonsillectom* or TE AND CENTRAL:TARGET

11 tonsil $^{*}$ or adenotonsil ${ }^{*}$ AND CENTRAL:TARGET

12 surg $^{\star}$ or laser ${ }^{\star}$ or extract* or resect $^{\star}$ or excis $^{\star}$ or operat ${ }^{\star}$ or dissect ${ }^{\star}$ or remov ${ }^{\star}$ or coblat* or ablat* AND CENTRAL:TARGET

\section{3 \#12 AND \#11 AND CENTRAL:TARGET}

14 \#10 OR \#13 AND CENTRAL:TARGET

15 intracapsular or partial ${ }^{\star}$ or subtotal or "sub total" or sub-total or TT or TP or subcapsular or "sub capsular" or sub-capsular or MT or ET AND CENTRAL:TARGET

16 \#14 AND \#15 AND CENTRAL:TARGET

17 \#9 OR \#16 AND CENTRAL:TARGET

18 \#8 AND \#17 AND CENTRAL:TARGET

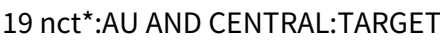

20 \#19 AND \#18

\section{Appendix 2. Previous CENTRAL search (searched via the Cochrane Library, Issue 6, 2017)}

$\# 1$ MeSH descriptor: [Sleep Apnea Syndromes] this term only

\#2 MeSH descriptor: [Sleep Apnea, Obstructive] explode all trees

\#3 MeSH descriptor: [Snoring] explode all trees

\#4 MeSH descriptor: [Airway Obstruction] explode all trees

\#5 MeSH descriptor: [Hypertrophy] this term only 
\#6 sleep* and (apnea* or hypopnea* or apneahypopnea* or apnoea* or hypopnoea* or apnoeic)

\#7 sleep* near/3 disorder* near/3 breath*

\#8 OSA or OSAS or OSAHS or SDB or SRBD or OSDB or SAHS

\#9 (hypertroph ${ }^{\star}$ or hyperplasia or obstructive or obstruction) and (tonsil ${ }^{\star}$ or adenoid ${ }^{\star}$ or adenotonsil ${ }^{\star}$ )

\#10 (nasal near obstruct*) or (airway near obstruct*) or (obstruct near symptom)

\#11 snoring

\#12 (nighttime or sleep* or "night time") and (((breath* or airway*) and (obstruct* or restric $\left.\left.{ }^{\star}\right)\right)$ or (mouth near/3 breath*))

$\# 13 \# 1$ or \#2 or \#3 or \#6 or \#7 or \#8 or \#9 or \#11 or \#12 or \#10 or \#4 or \#5

\#14 tonsillotom* or adenotonsillotom ${ }^{\star}$ or tonsilotom ${ }^{\star}$ or PITA or Tonsilloplast* or tonsiloplast* or adenotonsilloplast*

\#15 MeSH descriptor: [Tonsillectomy] explode all trees

\#16 tonsillectom ${ }^{\star}$ or tonsilectom ${ }^{\star}$ or adenotonsillectom ${ }^{\star}$ or TE

\#17 MeSH descriptor: [Palatine Tonsil] explode all trees and with qualifier(s): [Surgery - SU]

\#18 MeSH descriptor: [Palatine Tonsil] explode all trees

\#19 tonsil* or adenotonsil*

\#20\#18 or \#19

\#21 MeSH descriptor: [Surgical Procedures, Operative] explode all trees

\#22 surg* or laser $^{\star}$ or extract ${ }^{\star}$ or resect* or excis $^{\star}$ or operat $^{\star}$ or dissect ${ }^{\star}$ or remov* or coblat $^{\star}$ or ablat* or Microdebride $^{\star}$ or debride

\#23 \#21 or \#22

$\# 24 \# 20$ and \#23

\#25 \#15 or \#16 or \#17 or \#24

\#26 intracapsular or partial* or subtotal or "sub total" or sub-total or TT or TP or subcapsular or "sub capsular" or sub-capsular or MT or ET

$\# 27 \# 25$ and \#26

\#28 \#14 or \#27

\#29 \#13 and \#28

\section{H I S T ORY}

Protocol first published: Issue 11, 2014

Review first published: Issue 4, 2020

\section{CONTRIBUTIONS OF AUTHORS}

Protocol drafted by: Helen Blackshaw (HB), Roderick P Venekamp (RPV), Lai-Ying Zhang (LZ), Betty Wang (BW), Anne GM Schilder (AGMS) Screening search results: HB, RPV, LZ, LRS

Extracting data: HB, RPV, LZ, BW, LRS

Assessing risk of bias: HB, RPV, LZ, BW, LRS

Entering data into RevMan 5: HB, RPV

Carrying out the analysis: HB, RPV

Interpreting the analysis: HB, LRS, RPV, AGMS 
Writing the review: HB, LRS, RPV, AGMS

General advice on the review: HB, RPV, AGMS

\section{DECLARATIONS OF INTEREST}

Helen Blackshaw: none known.

Laurie R Springford: none known.

Lai-Ying Zhang: none known.

Betty Wang: none known.

Roderick P Venekamp: Roderick P Venekamp is editor of Cochrane ARI and ENT, but had no role in the editorial process for this review.

Anne GM Schilder: Anne Schilder is joint Co-ordinating Editor of Cochrane ENT, but had no role in the editorial process for this review. Her evidENT team at UCL is supported in part by the National Institute of Health Research University College London Hospitals Biomedical Research Centre. Their research is funded by the NIHR and EU Horizon2020. She is the national chair of the NIHR Clinical Research Network ENT Specialty. She is the Surgical Specialty Lead for ENT for the Royal College of Surgeons of England's Clinical Trials Initiative. She is coinvestigator on the NIHR PGFAR grant 'Defining best Management for Adults with Chronic RhinOsinusitis: the MACRO Programme'. In her role as director of the NIHR UCLH BRC Deafness and Hearing Problems Theme, she acts as an advisor on clinical trial design and delivery to a range of biotech companies.

\section{SOURCES OF SUPPORT}

\section{Internal sources}

- No sources of support supplied

\section{External sources}

- NIHR Research Professorship Award, UK

Professor Anne Schilder's team is supported by an NIHR Research Professorship Award

- National Institute for Health Research, UK

Infrastructure funding for Cochrane ENT

\section{DIFFERENCES BETWEEN PROTOCOLAND REVIEW}

This review was based upon our published protocol (Blackshaw 2014). Differences between the protocol and the review can be found below.

Exclusion criteria:

- We now no longer exclude RCTs including children with Down syndrome, craniofacial malformations and cerebral palsy.

Outcomes:

- We added time points to our first primary outcome and our secondary outcomes, to allow us to split the analysis of the data into short-, medium- and long-term findings.

- We refined our second primary outcome to concentrate on two aspects of adverse event complications and morbidity: peri-operative bleeding and postoperative complications requiring medical intervention with or without hospitalisation. We combined the elements of bleeding, infection and dehydration into this second outcome measure.

- We moved the two outcome measures of postoperative pain and days until analgesics were no longer required into our secondary outcomes.

- We removed generic quality of life, cardiovascular disease, neurocognitive performance, attention and cost from our secondary outcomes list. We felt that these outcomes were more applicable to our review comparing tonsillectomy/adenotonsillectomy with nonsurgical management in children with oSDB (Venekamp 2015).

- We added detail on how we would extract data for our pre-specified time points for the outcomes in our review in the Methods section.

Data analysis:

- We included a section describing the 'method of Zelen' for randomisation and how we assessed those studies for risk of bias.

- We added 'SDB diagnosis' to our list of subgroup analyses given the findings of our first review (Venekamp 2015). 
- We removed the section stating that we would perform sensitivity analysis based on surgical technique (e.g. coblation) since this was not in line with the overall purpose of this review. 